\title{
"DECORATORE DI SUA MAESTÀ«- GIUSEPPE GALLI BIBIENA ALS BÜHNENBILDNER AN DER BERLINER HOFOPER FRIEDRICHS II. VON PREUSSEN
}

\author{
von ADELHEID RASCHE
}

\begin{abstract}
Giuseppe Galli Bibiena, Mitglied der bedeutendsten Familie italienischer Theaterarchitekten und Bühnengestalter des 18. Jahrhunderts, verbrachte seine letzten Lebensjahre am Berliner Hofe König Friedrich II. von Preußen. Zwischen 1750 und 1756 war er für die Ausstattung von elf Opernaufführungen im Königlichen Opernhaus zuständig, ab 1753 in der Funktion eines "Königlichen Hofarchitekten und Theateringenieurs". Durch die erstmalige Vorstellung eines 1754 angelegten Kulisseninventars des Opernhauses, von Rechnungen und Aktenstücken sowie mit Hilfe erhaltener Libretti lassen sich bislang unbekannte Einzelheiten des Bühnenbetriebes an der Berliner Hofoper nachweisen, die zu einer differenzierten Wertung des höfischen Repräsentationsaufwandes unter Friedrich dem Großen führen. Galli Bibiena entwarfüblicherweise nur einige Szenen jeder neuen Opernaufführung, für die übrigen fanden ältere Kulissen und Dekorationsteile Verwendung. Drei von der Kunstbibliothek unlängst erworbene Zeichnungen Galli Bibienas zu den Graunschen Opern Britannico bzw. Semiramide und weitere Zeichnungen seiner Berliner Jahre werden im Kontext dieser theater- und kunsthistorisch orientierten Studie ausführlich vorgestellt.
\end{abstract}

Mit der feierlichen Eröffnung des Königlichen Opernhauses Unter den Linden im Dezember 1742 begann die erste Blütezeit des Musiktheaters in Preußen. Friedrich II., der diesen repräsentativen Neubau unmittelbar nach seinem Regierungsantritt im Mai 1740 bei Georg Wenzeslaus von Knobelsdorff ${ }^{1}$ in Auftrag gegeben hatte, engagierte sich während der folgenden anderthalb Jahrzehnte bis zum Ausbruch des Siebenjährigen Krieges 1756 außerordentlich intensiv für die dort mehrmals jährlich produzierten Opernaufführungen. Auf sein Betreiben hin wurden in Italien Sängerinnen und Sänger, darunter Giovanna Astrua sowie die damals international berühmten Kastraten Giovanni Carestini und Felice Salimbeni angeworben, wurden Musiker, Tänzerinnen und Tänzer, Ballettmeister und Bühnenbildner an den Berliner Hof verpflichtet, um gemeinsam die neuen Opernkompositionen

Für Anregungen, kollegiale Hilfe und kritische Diskussionen danke ich:

Babette Ball-Krückmann, München; Wolfgang Cilleßen, Berlin; Ruth Freydank, Berlin; Christoph Henzel, Berlin; den Mitarbeitern im Geheimen Staatsarchiv Preußischer Kulturbesitz und in der Musikabteilung der Staatsbibliothek zu Berlin sowie meiner Berliner Arbeitsgruppe. von Hofkapellmeister Carl Heinrich Graun zu realisieren. ${ }^{2}$

Der König von Preußen konnte durch die vielbeachteten Produktionen seiner Hofoper in mehrfacher Weise seine Position im Wettstreit der europäischen Fürstenhöfe festigen. Das höfische Zeremoniell erlaubte dem König sowohl innerhalb des eigenen Landes wie gegenüber befreundeten Herrscherhäusern eine deutliche Zurschaustellung des eigenen Ranges, der nicht zuletzt in der baulichen Anlage des Opernhauses sinnfällig zum Ausdruck gebracht wurde. Seine Rolle als Förderer der Musik unterstrich Friedrich II. durch intensive Anteilnahme bei der Anwerbung der Sänger und Musiker; zudem verfaßte er einige Libretti auf der Grundlage französischer Bühnenstücke namhafter Autoren, darunter Jean Racine, Philippe Quinault und Voltaire.

\footnotetext{
1 Zuletzt: Ausst. Kat. „Zum Maler und zum grossen Architekten geboren« - Georg Wenzeslaus von Knobelsdorff 1699-1753, Berlin 1999, Kat. VII. 12 mit weiterführender Literatur.

2 Bis heute maßgeblich: Louis Schneider, Geschichte der Oper und des königlichen Opernhauses in Berlin, Berlin 1852; sowie: Christoph Henzel, Zu den Aufführungen der großen Oper Friedrichs II. von Preußen 1740-1756, in: Jahrbuch des Staatlichen Instituts für Musikforschung Preußischer Kulturbesitz, Berlin 1997, S. 9-57, dort weitere Literatur.
} 


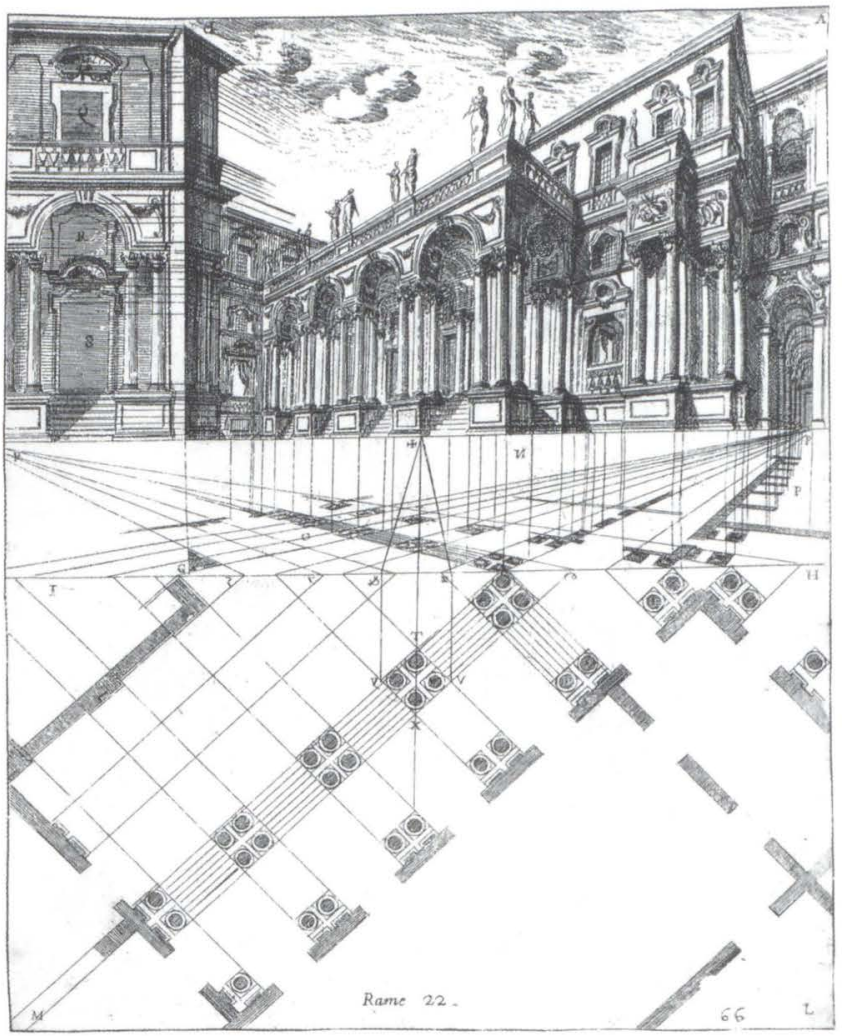

Abb. 1 Ferdinando Galli Bibiena, „Per disegnare le scene vedute per angolo, e prima di quelle d'un Cortile«, Radierung in L'Architettura Civile, Parma 1711. Staatliche Museen zu Berlin, Kunstbibliothek (OS 2628)

Mindestens gleichviel Bedeutung kam der dritten, für den Erfolg einer Opernaufführung manchmal entscheidenden optischen Komponente zu. Bühnendekorationen und Kostüme der Sänger und Tänzer ermöglichten dem Publikum einen raschen Einstieg in die dargestellten Situationen und Inhalte, die häufig in Apotheosen und Fürstenlob mündeten. Mittels ihrer prachtvollen Wirkung entstand auf der Bühne eine Phantasiewelt aus glaubhaften Illusionen, die dem Zuschauer einen scheinbar nahtlosen Übergang zum eigenen Leben innerhalb des höfischen Ranggefüges ermöglichte.

Zu den größten Meistern der barocken Bühnengestaltung zählen die Mitglieder der über vier Generationen tätigen italienischen Künstlerfamilie Galli Bibiena. ${ }^{3}$ Vor allem die Brüder Ferdinando und Francesco, ausgebildet als Architekten und Dekorationsmaler, gelten als maßgebliche Erneuerer der Bühnendekoration. ${ }^{4}$ Durch die Einführung der

3 Gebürtig aus Bibbiena zwischen Arezzo und Florenz, nahm de Maler Giovan Maria Galli (1625-1665) den Ortsnamen in seinen Familiennamen auf.

4 Unter den zahlreichen Studien seien hervorgehoben: Corrado Ricci, I Bibiena, architetti teatrali, Milano 1915; Ausst. Kat. Disegn teatrali dei Bibiena, Fondazione Cini Venezia 1970; Hélène Leclerc, Les Bibiena, une dynastie de scénographes baroques, in: Revue d'Histoire du Théâtre, 22, 1971, S. 7-39; Ausst. Kat. Meravigliose Scene, piacevoli inganni - Galli Bibiena, Accademia Bibbiena 1992
Winkelperspektive und raffinierte Kombinationen aus gebauten Architekturelementen mit illusionistisch gemalten Hintergründen gelang ihnen eine enorme Steigerung der Raumwirkung. (Abb. 1) Ab den 1690er Jahren waren sie in ganz Europa zur Ausstattung von Theateraufführungen, höfischen Festen und Trauerzeremonien begehrt; außerdem realisierten sie zahlreiche Theaterbauten, Kirchen und Adelspaläste, erhielten Aufträge für Fresken und Altargemälde und anderes mehr.

Unter den Söhnen der Bibiena-Brüder, die als Architekten, Bühnenbildner und Maler unter anderem an den Höfen in Lissabon, Wien und Mannheim wirkten, gilt Giuseppe Galli Bibiena unser besonderes Augenmerk, da er auf dem Höhepunkt seiner Karriere im August 1750 von Friedrich II. nach Berlin geholt wurde, um Bühnenbilder für die Hofoper zu entwerfen.

\section{Zur Biographie Giuseppe Galli Bibienas}

Giuseppe Galli Bibiena, am 5. Januar 1696 in Parma geboren, verbrachte dort seine Jugendjahre und kam 1708 nach Barcelona, wo sein Vater Ferdinando für die Ausstattung der Hochzeitsfeierlichkeiten Karls III. verantwortlich war. Ab 1712 lebte Ferdinando gemeinsam mit Giuseppe und dessen älterem Bruder Alessandro am kaiserlichen Hof in Wien, hier wurde Giuseppe 1717 von Kaiser Karl VI. als "Ingegnere ed architetto teatrale» eingestellt und gestaltete gemeinsam mit seinem Vater zahlreiche Bühnenausstattungen und Festlichkeiten. Als sein Vater aus gesundheitlichen Gründen nach Italien zurückging, wurde Giuseppe 1723 die Oberleitung des Ausstattungswesens am kaiserlichen Hof übertragen, eine Position, die er fast zwei Jahrzehnte innehatte. Aufträge an anderen Höfen und in Schlesien, Linz und Graz, Architekturprojekte und seine Lehrtätigkeit an der Accademia Clementina in Bologna führten ihn in den folgenden Jahrzehnten quer durch Europa. ${ }^{5}$ Im Januar 1748 trat er als Hofdekorateur in den Dienst des sächsischen Kurfürsten Friedrich August ${ }^{6}$ und vollendete im selben Jahr zusammen mit seinem Sohn Carlo das

5 Zur Biographie Giuseppe Galli Bibienas siehe u. a. Ausst. Kat. Meravigliose Scene, piacevoli inganni (wie Anm. 4), S. $108 \mathrm{f}$ mit weiterführender Literatur; sowie: Allgemeines Künstlerlexikon, München 1995, Bd. 10, S. 480 f.

6 Moritz Fürstenau, Zur Geschichte der Musik und des Theaters am Hofe der Kurfürsten von Sachsen und Könige von Polen, Dresden 1861-62, Bd. 2, S, 256. Galli Bibienas Jahresgage betrug 2.266 Taler, seine Ernennungsurkunde erhielt er erst am 10. Mai 1750. Der sächsische Kurfürst war zugleich König von Polen. 
nach seinen Entwürfen errichtete Opernhaus in Bayreuth als Auftragsarbeit der dortigen Markgräfin Wilhelmine, der Schwester Friedrichs II. ${ }^{7}$

Für den preußischen Hof in Berlin arbeitete Giuseppe Galli Bibiena zum ersten Mal im August 1750 im Rahmen der Festlichkeiten während des Besuches des Bayreuther Fürstenpaares. Eigens zu diesem Anlaß entwarf er ein neues Anfangs- und Schlußbild zur Graun'schen Oper Fetonte, die bereits im März desselben Jahres mit Dekorationen des Hofdekorateurs Innocente Bellavite gezeigt worden war. Die neue Opern-Ausstattung muß sehr zur Zufriedenheit des Königs ausgefallen sein, denn ab der nächsten Saison war Galli Bibiena häufig zwischen Dresden und Berlin unterwegs, um zwischen 1751 und 1753 an den Dekorationen für weitere vier Opern in Berlin mitzuwirken. Da er weiterhin in sächsischen Diensten stand, wurden die Berliner Produktionen im »Werkvertrag « entlohnt, zusätzlich erhielt er die Kosten seines Aufenthalts und die Reisespesen erstattet. (s. S. 109) Wie noch im einzelnen gezeigt werden wird, waren diese Berliner Opernausstattungen durchweg gemeinsame Arbeiten Galli Bibienas mit dem seit 1747 festangestellten Bellavite. Offensichtlich konnte Galli Bibiena aufgrund seiner künstlerischen Wertschätzung selbst bestimmen, welche Einzelszenen er gestalten wollte; Bellavite nahm sich der übrigen Dekorationen an. Die Ausführung des Entwurfs in den Werkstätten wie auch die Auswahl der Theatermaler übernahm jeder Bühnenbildner für sich, erst auf der Bühne kamen die Szenenbilder in ihrer vorgesehenen Abfolge zusammen.

Giuseppe Galli Bibiena in preußischen Diensten

Einen letzten Wechsel seines Dienstherren vollzog Giuseppe Galli Bibiena im Jahre 1753 und verlegte seinen Wohnsitz zu einem nicht genauer bekannten Zeitpunkt von Dresden nach Berlin. Bis heute sind keine Urkunden, Briefe oder Protokolle bekannt geworden, die mit Galli Bibienas Bestallung oder Ernennung am preußischen Hof in Zusam-

7 Ausst. Kat. Paradies des Rokoko: Galli Bibiena und der Musenhof der Wilhelmine von Bayreuth, hrsg. von Peter Krückmann, München 1998.

8 Textbuch Semiramide, 1754, Bayerische Staatsbibliothek München, Musikabteilung, Sign. Her 1611.

9 Luigi Crespi, Vite de'Pittori Bolognesi, Roma 1769, Bd. 3, S. 89-90. 10 Noch wesentlich früher läßt sich aufgrund eines neuen Quellenfundes durch Christoph Henzel Giuseppe Galli Bibienas regelmäßige Bezahlung in Berlin nachweisen. Zwischen Juni 1753 und Februar 1757 erhielt er monatlich 200 Taler aus der Schatulle des Königs ausbezahlt; wodurch die oben aufgestellte Hypothese deutlich erhärtet wird. In Vorbereitung: Christoph Henzel, Die Schatul-

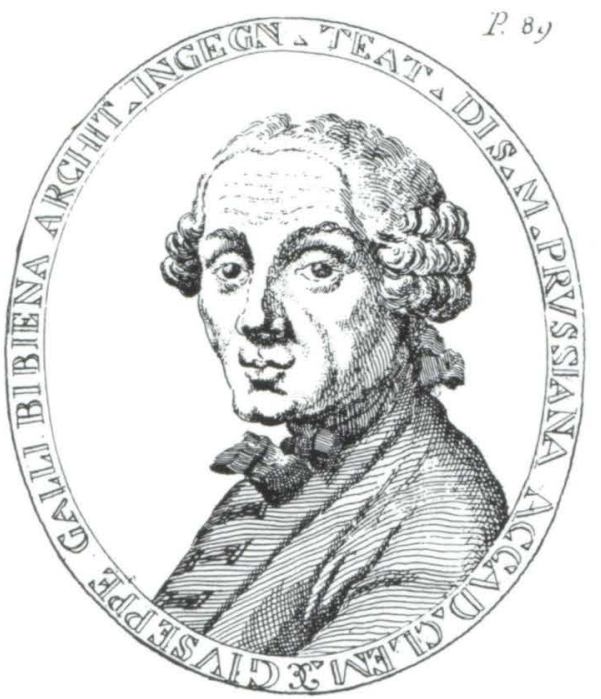

Abb. 2 Porträt Giuseppe Galli Bibiena, um 1755, Radierung in Felsina Pittrice, Vite de'Pittori Bolognesi von Luigi Crespi, Roma 1769. Nachdruck Bologna 1970

menhang stehen. (Abb. 2) Die bisherige Forschung geht davon aus, daß er erstmals bei Semiramide als "Architecti und Decoratoris der Schauplätze Sr. Königl. Majestät ${ }^{8}$ tätig gewesen sei; auch sein erster Biograph Crespi ${ }^{9}$ schreibt, daß Galli Bibiena erst 1754 »al servigio della Corte di Berlino « getreten sei. Die Auswertung des Textbuches zur Oper Cleofide, am 14. Januar 1754 in Berlin uraufgeführt, erlaubt dagegen die Schlußfolgerung, daß Galli Bibiena schon mindestens seit Dezember 1753 in preußischen Diensten war. ${ }^{10}$

Nicht eindeutig zu klären ist der Zusammenhang von Galli Bibienas Anstellung mit dem Weggang Innocente Bellavites. Im Winter 1753/54 werden beide Künstler als "theatralische Architekten und Decoratore «11 bezeichnet, auch in einem im April 1754 verfaßten Text erwähnt der Autor »die beyden gegenwärtigen Decoratores «12. Einer 1994 erschienenen biographischen Notiz zufolge soll Bellavite sogar bis 1756 in königlichem Dienst gestanden haben, und zwar als Werkstattleiter für Bühnenbildnerei an der Hofoper. ${ }^{13}$ Gegen diese weitere Beschäftigung Bellavites spricht die letztmalige Auszahlung seiner Jahresgage von 700 Ta-

le Friedrichs II. von Preußen und die Hofmusik - Teil 1, in: Jahrbuch des Staatlichen Instituts für Musikforschung Preußischer Kulturbesitz, Berlin 1999, im Druck.

11 Textbuch Cleofide, 1754, Theaterwissenschaftliche Sammlung Köln, Sign. Knth OT Inv. 10606.

12 Friedrich Wilhelm Marpurg, Historisch-Kritische Beyträge zur Aufnahme der Musik, Berlin 1754-55, 9. Kapitel, S. 79.

13 Allgemeines Künstlerlexikon, München 1994, Bd. 8, S. 445, Artikel verfaßt von $\mathrm{M}$. Angiolillo nach Mitteilungen von Christiane Kruse. In den verwendeten Akten der Hofoper ist sein Name nach 1754 nicht mehr präsent. 
lern im Februar 1754 aus dem Kapellenetat der Hofverwaltung ${ }^{14}$ wie auch die Tatsache, daß anschlieBend alle Operndekorationen nach Entwürfen Galli Bibienas ausgeführt wurden und Bellavites Name nicht mehr in den Rechnungsakten auftaucht.

Galli Bibienas letzte Berliner Bühnendekoration entstand für die am 27. März 1756 aufgeführte Oper Merope, danach verliert sich seine Spur, nicht zuletzt durch die veränderte Situation nach Ausbruch des Siebenjährigen Krieges, der zur mehrjährigen Unterbrechung der höfischen Unterhaltungen führte. Es gilt als wahrscheinlich, daß Galli Bibiena in Berlin blieb und hier starb, seine Bezahlung ist bis Februar 1757 dokumentiert, danach fehlen die Akten der Königlichen Schatullrechnungen. Crespi ${ }^{15}$ gibt als Todesjahr 1756 an; nach einem anonymen Manuskript vom Ende des 18. Jahrhunderts ${ }^{16}$ soll Galli Bibiena in den ersten Monaten 1757 gestorben sein. Trotz dieser Überlieferungen muß erwogen werden, ob Galli Bibiena nicht im Frühjahr 1757 versucht haben könnte, in seine italienische Heimat zurückzukehren. ${ }^{17}$ Bereits 1754 war seine aus Wien gebürtige Frau Eleonora Kinsky mit fünf Kindern von Dresden direkt nach Bologna gezogen. Für Giuseppe könnte die neue Berliner Situation ohne Aussicht auf neue Opernaufführungen ein willkommener Anlaß gewesen sein, ihr zu folgen. Die Heimatstadt seiner Familie scheint er jedoch nicht erreicht zu haben.

\section{Forschungsstand}

Das bekannte Euvre Giuseppe Galli Bibienas ist vor allem durch seine langjährige Entwurfstätigkeit am Wiener Hof und durch seine Dresdner Festentwürfe geprägt. ${ }^{18}$ Erhaltene Skizzenbücher in Wien, Rom und in der Houghton Library an der Harvard University, seine ab 1740 publizierte Kupferstichfolge "Architetture e Prospettive ${ }^{19}$ sowie eine Reihe zugeschriebener Entwurfszeichnungen ermöglichen eine detaillierte Auseinandersetzung mit seinen variantenreichen Raumschöpfungen und seinem Zeichenstil zwischen 1720 und 1745. Sie zeigen jedoch zugleich eine grundlegende Problematik jeder Beschäftigung mit den Bühnenbildentwürfen der Galli Bibiena auf. Mehrere tausend
Entwurfszeichnungen für Bühnendekorationen werden mit den einzelnen Mitgliedern dieser hochproduktiven Künstlerfamilie, ihren Werkstattmitarbeitern und Nachfolgern in Zusammenhang gebracht, nur selten aber lassen sich die Aufschriften der Blätter eindeutig interpretieren und auf eine bestimmte Aufführung zurückführen. In Phasen enger Zusammenarbeit, beispielsweise während der gemeinsamen Jahre von Ferdinando, Alessandro und Giuseppe Galli Bibiena in Wien, entwickelte sich ein schwer zu unterscheidender »Gruppenstil«. Einmal entworfene Bühnenräume wurden in zahllosen Varianten abgewandelt, Bildideen vom Vater an die Söhne weitergegeben, manche Motive tauchen nach Jahrzehnten in Entwürfen unterschiedlicher Bühnendekorateure erneut auf. Die von Ferdinando Galli Bibiena in seinem 1711 erschienenen Traktat "Architettura Civile« beschriebene Winkelperspektive (scena per angolo) mit ihren auf Unendlichkeit angelegten Blickachsen und raffinierten Illusionsmalereien wurde rasch von allen Bühnenbildnern des 18. Jahrhunderts angewandt. ${ }^{20}$

Die speziellen Zuschreibungsprobleme für Entwürfe der Galli Bibiena-Familie werden durch die gängige Bühnenbildpraxis der barocken Oper verstärkt, wo notwendige Szenenwechsel lediglich mit knappen Angaben - etwa »Königlicher Lustgarten«, »Kerker-Vorhof" oder »Schlachtfeld « - festgelegt sind. ${ }^{21}$ Die typologisch eingeteilten Bühnenbilder ließen der Phantasie des Entwerfers freien Lauf in der gestalterischen Realisierung, was sich in der späteren Zuordnung auf konkrete Opernproduktionen als häufig unlösbare Schwierigkeit erweist.

Aus Giuseppe Galli Bibienas letzter Schaffensperiode in Berlin lagen bis vor kurzem, als die Staatlichen Museen zu Berlin drei Skizzen für die 1751 bzw. 1754 an der Hofoper aufgeführten Opern Britannico und Semiramide erwerben konnten, keine gesicherten Entwürfe vor. Im Rahmen dieser Studie wird versucht, alle elf Aufführungen, die unter Beteilung Galli Bibienas zwischen 1750 und 1756 in Berlin gezeigt wurden, im Hinblick auf die Bühnengestaltung detailliert vorzustellen und daraus konkrete Aussagen über seine Arbeiten am preußischen Hof zu gewinnen. Die Auswertung der verfügbaren schriftlichen Quellen erlaubt unerwartet präzise Aussagen zur gängigen Aufführungspra-
14 Siehe Henzel (wie Anm. 2), S. 40, Anm. 107.

15 Crespi (wie Anm. 9), Bd. 3, S. 89-90.

16 Biblioteca Comunale di Bologna, ms. B. 13, zitiert in: Ausst. Kat. Meravigliose scene, piacevoli inganni (wie Anm. 4), S. 109.

17 Eine Prüfung der katholischen und evangelischen Kirchenbücher Berlins im Bezug auf Bestattungen der Jahre 1756 bis 1758 verlief negativ.

18 Joseph Gregor, Giuseppe Galli-Bibiena, Wien 1954; Kalman A. Burnim, The Theatrical Career of Giuseppe Galli-Bibiena, in: Thea- tre Survey, 1965, S. 32-53.

19 Arthur H. Saxon, Giuseppe Galli Bibiena's ,Architetture e prospettive, in: Maske und Kothurn, XV, 1969, S. 105-118.

20 Hierzu grundlegende Ausführungen bei: Alexandra Glanz, Alessandro Galli Bibiena am kurpfälzischen Hof in Mannheim, bearbeitet von H. Zielske, Berlin 1991.

21 Siehe Leclerc (wie Anm. 4), S. 8 und Glanz (wie Anm. 20), S. 78. 
xis der Hofoper, wo in jeder Neuproduktion auch ältere Dekorationen unverändert zum Einsatz kamen. Damit läßt sich Galli Bibienas Berliner Entwurfstätigkeit auf rund 35 Szenenbilder eingrenzen. Auf dieser gesicherten Basis lassen sich künftig weiterführende kunsthistorisch orientierte, stilistische Zuschreibungen wesentlich besser durchführen.

II.

"Acta von Anfertigung derer Decorationes die Überlieferung der

Dekorations- und Aufführungsrechnungen

Trotz großer Lücken in der historischen Überlieferung des 18. Jahrhunderts in Brandenburg-Preußen sind die Aufführungen der Berliner Hofoper der 1750 er Jahre bis heute erstaunlich gut dokumentiert. ${ }^{22}$ Wenngleich nicht bei jeder einzelnen Produktion die komplette Historie ihrer Entstehung, Herstellung und Aufführungen durch schriftliche Zeugnisse rekonstruierbar ist, erlaubt das Studium der erhaltenen Einzelrechnungen der Handwerker und des Opernpersonals, von Gesamtaufstellungen, Gesprächsprotokollen und Aktennotizen eine recht konkrete Beschreibung vieler bislang unbekannter Details des Berliner Opernbetriebes dieser Jahre. ${ }^{23}$ Giuseppe Galli Bibienas erhaltene Schriftstücke können bei Zuschreibungen signierter oder kommentierter Zeichnungen als Vergleich herangezogen werden. (Abb. 3 und 4)

Der größte Teil der Akten, die die Königliche Hofoper betreffen, ist im Geheimen Staatsarchiv Preußischer Kulturbesitz erhalten, und zwar überwiegend in der Repositur 36 »Hof- und Güterverwaltung « der ersten Hauptabteilung, chronologisch nach den Titeln der Opern abgelegt. Lediglich einzelne Akten ${ }^{24}$ sind in der Repositur 9 »Allgemeine Verwaltung« der ersten Hauptabteilung eingeglie-

22 Eine systematische Auswertung steht bis heute aus. Schneider (wie Anm. 2) publizierte im Anhang seiner Operngeschichte Berlins vor allem die Akten zum Engagement der Tänzerin Barberina. Die beste Analyse lieferte kürzlich Henzel (wie Anm. 2).

23 Als Beispiel sei die „General-Berechnung der Opera Orpheus und Didone vom Monat December 1752 und January 1753 « genannt. Von den Gesamtausgaben in Höhe von 13.200 Talern entfielen 4.474 Taler auf die Kleider der »Acteurs, Täntzer und Comparsen«, wesentlich günstiger war die Dekorationsherstellung mit 1.811 Taler. 520 Taler erhielt der Theatermaler Carl Friedrich Fechhelm, weitere Rechnungen stellten folgende Handwerker und Zulieferer: Tischler, Nagelschmied, Schlosser, Drechsler, Lichtzieher, Leinwandhändler, Seiler, Klempner, Vergolder, Bildhauer sowie der Kastellan der Oper zur Bewachung der Aufbauten. Die beiden Bühnendekorateure - Bellavite und Galli Bibiena - sind in den Ausga-

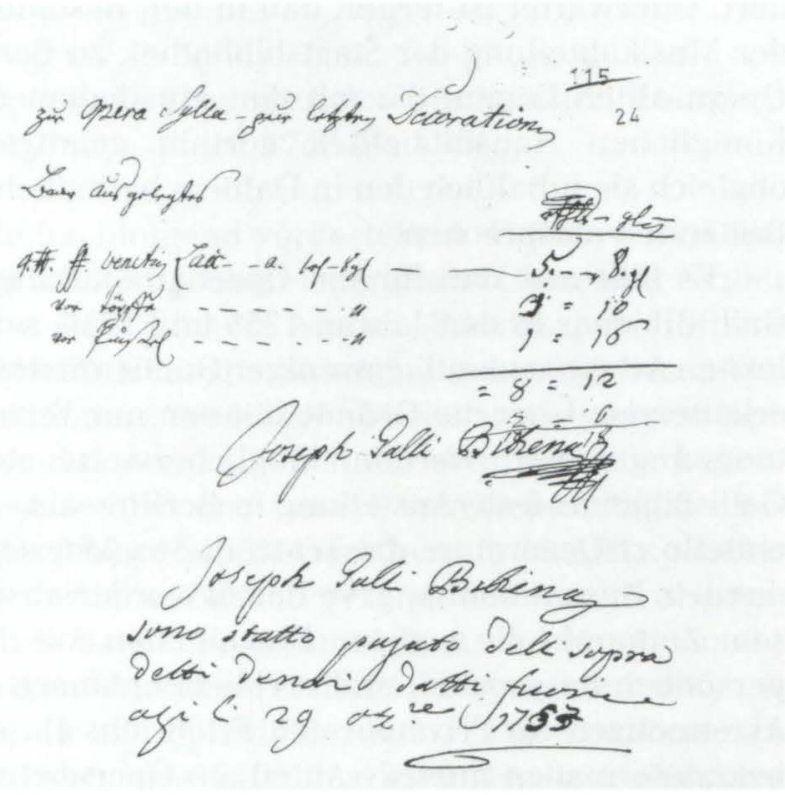

Abb. 3 Eigenhändige Zahlungsbestätigung Giuseppe Galli Bibienas, Berlin 29. Oktober 1753. Geheimes Staatsarchiv Preußischer Kulturbesitz, I. HA Rep. 9 Allgemeine Verwaltung, LL.7c Fase. 9, fol. 24

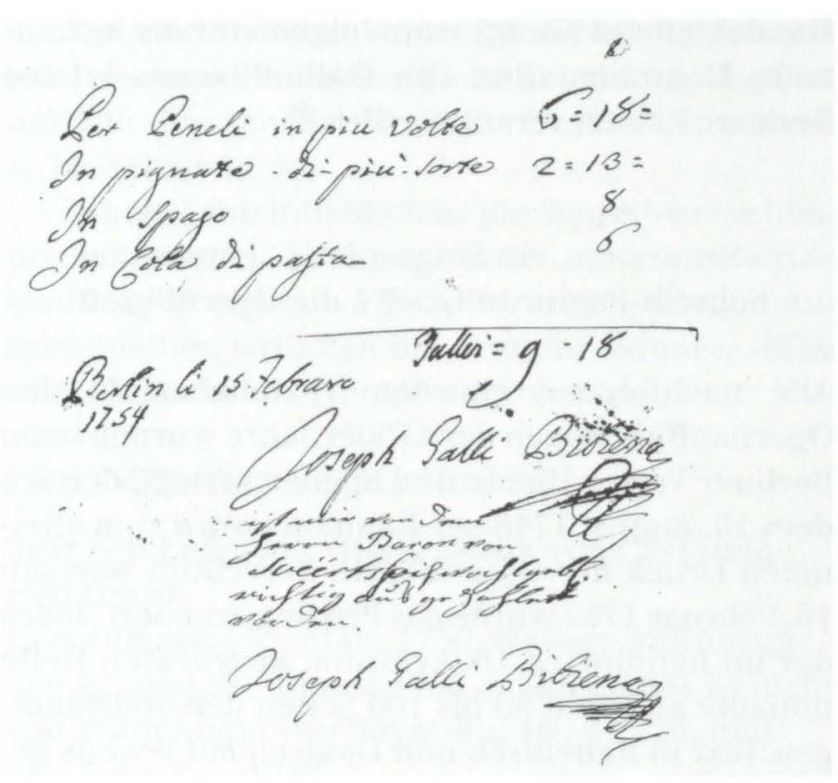

Abb. 4 Eigenhändige Rechnung Giuseppe Galli Bibienas, Berlin 15. Februar 1754. Geheimes Staatsarchiv Preußischer Kulturbesitz, I. HA Rep. 36 Hofverwaltung, Nr. 2655 unpaginiert

benlisten des Opernhauses nicht berücksichtigt. Die Bezahlung Bellavites erfolgte über den Kapellenetat, Galli Bibiena wurde direkt aus den Handgeldern des Königs bezahlt. - Jede einzelne der insgesamt 16 Vorstellungen schlug mit rund 370 Talern zu Buche. Die größten Beträge wurden für die bei jeder Aufführung eingesetzten 240 Tischler und Handlanger benötigt, die auf der Bühne für Umbauten, Auf- und Abbau zuständig waren, ferner für die „Fornitur der Acteurs und Täntzer« (Garderobenpersonal) und die Beleuchtung von Bühne und Zuschauerraum mit Kerzen, Öl- und Talglampen. Die »Aufsicht auf dem Theater bey deren Representationes" hatte Carl Friedrich Fechhelm gegen ein Abendhonorar von 1 Taler inne. Vgl. Staatsbibliothek zu Berlin PK, Musikabteilung, Königliche Hausbibliothek, KHM 6826.

24 Zu Silla (1753) und Merope (1756). 
dert. Unerwartet ist ferner, daß in den Beständen der Musikabteilung der Staatsbibliothek zu Berlin Opern-Akten liegen, die mit den Musikalien der Königlichen Hausbibliothek dorthin gelangten, obgleich sie inhaltlich den in Dahlem befindlichen Beständen entsprechen.

Es fällt auf, daß für die Opernausstattungen Galli Bibienas in den Jahren 1755 und 1756, seine letzten Arbeiten, deutlich weniger Quellenmaterial erhalten ist. Über die Gründe können nur Vermutungen geäußert werden. Möglicherweise steht Galli Bibienas feste Anstellung in Berlin - als "Architetto et Decoratore de' Teatri di Sua Maestà« damit in Zusammenhang. Vielleicht wurden ab diesem Zeitpunkt die meisten Einzelheiten mit ihm persönlich besprochen und verblieben danach als Aktennotizen im Privatbereich Friedrichs II., der bekanntermaßen intensiv Anteil am Opernbetrieb nahm. Für eine solche These spricht, daß - wie erwähnt - noch heute kleinere Teile der Aufführungsrechnungen aus den 1750er Jahren in der Königlichen Hausbibliothek erhalten sind. Der Verlust von Teilen der Königlichen Hausbibliothek und der Handakten des Königs wäre folglich für die lückenhafte Dokumentation von Galli Bibienas letzten Berliner Jahren verantwortlich. ${ }^{25}$

"Semiramis, ein Singespiel, [...] kostet auf Schreib-Papier 10 Gr. ${ }^{26}$ - die Opernlibretti

Alle nachfolgend zitierten Textbücher zu den Opernaufführungen der 1750er Jahre wurden beim Berliner Verlag Haude und Spener verlegt, der seit dem 19. August 1746 per Kabinettsordre zum alleinigen Druck der Opernlibretti berechtigt war; am 16. Februar 1752 wurde das Privileg erneuert. Jedes der im handlichen Oktavformat gedruckten Hefte umfaßte auf rund 80 bis 100 Seiten den vollständigen Text in Italienisch und Deutsch auf jeweils gegenüberliegenden Seiten: So konnte das Opernpublikum der in italienisch gesungenen Aufführung problemlos folgen, indem es die deutsche Übersetzung unterstützend beizog. ${ }^{27}$ Die ersten Seiten jedes Buches informieren über den Anlaß der Aufführung, listen die Rollen der Sänger auf, nennen Text-

25 Im Brandenburg-Preußischen Hausarchiv konnten keine Be stände zur Operndekoration unter Friedrich II. ausgemacht wer den. Bedauerlich ist ferner der geringe Bestand an Briefen Friedrich II. mit Aussagen zum Musiktheater. Die nur in Ausschnitten publi zierten Briefe an seine Schwester Wilhelmine (G. B. Volz [Hrsg.], Friedrich der Große und Wilhelmine von Bayreuth, Berlin 1924-1926) wie auch der Briefwechsel mit Fredersdorf (J. Richter [Hrsg.], Die Briefe Friedrichs des Großen an seinen vormaligen Kammerdiener Fredersdorf, Berlin 1926) sind im Original verloren bzw. in Familienbesitz. Von besonderem Interesse wäre die Kenntnis des vollständigen Briefes Fredersdorfs an den König vom 23 . Fe- autor, Komponisten, Tanzmeister sowie Bühnenausstatter und erläutern die Szenenbilder ${ }^{28}$ der einzelnen Akte. Am Ende steht die Beschreibung der Tanzeinlagen mit Nennung der beteiligten Tänzer sowie die sog. »Comparse«-Rollen, die "Stummen Personen«.

Für die hier vorgelegte Untersuchung werden lediglich die für die Bühnendekoration relevanten Passagen zitiert. Die Auflistung der Szenenbilder in den Libretti erfolgte nach Akten und ohne Numerierung; zur Vereinfachung sind in unserem Text die Szenenbilder jeder Oper durchgezählt. Ausgewählt wurde die italienische Version, da dies die gängige Bühnensprache der Zeit war, und alle in Berlin tätigen Bühnendekorateure und -architekten aus Italien stammten.

»Inventaire des decorations de l'Opera du Roi, fait en fevrier $1754,55,56$ «

Ein singuläres Dokument für die Berliner Hofoper in der Mitte des 18. Jahrhunderts und die Geschichte der barocken Bühnendekoration stellt das auf Veranlassung des Opernintendanten, Baron Ernst Maximilian Ignatz von Sveerts, 1754 erstellte Kulisseninventar der Hofoper Friedrichs II. dar, das bis 1756 fortgeschrieben wurde. ${ }^{29}$ Kürzlich von Henzel erstmals vorgestellt, wird es im Anhang vollständig wiedergegeben. Der 35 × $22 \mathrm{~cm}$ große Pappband enthält nach einem zweiseitigen Vorwort des »Inspecteur de l'Opera« Angelo Cori - mit einer Ergänzung des Opernintendanten von Sveerts - auf 25 Seiten detaillierte Angaben zu einzelnen Bühnendekorationen. Im Frühjahr 1756 brechen die Eintragungen ab, die restlichen, bis 72 vornumerierten Seiten blieben leer.

Cori erläutert im Vorwort, daß seit der Eröffnung des Königlichen Opernhauses kein Aufwand gescheut worden sei, für jede dort gezeigte neue Aufführung prächtige und kostspielige Dekorationen zu realisieren. Dadurch sei nach nunmehr elf Jahren ein großer Vorrat an Dekorationen und Kulissenteilen zusammengekommen, die allerdings aufgrund schlechter Lagerung, Staub und Feuchtigkeit teils bereits zerstört oder gefährdet seien.

bruar 1754, dessen dritter Abschnitt von Galli Bibiena handeln soll. 26 Berlinische Nachrichten von Staats- und gelehrten Sachen, 26. März 1754, Nr. 37, S. 148

27 Einige Textbücher sind zusätzlich in Französisch erschienen, siehe die französische Ausgabe von Cleofide, Württembergische Landesbibliothek Stuttgart, Sign. D. oct 10500 T.3, 6 N.

28 »Mutazioni di Scene« bzw. "Veränderungen des Schauplatzes«. 29 Geheimes Staatsarchiv Preußischer Kulturbesitz (= GStA PK), I. HA Rep. 36 Hofverwaltung, Nr. 2628: „Inventaire des decorations de l'Opera du Roi, fait en fevrier 1754, 55, 56« (= Inventaire). 
Der Opernintendant Sveerts habe deshalb angeordnet, „de faire emploier les plus vielles decorations, et celles, qu'ont souffert le plus pour en faire des nouvelles«. Mit der Erstellung eines Inventars erhoffte man, den aktuellen Bestand an wiederverwendbaren Dekorationen zu dokumentieren und zugleich den König von der Notwendigkeit eines bislang nicht vorhandenen, geeigneten Kulissendepots zu überzeugen.

Das Inventaire kann in hohem Maße für zuverlässig gehalten werden, da es unmittelbar nach der Entstehung der einzelnen Produktionen von kompetenter Hand angelegt wurde..$^{30}$ In bislang unbekannter Detailgenauigkeit beschreibt Cori die Einzelteile der vorhandenen Dekorationen und ermöglicht damit eine realitätsnahe Vorstellung von der bühnentechnischen und baulichen Ausführung einzelner Bilder. In sich chronologisch aufgebaut und mit den Namen einzelner Entwerfer versehen, kann das Inventaire die heutigen Kenntisse über die Arbeiten der unter Friedrich II. tätigen Bühnendekorateure wesentlich erweitern und präzisieren. Allein die Beschreibung von Galli Bibienas Bühnenbildern umfaßt 13 Seiten. Auf den ersten sechs Seiten sind die vor Niederschrift des Inventaire entstandenen Dekorationen mit ihren jeweiligen Bestandteilen beschrieben. Lediglich bei jeder zweiten Eintragung ist die Opernproduktion angegeben, häufig scheint Cori die ursprüngliche Verwendung nicht mehr gekannt zu haben. ${ }^{31}$ Alle nach Februar 1754 entstandenen Dekorationen wurden dagegen unmittelbar nach ihrer Herstellung eingetragen. Die deutlich veränderte Anlage dieser Einträge geht weit über eine bloße Auflistung des Lagerbestandes hinaus. Jede Opernproduktion wird mit dem Datum ihrer Erstaufführung vermerkt, danach sind die neu hergestellten Bilder mit ihren Einzelteilen eingetragen, ferner wird angegeben, welche weiteren Szenenbilder aus den vorrätigen Dekorationen zum Einsatz kamen. Die Bedeutung dieser im Detail noch zu erörternden Praxis mehrfach genutzter Bühnendekorationen wird im letzten Abschnitt näher vorzustellen sein.

30 Fehlerhaft sind nach unserer Kenntnis einige Rückbezüge auf falsche Seitenangaben, die sich jedoch ohne Schwierigkeiten klären lassen. Vorsichtig sollten auch die weiter zurückliegenden Angaben gelesen werden, was die Urheberschaft einiger Dekorationen der ersten Jahre betrifft.

31 Durch die Analyse der Akten und Textbücher ließen sich indes viele Bilder mit hoher Wahrscheinlichkeit auf eine Oper festlegen. Die entsprechenden Angaben sind im Abdruck des Inventaire (Anhang) in eckigen Klammern ergänzt.

32 Er wurde hier nicht für Festausstattungen oder Kostümentwür fe herangezogen.

33 Einzig zur Oper Orfeo, die am 27. März 1752 im Opernhaus zur Uraufführung kam, wurde Galli Bibiena nicht beigezogen. Zu hier
III.

Opernaufführungen der Königlichen Hofoper, 1750 bis 1756

Alle nachfolgend vorgestellten Aufführungen fanden im Königlichen Opernhaus Unter den Linden statt, Galli Bibiena war am Preußischen Hof ausschließlich für die Bühnenausstattung dieser Vorstellungen zuständig. ${ }^{32}$ Üblicherweise wurden Neuproduktionen anläßlich der »Winterlustbarkeiten" im Dezember und Januar, zum Geburtstag der Königin-Mutter Sophie Dorothea am 27. März oder bei auswärtigem Besuch gezeigt. Die jeweils angegebenen Daten der Aufführungen sind den Akten und zeitgenössischen Zeitschriften entnommen, sie weisen alle Spieldaten nach. ${ }^{33}$ Die Angaben zum Verfasser des Librettos sind den einschlägigen Fachlexika entnommen, in unserem Zusammenhang konnte nicht auf mögliche Urheberschaftsfragen eingegangen werden. ${ }^{34}$

Die Schreibweise von Eigennamen ist im behandelten Zeitraum uneinheitlich. Aus Gründen der Übersichtlichkeit wurde für die häufig genannten Personen eine einheitliche Form festgelegt, innerhalb zitierter Quellen ist die Orginalschreibweise beibehalten.

Ebenso uneinheitlich ist die Schreibweise bühnentechnischer Fachausdrücke in den zitierten Quellen; in eigenen Formulierungen wurden aus sprachlichen Gründen die Termini »Szene«, »Bild« und »Dekoration« synonym verwendet.

\section{FETONTE, Tragedia per Musica ${ }^{35}$}

Text von Leopoldo Villati, Musik von Carl Heinrich Graun

Uraufführung 31. März 1750, weitere Aufführungen 22. und 24. August 1750 anläßlich des Besuchs von Wilhelmine von Bayreuth, 18., 21., 25. und 28. Dezember 1750

Das Textbuch weist folgende Szenenbilder aus: 1. Giardino con Grottesca, e Mare in Lontananza

nicht behandelten Einzelheiten des Opernbetriebes siehe die erkenntnisreiche Studie von Henzel (wie Anm. 2).

34 Jürgen Maehder, Die Librettisten des Königs. Das Musiktheater Friedrichs des Großen als theatralische wie linguistische ItalienRezeption, in: Theater im Kulturwandel des 18. Jahrhunderts, hg. von E. Fischer-Lichte u. J. Schönert. Göttingen 1999, S. 265-304. 35 Verwendete Quellen: Textbuch 1750, Staatsbibliothek zu Berlin PK, Musikabteilung Sign. T 61 (4); Inventaire (wie Anm. 29), S. 7 Nr. 7, S. 10 Nr. 1, S. 13 Nr. 1 und Nr. 3, GStA PK, I. HA Rep. 36, Nr. 2628; „Berechnung der Oper Phaeton, 31. März 1750«, Staatsbibliothek zu Berlin PK, Musikabteilung, Königliche Hausbibliothek, KHM 6818; „Rechnung über die Aufführung der Opern Phaeton und Iphigenia anläßlich des Besuches des Bayreuther Hofes im August 1750«, GStA PK, I. HA Rep. 36, Nr. 2648. 
2. Grand'Atrio del Palazzo Reale d'Egitto, sontuosamente adornato per una grande festa

3. Tempio d'Iside, che poi si cangia in un Abisso orribile, che vomita fiamme, e donde n'escono Furie, e Fantasmi terribili

4. Reggia di Sole

5. Campagna amena. Aurora con Nuvole, dissipate le quali, si scorge Fetonte elevarsi sopra l'Orizonte, affiso sul Carro del Sole, dal quale poi si vede fulminato cadere

Nach den Angaben im Textbuch sind alle Dekorationen "d'invenzione del Sig. Innocente Bellavita, Decoratore di Sua Maestà«. Durch hier erstmalig vorgestellte Quellen kann jedoch belegt werden, daß dies nur für die erste Aufführung im März zutrifft, für die beiden im August gezeigten Vorstellungen wurden das erste und fünfte Bild nach neuen Entwürfen von Giuseppe Galli Bibiena realisiert. Galt bislang in allen operngeschichtlichen Untersuchungen die Aufführung von Armida im März 1751 als Galli Bibienas erste Berliner Bühnendekoration, läßt sich nun sein Engagement am preußischen Hof ein halbes Jahr früher ansetzen.

In den erhaltenen Dekorations-Rechnungen ist eine Aufstellung des Malers Friedrich Wilhelm Hoeder aufschlußreich, in der er 21 von ihm gemalte Dekorationselemente für Fetonte aufführt, die er bis Ende März nach Bellavites Anweisungen fertiggestellt hatte. ${ }^{36}$ Für das erste Bild verrechnete er: "Den Garten repariret - 8 Thaler « und »Eine Grotte gemahlt - 3 Thaler«. Dem letzten Bild zugehörig ist "Eine Decoration welche vorstellet ein feldt mit bäumen - 100 Thaler", "Zwei Seiten Ceenen mit bäumen gemahlt - 10 Thaler", "Der Phaitons Waagen gantz vergoldt nebst die zwey pferd gemahlt 5 Thaler" sowie "Die Sonne an den Phaiton nebst den Feuer Flammen transparent gemahlt wie auch die große Sonne darhinter vergoldet nebst den Wolcken gemahlt - 5 Thaler«.

Für Fetonte wurde demnach für das erste Bild nach der mehrfach nachweisbaren Praxis verfahren, ältere Dekorationen zu überarbeiten und in die neue Opernaufführung zu integrieren. Bei der Vorbereitung des Unterhaltungsprogrammes für den Bayreuther Besuch scheint Friedrich II. hiermit nicht mehr zufrieden gewesen zu sein. Ein erster
Hinweis auf eine teilweise Neubearbeitung der Dekorationen bietet ein scheinbar unwesentlicher Nebensatz in einer umfangreichen Rechnungsakte zu den beiden August-Vorstellungen von Fetonte ${ }^{37}$. Der Kastellan der Oper, Monsieur Telmy, reichte Rechnungen für verschiedene Hauswartsdienste ein, darunter »als die Decorationes von Mr. Bibiani von Ihro Königl. Majestät besehen worden, Einen Mann wegen der beleuchtung 1 Nacht zu wachen. ${ }^{38}$ Offensichtlich überzeugte sich der König selbst von der Qualität der neuen Bühnendekoration nach den Entwürfen des berühmten Theaterarchitekten, den er erstmalig nach Berlin holen ließ. Es ist heute nicht mehr zu beantworten, warum Galli Bibiena erst für die zweite Aufführungsserie von Fetonte engagiert wurde. Im Frühjahr 1750 war Galli Bibiena vermutlich durch Verpflichtungen in Dresden festgehalten und konnte die Berliner Bühnendekoration erst in den spielfreien Sommermonaten planen und realisieren. ${ }^{39}$ Denkbar wäre auch eine bewußte Entscheidung Friedrichs II., Galli Bibiena speziell für den Besuch seiner musikliebenden Schwester Wilhelmine zu engagieren, die selbst zwei Jahre vorher das Bayreuther Opernhaus nach Entwürfen Giuseppe und Carlo Galli Bibienas eröffnet hatte.

Genauere Hinweise auf die neuen Entwürfe bieten die Eintragungen im Inventaire. (Abb. 5) Unter den ersten Bühnendekorationen Galli Bibienas ist vermerkt: „Campagne pour l'Opera Phaeton - 40 Pieces qui forment le Prospet en Scene longue, 8 Culises, Un Rideau en prospet pour la rendre Scene Courte, 4 grandes pieces detachées, 2 autres petites pieces«. Die detailliert aufgezählten Bühnenelemente lassen erkennen, daß Galli Bibiena eine vollständige, umfangreiche Dekoration entworfen hatte. Es ist weiterhin nachweisbar, daß außer diesem Schlußbild auch das erste Bild - ein Lustgarten mit Blick aufs Meer - von ihm neu entworfen wurde, denn bereits bei den Vorbereitungen der folgenden Opernaufführung Armida im Frühjahr 1751 wurden vorhandene "Seiten Scenen von des Hr. Bibiena seinem Garten« wiederverwendet, die nur aus Fetonte stammen können. Das Gartenbild bestand insgesamt - nach den Angaben im Inventaire ${ }^{40}$ - aus $" 44$ pieces en prospet presque toutes peintes en carton, 6 culises, 4 pieces pour la supente«.

37 GStA PK, I. HA Rep. 36, Nr. 2648.

38 Ebd., fol. 2 .

39 Zwischen April und Oktober 1750 war der Dresdner Hof in Warschau, folglich konnte Galli Bibiena in dieser Zeit andere Verpflichtungen wahrnehmen. Siehe Fürstenau (wie Anm. 6), Bd. 2, S. 261

40 Inventaire (wie Anm. 29), S. 13 Nr. 1. 


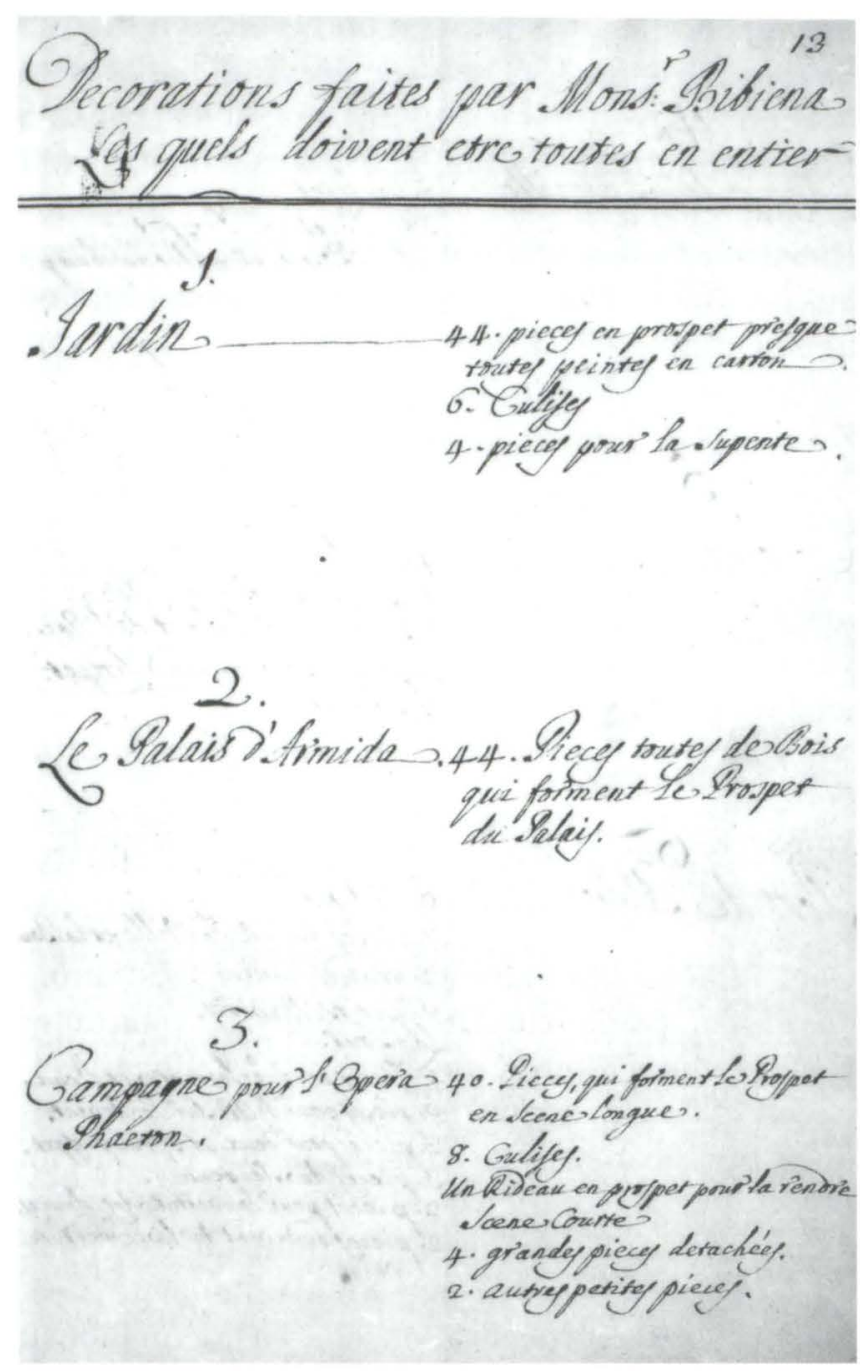

Abb. 5 Inventaire des decorations de l'Opera du Roi, Berlin 1754-1756, S. 13. Geheimes Staatsarchiv Preußischer Kulturbesitz, I. HA Rep. 36 Hofverwaltung, Nr. 2628

Über den hohen Aufwand, mit dem Friedrich II. das mehrwöchige Unterhaltungsprogramm für seine Gäste vorbereiten ließ, unterrichtet unter anderem eine eigens gedruckte »Historische Nachricht von denen Lustbarkeiten ${ }^{41}$. Ungewöhnlich ausführlich wird hier die Opernaufführung vom 22. August besprochen: "Noch denselben Abend wohnte man der Italienischen Oper, Phaethon, bei, welche auf dem großen Theater vorgestellet wurde, das der König

41 Historische Nachricht von denen Lustbarkeiten, welche der König bei Gelegenheit der Ankunft I. Königlichen Hoheit und des Durchlauchtigsten Marggrafens von Brandenburg-Bareuth, im Monate, August, 1750, zu Potsdam, zu Charlottenburg und zu Berlin angestellet hat. Berlin, gedruckt und zu finden bei Christian Friedrich Henning, Königlichem privil. Buchdrucker. GStA PK, Königl. Hausbibliothek Preußen E. 1. i. 275.

42 Ebd., S. $10 f$

43 Darauf deutet auch ein Umbauprojekt Galli Bibienas für die Berliner Hofoper aus dem Jahre 1750 hin. Siehe: Ausst. Kat. Paradies des Rokoko (wie Anm. 7), Kat. Nr. 284, sowie: Babette Ball-Krückmann, Giuseppe Galli Bibiena: Ein unbekanntes Umbauprojekt für
[...] nach den Anlagen des Barons von Knobelsdorf hat aufbauen laßen. Diese Oper ist eine Übersezung aus dem Quinaut. Das Schauspiel war ungemein vorzüglich und von den allervollkommensten, so wol in der Absicht der Ausarbeitung, als auch in Betrachtung der ausnehmenden Stimmen, der reichen Kleidungen und der prächtigen Auszierungen. Unter diesen wurde der Pallast der Sonne am meisten bewundert. Durchscheinende Säulen von Cristalle mit vergüldeten Unter-Lagen und Haupt-Gesimsen trugen das Gewölbe, welches von nichts, als Golde und Edelgesteinen, blizte. Der Thron, welcher in einer Entfernung stand, war mit den Sonnen-Stralen umgeben. Diese aber warfen einen so großen Glanz, daß die geblendeten Augen Mühe hatten, sie zu unterscheiden. ${ }^{42}$ Der Einstand Galli Bibienas am Preußischen Hof scheint in höchstem Maße gelungen verlaufen zu sein ${ }^{43}$, schon bei den Verhandlungen zu Armida konnte er - seiner Wertschätzung bei Hof entsprechend - eigene Vorstellungen in die Verhandlungen einbringen. So wählte er selbst die von ihm zu entwerfenden Szenen aus und konnte erreichen, daß die dafür notwendigen finanziellen Mittel nicht wie üblich zu Beginn festgelegt wurden. Bellavite, verantwortlich für die drei mittleren Verwandlungen in Fetonte ${ }^{44}$, mußte sich künftig bei weiteren vier Operninszenierungen die Bühne mit Galli Bibiena teilen, bevor letzterer regulär angestellt wurde und nun alleinverantwortlich für die Bühnenausstattungen der Berliner Hofoper war.

\section{ARMIDA, Dramma per Musica ${ }^{45}$}

Text von Leopoldo Villati nach Philippe Quinault, Musik von Carl Heinrich Graun Uraufführung 27. März 1751, weitere Aufführungen 6., 10., 13. Dezember 1751 und 3. Januar 1752, Wiederaufführung 1784 mit dieser Ausstattung

Das Textbuch weist folgende Szenenbilder aus:

1. Gran Piazza, ornata d'un Arco trionfale, con Luogo elevato per i Principi

2. Campagna amena, in cui scorre un fiume, e forma un'isola deliziosa

die Berliner Oper, in: Opernbauten des Barock, München 1999 (= ICOMOS, Hefte des Deutschen Nationalkomitees Bd. 30), im Druck.

44 Im Inventaire sind vermerkt: der Isis-Tempel (S. $10 \mathrm{Nr}$. 1) - als Mitarbeiter ist der Bologneser Theatermaler Girolamo Bon angeführt - und die "Reggia di Sole" (S. 7 Nr. 7). Es fehlt die zweite Szene, für die vermutlich ältere Dekorationen verwendet wurden. 45 Verwendete Quellen: Textbuch 1751, Staatsbibliothek zu Berlin PK, Musikabteilung Sign. T 48 (2); Inventaire (wie Anm. 29), S. 4 , S. 7 Nr. 6, S. 13 Nr. 2, GStA PK, I. HA Rep. 36, Nr. 2628; „2 Rechnungen sowie Schriftwechsel über die Aufführung der Opern Armida und Britannicus am 27. März 1751 «, GStA PK, I. HA Rep. 36, Nr. 2649 
3. Bosco, ripieno d'alberi molto folti, ed alti. Nel mezzo del bosco medesimo si scorge un gran Cipresso, nel quale tiene Armida custodita I'Armatura di Rinaldo

4. Luogo ameno

5. Continua il suddetto Luogo ameno

6. Ritorna il Bosco mentovato di sopra

7. Giardino amenissimo con Veduta del palazzo d'Armida nel fondo, circondato dal Mare, alla riva del quale si vede il palischermo magico, in cui venne Ubaldo

Im Textbuch zu Armida wird der als Gast verpflichtete Bühnenbildner zum ersten Mal - angemessen und wohl nicht ohne Stolz - genannt: »Szenen von der Erfindung des Herrn Giuseppe Galli Bibiena Theatral-Ingenieur Sr. Majst. des Königs von Pohlen«.

Es ist nicht bekannt, zu welchem Zeitpunkt die Planungen zu Armida begonnen wurden. Erhalten sind dagegen schriftliche Ausführungen des Opernintendanten Sveerts, die während der konkreten Entwurfsphase entstanden sind. Am 11. Februar 1751 schrieb Sveerts dem König, daß er seit drei Tagen intensiv mit Galli Bibiena verhandle. ${ }^{46}$ Dieser habe nun zugesagt, daß er »den größten theile zur Armida verfertigen will; aber ohne accord, was es kosten werde, indem es keine ganze decoration ist, sondern nur stück-weise zurecht gemacht werden muß.« Sveerts fährt fort, daß sich Galli Bibiena nicht auf die Gesamtausstattung einlassen wolle, da zu wenig Zeit zur Verfügung stünde; deshalb solle gleichzeitig Bellavite an den restlichen Szenen arbeiten. Ausdrücklich ließ Galli Bibiena Friedrich II. um Verständnis bitten, daß er weiterhin im Dienst des Königs von Polen bleiben wolle und deshalb mehrfach nach Dresden reisen werde. Abschließend informierte Sveerts den König voll Sorge, daß er den Kostenaufwand für die von Galli Bibiena vorgelegten Entwürfe wesentlich höher als bisher vorgesehen einschätze, und bittet seinen Dienstherren um weitere Anweisungen. Das Schreiben enthält keine Randbemerkungen; offensichtlich fand zur Klärung eine persönliche Besprechung der Beteiligten in Potsdam statt, auf die sich drei beigefügte Protokolle vom 12. Februar 1751 zu Bühnendekoration und -kostümen beziehen. Der vollständige erste Text lautet:

"In der Opera Armida Machet Hr. Bibiena

Ersten Act. Erste Scene.

Einen neuen Vorhang zur Perspective mit großer
Stiege, Portalen, Collonaden und Gallerien. Hierzu bleiben die Seiten-Scenen von des Hr. Fanti seinem Vorhoff.

Erster Act. dritte Scene. [falsch bezeichnet, 1. Akt 2. Bild]

Hiezu wird gebraucht der alte Wald des Hr. Bibiena aus der Opera Phaeton; im Prospect machet Er eine neue Öffnung [?], welche eine Insel im Fluße vorstellet, wo Abaldo im Nachen anlanget.

Zweiter Akt. letzte Decoration [falsch bezeichnet, 3. Akt 3. Bild]

Hiezu wird gebrauchet die Seiten Scenen von des Hr. Bibiena seinem Garten, und ein Prospect machet er neu einen prächtigen Pallast der Armida von einer großen Colonade umfangen, welcher zuletzt im Feuer verzehret wird.

NB. Hier wird der Italiäner sein Feuerwerk anbringen.

Von Sr. Königl. Majestät allergnädigst approbiert. Potsdam den 12. Febr. 1751.«47

Galli Bibiena übernahm demnach die Gestaltung des ersten, zweiten und letzten Bildes, jeweils unter Einbeziehung älterer, unveränderter Teile. Abweichend zu den hier getroffenen Festlegungen für das erste Bild liest sich der entsprechende Eintrag im Inventaire: „Decoration de Monsieur Fanti en entier - Cour ou Cortile, 8. Culises. 1. Toile, qui descende en soupente sur le Prospet. NB Mr. Bellavite a retouché toute cette decoration, et il y a fait un Rideau nouveau pour Prospet, pour l'Opera Armida.« Da weitere Belege fehlen, läßt sich heute nicht entscheiden, ob Galli Bibiena oder Bellavite das erste Bild realisiert hat. Für das zweite Bild wurde der Wald von Galli Bibienas "Campagna amena" aus Fetonte wiederverwendet, für das siebente Bild die Seitenkulissen des »Giardino « aus Fetonte. Der hierzu ergänzte »Palazzo d'Armida « bestand aus »44 Pieces toutes de Bois qui forment le Prospet du Palais $\aleph^{48}$.

Ein zweites Protokoll dieser Besprechung legte Bellavites Arbeiten fest:

»In der Opera Armida Machet Herr Bellavita

Zweiter Act. Erste Szene

Die Verwandlungs-Decoration aus der Opera Angelica, u. Medoro wird auf der einen Seiten, wo die unterirdischen Gräber gemahlt sind, überstrichen, und dagegen in ein angenehmes Lustwald gemahlet.

Hierzu einen hundert-augigen Riesen Briaico [?], welcher aus einem Cypreßen-Baum hervorsteiget. 
Item machet Er zu dieser Opera den Wagen, mit zwey Drachen bespannet, worauf die Armida, oder die ihre Person vertritt, davon fährt.

Ein Canape, worauf Rinaldo schläfet, und hernach vor seinen Augen verschwindet.

Von Sr. Königl. Majestät allergnädigst approbiert. Potsdam d. 12. Febr. 1751.«49

Die von Bellavite ausgestattete Szene diente als Verwandlungsdekoration für das dritte und vierte Bild, sie blieb auch während des fünften Bildes auf der Bühne, im sechsten Bild erfolgte die Rück-Verwandlung zum "Bosco«. In dieser Form findet sich die Dekoration auch im Inventaire unter Bellavites Arbeiten vermerkt: „Bois sombre, ou Sotterranei qui se transforment en un lieu delicieux « ${ }^{50}$.

Die Gesamtkosten für die Anfertigung der Dekorationen ${ }^{51}$ lagen mit 2.071 Talern deutlich höher als die Kostümrechnungen, die sich auf 1.377 Taler beliefen. Galli Bibiena und Bellavite rechneten ihre Ausgaben für die von ihnen beschäftigten Theatermaler, für Leinwand und Farben, Farbenreiber, Nagelschmiede und andere Handwerker jeweils individuell mit dem Opernhaus ab. Galli Bibiena reichte u. a. Rechnungen für den Theatermaler Carl Friedrich Fechhelm ein, der zwischen 6. Februar und 21. März mit einem Gesamtlohn von 86 Talern für ihn arbeitete ${ }^{52}$, ferner für die Theatermaler Luigi Franceschini und Daniel Mändlich. Bellavite beschäftigte einen nicht näher zu ermittelnden G. Hagen, der selbst wiederum vier namentlich nicht genannte Maler mitgebracht hatte. Hagen beschrieb seine Arbeiten für die Verwandlungsdekoration, die auf drehbare Bühnenelemente gemalt wurde, knapp: "Zur Opera Armida ist auf die Bretter machinen ein Goldener Garten gemahlet, und auf der anderen Seite der Wald repariert worden. «53

Galli Bibiena gestaltete alle ihm übertragenen Szenenbilder in Armida unter Einbeziehung und Nutzung älterer Kulissen, die teils aus seiner $\mathrm{Fe}$ tonte-Ausstattung, teils aus Dekorationen anderer Entwerfer stammten. Neu gefertigt wurden jeweils die mit Holzrahmen verstärkten Prospekte in Theatermalerei, mit deren Hilfe eine kostengünstige und relativ schnell zu realisierende Bühnengestaltung erreicht werden konnte.

49 GStA PK, I. HA Rep. 36, Nr. 2649, fol. 6.

50 Inventaire (wie Anm. 29), S. 7 Nr. 6

51 GStA PK, I. HA Rep. 36, Nr. 2649, fol. 24-66.

52 Dies ist der früheste Nachweis über Fechhelms Berliner Tätigkeit. Siehe Henzel (wie Anm. 2), der Fechhelms Malerarbeiten für Orfeo 1752 als frühesten Nachweis nennt, S. 42, Anm. 113.

53 GStA PK, I. HA Rep. 36, Nr. 2649, fol. 41.

54 Verwendete Quellen: Textbuch 1751, Staatsbibliothek zu Berlin PK, Musikabteilung Sign. T 67 (2); Inventaire (wie Anm. 29) S. 14 Nr. 5, S. 15 Nr. 7 und 8, S. 16 Nr. 9, GStA PK, I. HA Rep. 36, Nr. 2628; „2 Rechnungen sowie Schriftwechsel über die Aufführung der
BRITANNICO, Tragedia per Musica ${ }^{54}$

Text von Leopoldo Villati nach Jean Racine, Musik von Carl Heinrich Graun

Uraufführung 17. Dezember 1751, weitere Aufführungen 20., 24., 27., 31. Dezember 1751, 7., 10., 14., 17., 21. und 24. Januar 1752

Das Textbuch weist folgende Szenenbilder aus: Alle Szenen spielen im Palast Neros

1. Sala Magnifica, con trono da un lato, destinata alle Pubbliche Udienze

2. Giardino

3. Cortile

4. Gabinetto di Nerone

5. Ritorna il Cortile

6. Salone illuminato in tempo di notte, con varie credenze intorno. Gran mensa nel mezzo con due sedie in faccia, e due altri sedili minori alle due parti.

Britannico ist die erste vollständig von Galli Bibiena ausgestattete Oper in Berlin, alle fünf Szenenbilder - der "Cortile« kommt im dritten und fünften Bild auf die Bühne - sind neue Entwürfe, vermutlich wurden hierfür auch keine älteren Teile verwendet. Obwohl kaum Akten zur Herstellung dieser Dekorationen erhalten sind, kommt Britannico insofern eine besondere Bedeutung zu, als es die einzige Opernproduktion dieser Jahre ist, zu der die "Berechnung mit dem Decorateur Herrn Bibieni ${ }^{55}$ erhalten ist. Demnach erhielt Galli Bibiena, der in Dresdner Diensten stand und in Berlin lediglich im "Werkvertrag « arbeitete: "Vor 5. Decorationes alle von Architektur, und eine Mutation, der an ein großer Saal von Transparens zu mahlen, in öl Farben, à 700 th.« - eine Gesamtsumme von 3.500 Talern. Dazu kamen insgesamt 280 Taler »an accordirte Kostgeld, von 1ten April bis den 20ten August à 60 th. monatlich« sowie 37 Taler Reisegeld für die Postkutsche nach Dresden. An diesen auffällig hohen Honoraren zeigt sich deutlich die Wertschätzung dieses Theaterarchitekten, der solche Summen vermutlich selbst fordern konnte. ${ }^{56} \mathrm{Im}$ Inventaire lassen sich einzelne verzeichnete Dekorationen zuordnen, auch wenn der konkrete $\mathrm{Na}$ menshinweis auf Britannico fehlt. Als erste Szene fand vermutlich die »Petite Salle« Verwendung, als

Opern Armida und Britannicus am 27. März 1751«, GStA PK, I. HA Rep. 36, Nr. 2649; "Dekorationsbelege für die Opern Didone u. Orpheus 1752/53«, Staatsbibliothek zu Berlin PK, Musikabteilung, Königliche Hausbibliothek, KHM 6827.

55 GStA PK, I. HA Rep. 36, Nr. 2649, fol. 11.

56 Galli Bibienas Bezahlung für Britannico erfolgte aus dem Etat des Opernhauses, das direkte Zuwendungen vom König bezog. Vergleichsweise gering war dagegen Bellavites Jahresgage; er erhielt jährlich 700 Taler aus dem Kapellenetat. Hierzu Henzel (wie Anm. 2), S. 18. 


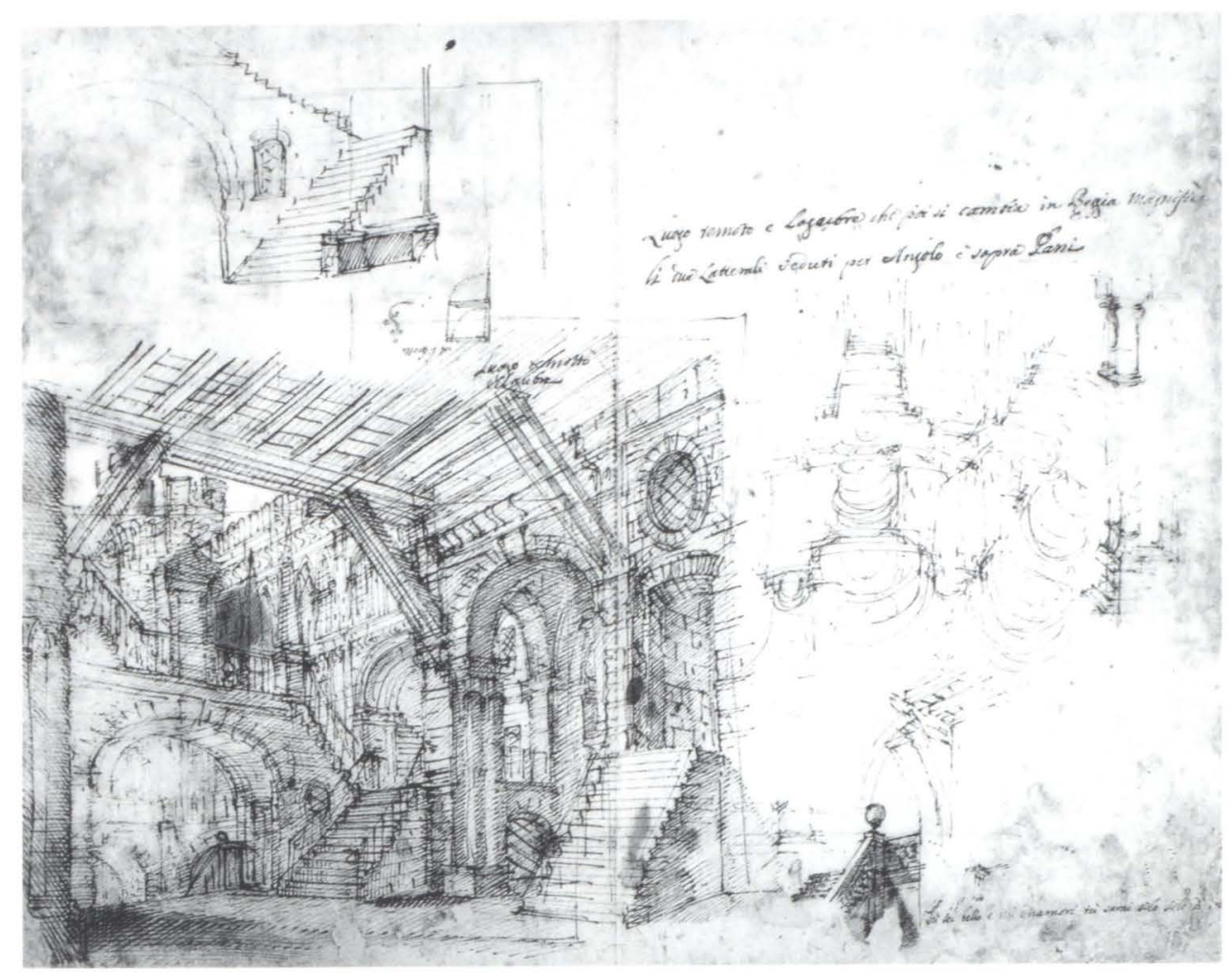

Abb. 6 Giuseppe Galli Bibiena, Entwurf zum fünften Bild in Britannico, 1751, Feder mit brauner Tinte. Staatliche Museen zu Berlin, Kunstbibliothek (Lipp-HdZ 5131 recto)

Hof eine davor eingetragene "Avant Cour", als viertes Bild ein "Cabinet« aus wenigen Elementen, als Schlußbild schließlich eine "Sale magnifique Transparente ${ }^{57}{ }^{57}$

Die oben zitierte Szenenabfolge vom fünften zum sechsten Bild (Cortile - Salone illuminato), die bei den in Berlin gezeigten Opern nur in Britannico vorkommt, sowie die genannte Beschreibung »eine Mutation, der an ein großer Saal von Transparens zu mahlen« erlaubt es, eine bereits früher vorgenommene Zuschreibung einer erhaltenen Entwurfszeichnung Galli Bibienas für Britannico zu untermauern. ${ }^{58}$ Das mehrteilig ausgeführte Blatt ${ }^{59}$ (Abb. 6 und 7), wohl einem aufgelösten Skizzenbuch Galli Bibienas dieser Jahre entnommen, zeigt im linken unteren Bereich als zentrale Darstellung einen detailliert ausgeführten Bühnenbildentwurf eines düsteren Burghofes mit Treppen, die in tiefer und höher gelegene Geschosse führen. Eine eigenhändige Aufschrift Galli Bibienas erläutert: "Luogo remoto e Logubre che poi si cambia in Reggia Magnifica/li due Latterali veduti per angolo è sopra Pani«. Der Szenenwechsel sollte demnach auf offe-

57 Inventaire (wie Anm. 29) S. 14 Nr. 5, S. 15 Nr. 7 und 8, S. 16 Nr. 9. Nicht nachweisbar ist das zweite Bild.

58 Hein-Th. Schulze Altcappenberg, Eine unbekannte Sammlung italienischer Zeichnungen aus Berliner Privatbesitz. Neuerwerbungen des Kupferstichkabinetts und der Kunstbibliothek, mit Beiträgen von B. Evers und A. Rasche, Ausst. Katalog Berlin 1997 , Kat. 34. ner Bühne mit einer sichtbaren Verwandlung vonstatten gehen; hierfür konnten drehbare Bühnenelemente und gestaffelt hängende Soffitten und Prospekte eingesetzt werden. Eine unscheinbare Detailzeichnung oben links mit der Bezeichnung »a libretto« (= zum Falten) erläutert eine Konstruktion für die geplante Verwandlung. Andere Skizzen auf diesem Blatt zeigen Details und Varianten der Treppe bzw. der abschließenden Brüstung sowie - in $180^{\circ}$ Drehung - einen zentralperspektivisch angelegten, doppelstöckigen Saal mit überkuppelten Raumzonen, der möglicherweise mit dem Schlußbild in Britannico in Zusammenhang steht. ${ }^{60}$

Eine Vorstellung von der Umsetzung des zeichnerischen Entwurfs in Bühnenarchitektur und -malerei ermöglichen die detaillierten Angaben im Inventaire. Die Hof-Dekoration bestand demnach aus sechs Kulissen, die als bespielbare Elemente zu beiden Seiten den Vordergrund bildeten, darüber waren ebensoviele Bauteile (6. pieces sur les Culises) befestigt, die den Übergang zur Balkenkonstruktion bildeten (1. piece qui forme l'Arc, 8. pieces des Arcs du dessous). Im Hängeboden befanden

59 Staatliche Museen zu Berlin, Kunstbibliothek, Lipp-HdZ 5131; Feder mit brauner Tinte, 42,5 x 54,6 cm; beidseitig mit eigenhändigen Beischriften und weiteren Skizzen.

60 Auf dem Verso sind einzelne Architekturdetails und ein mit wenigen Strichen entworfener Lustgarten skizziert. Eine zweifelsfreie Zuordnung zu anderen Szenen aus Britannico läßt sich nicht vornehmen. 


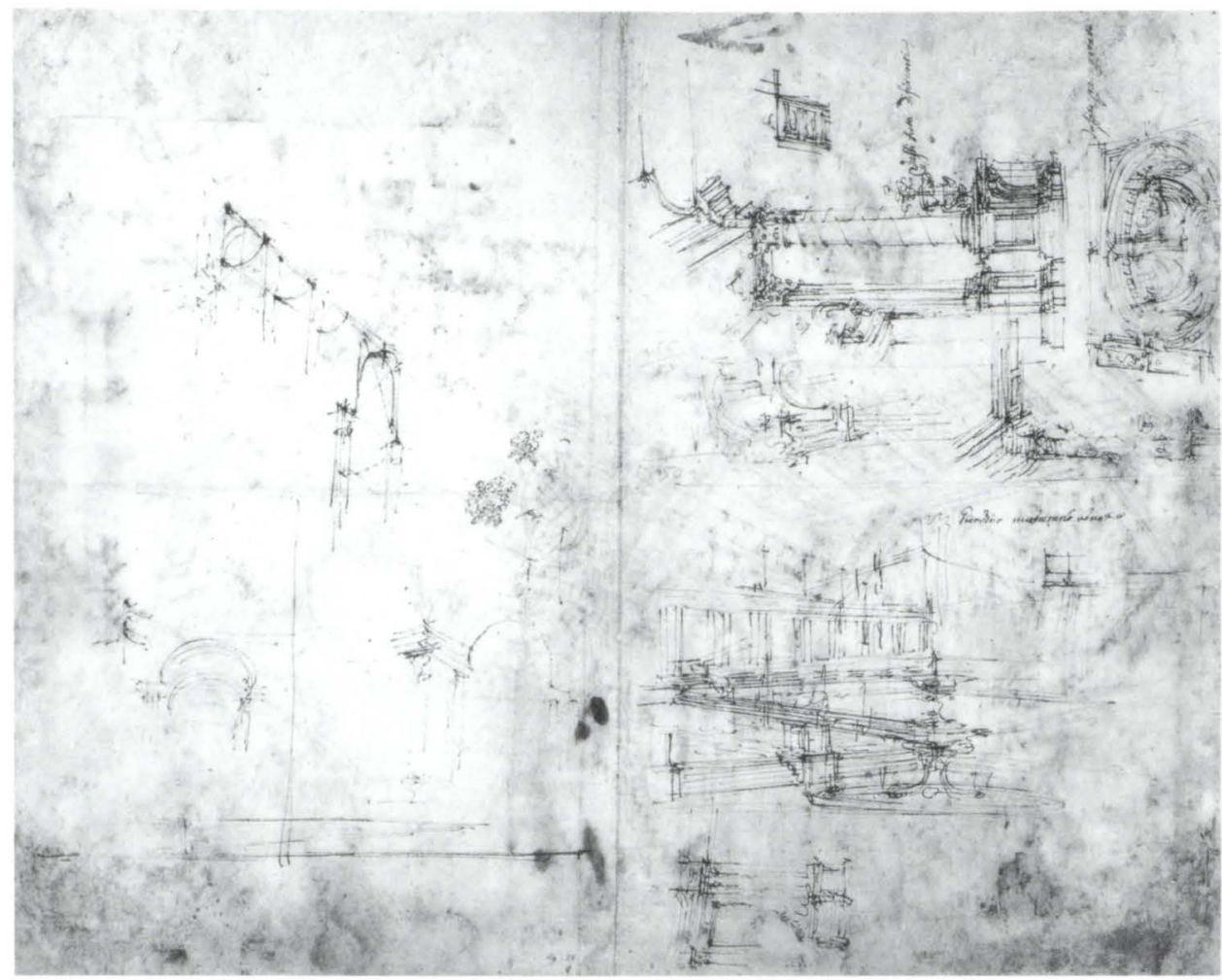

Abb. 7 Giuseppe Galli Bibiena, Entwurfszeichnungen und -skizzen, 1751, Feder mit brauner Tinte. Staatliche Museen zu Berlin, Kunstbibliothek (Lipp-HdZ 5131 verso)

sich weitere sieben Bauteile für den Plafond. Zur Schaffung einer zweiten Bodenebene wurden im Vordergrund flache Podeste (2. pieces au parterre) eingesetzt. Den rückwärtigen Raumabschluß bildete ein zweiteiliger Bühnenprospekt in Illusionsmalerei, vermutlich mit allen Architekturdetails, die in der Zeichnung an die halbstöckige, mittlere Treppe bzw. oberhalb des Kellerdurchgangs anschlieBen. Die gesamte Dekoration bestand aus schräg auf die Bühne gesetzten Bauteilen, die etwa in der Bühnenmitte aufeinanderstießen. Der gemalte Prospekt öffnete einen weiten Durchblick auf ein im Hintergrund sichtbares Wohngeschoß und einen zinnenbesetzten Rundturm.

\section{DIDONE ABBANDONATA, Tragedia ${ }^{61}$}

Text von Pietro Metastasio, Musik von Johann Adolph Hasse

Uraufführung 7. Oktober 1742 Schloß Hubertusburg bei Dresden

Berliner Erstaufführung 29. Dezember 1752, weitere Aufführungen 1., 5., 8., 12., 15., 19., 22., 26. und 29. Januar 1753, und 24. April 1753 anläßlich des Besuchs von Wilhelmine von Bayreuth

61 Verwendete Quellen: Textbuch 1752, Staatsbibliothek zu Berlin PK, Musikabteilung, Sign. T 67 (6); Inventaire (wie Anm. 29), S. 8 Nr. 8, S. 11 Nr. 6, S. 14 Nr.6. GStA PK, I. HA Rep. 36, Nr. 2628; verschiedene Berechnungen und Dekorationsbelege für die Opern
Das Textbuch weist folgende Szenenbilder aus: 1. Luogo magnifico destinato alle pubbliche Udienze con Trono da un Lato

2. Tempio di Nettuno con simulacro del medesimo

3. Gabinetto

4. Porto di mare

5. Arborata

6. Reggia con veduta di Città in prospetto, che poi s'incendia

Es fehlt im Textbuch die sonst übliche Nennung des für die Gesamtausstattung verantwortlichen Bühnengestalters, lediglich eine Szene wird hervorgehoben: "La decorazione del'Incendio e del Sig. Bellavita, Decoratore del Regio Teatro. Eine Bestätigung dieser Angabe findet sich im Inventaire. Unter Bellavites "Erfindungen" ist die "Roiale de Didon, ou Cartage, Scene de Geants avec le Palais de Didon" verzeichnet, sie bestand aus " 8 . Culises faites des vielles scenes. 5 pieces pour la Soupente. Au milieu une montée. Au fond la Ville de Cartage sujette a l'incendie. $\aleph^{62}$

Die Betonung des Schlußbildes als Entwurf Bellavites läßt darauf schließen, daß die fünf anderen Bilder auf Entwürfen Galli Bibienas basierten; die erhaltenen Quellen liefern zumindest

Orpheus und Didone, 1752/53, Staatsbibliothek zu Berlin PK, Musikabteilung, Königliche Hausbibliothek, KHM 6824, 6826, 6827, 6830. 62 Inventaire (wie Anm. 29), S. 8 Nr. 8. Die Ausführung erfolgte durch Carl Friedrich Fechhelm, der am 4. Januar 1753 seine Rech- 


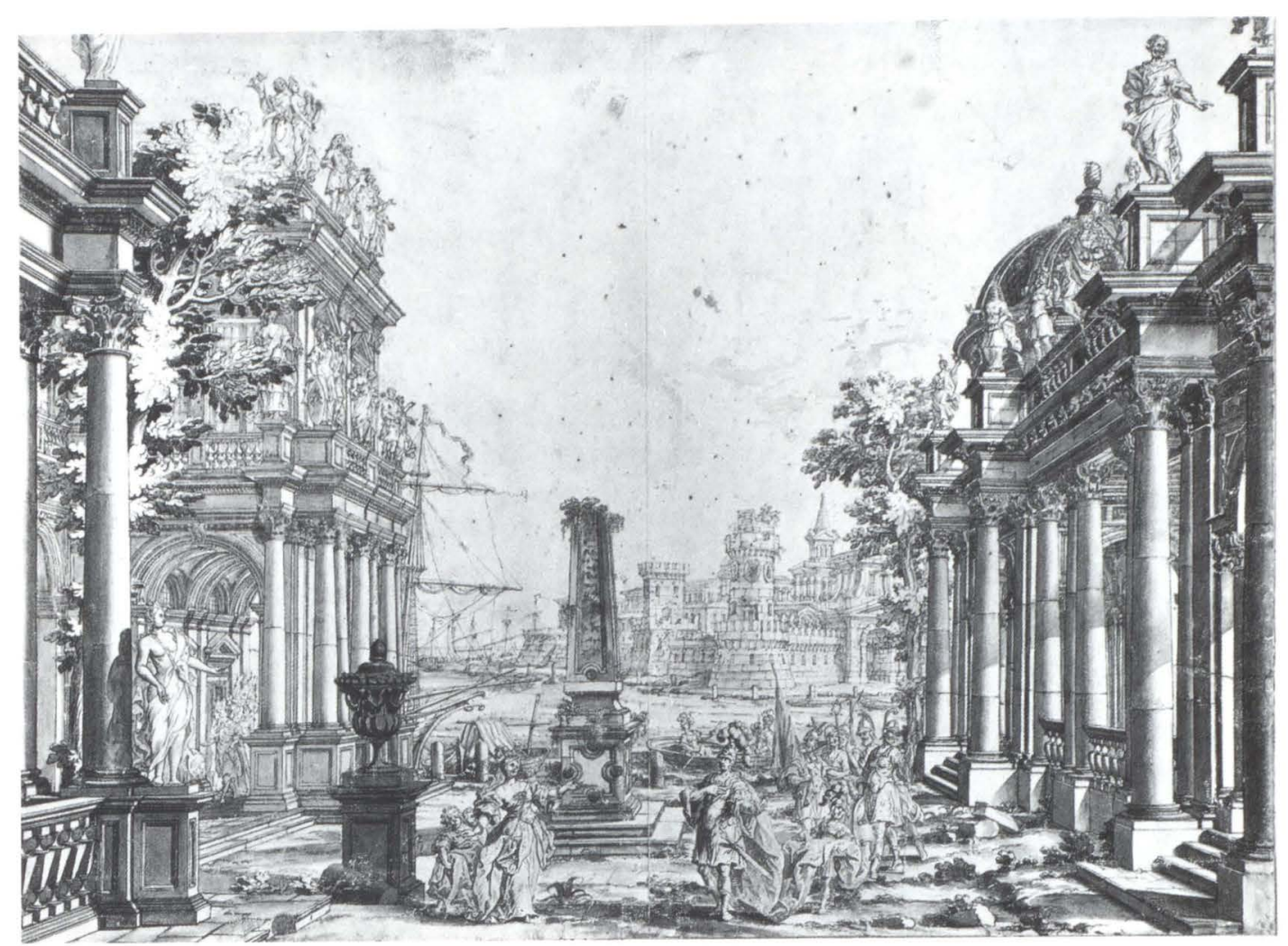

Abb. 8 Giuseppe Galli Bibiena, Forum in Karthago mit der Begegnung von Dido und Aeneas, Feder mit brauner Tinte. Graphische Sammlung Albertina, Wien (Inv. 14401)

teilweise die Bestätigung dieser Folgerung. Eine Rechnung des Theatermalers Carl Friedrich Fechhelm vom 14. November 1752 ist hierfür aufschlußreich:

"Zweyhundert Reichs Thaler sind mir Endes unterschrieben vor die 8 Plafonds zu mahlen welche an denen Bibienischen Decorationes gefehlet, nebst einem Wald Prospect, einem Thron, und die Stadu des Neptun welcher zur neuen Opera Dido gehörig, von dem Herrn Geheimbten Cämmer Frödersdorff richtig und baar bezahlet worden worüber mit gebührend Dank quittiere, Berlin den 14. Novembr. 1752, C. F. Fechhelm Mahler.»

Eine beiliegende Erläuterung von seiner Hand hilft bei der Bestimmung der Szenen weiter:

»Auf Ordre Ihro freyhrl. Gnaden des Herrn Baron von Schwertz, etc. habe nachstehende Stücken zur Opera Dido gemahlet als,

\footnotetext{
nung ablieferte: "Auf Ordre Ihro Gnaden des Herrn Baron von Sveertz, habe zur neuen Opera Dido die letzte Decoration neu gemahlt als bestelet: 8 Seiten Scenen/ 5 Plaffonds/ 8 einsetz Stücken auf Rahmen in Mittel die gantze Stadt im Prospect/ Summa 350 Rthlr/ C. F. Fechhelm, Theatr Mahler«. Bellavita bestätigte die gelieferte Arbeit, mit Nennung seines Titels »Decoratore del Regio Teatro«. Sveerts ließ die Summe auf 320 Taler kürzen, die Auszahlung erfolgte am 18. Januar 1753. Staatsbibliothek zu Berlin PK, Musikabteilung, KHM 6827, fol. 2 .
}

8. Pladfonds, zu den Bibienischen Decorationes

- 2 zum Cabinet

- 3 zum kleinen Saal

- 3 zum Vor-hoff, sind accordirt a $20 \mathrm{Th} \quad 160 \mathrm{Th}$

1 Thron gantz neu

$15 \mathrm{Th}$

1 Stadu, den Neptun

$5 \mathrm{Th}$

1 Wald Prospect übermahlt

Berlin, den 14. Novbr. 1752, C. F: Fechhelm « ${ }^{63}$

Die Aufstellung wurde von Bellavite zum Zeichen seines Einverständisses unterschrieben, auch Sveerts gab seine Zustimmung, die geforderte Summe aus dem »decorationes-fundo" zu bezahlen. Die beiden Schriftstücke belegen, daß die meisten Dekorationsteile zu diesem Zeitpunkt bereits fertiggestellt waren und Fechhelm hier nur einige Ergänzungen abrechnete. ${ }^{64}$ Er malte demnach die Deckenelemente zum dritten Bild »Gabinetto«, den Thron aus dem ersten Bild, die Neptun-Statue des zweiten Bildes und den Prospekt zum fünften Bild

63 Staatsbibliothek zu Berlin PK, Musikabteilung, KHM 6827, fol. 1 und Beilage.

64 Eine am 21. Oktober 1752 ausgestellte Rechnung der Berliner Tuchhändler Sonnin \& Bando über 21 Stück »rohe Leinwandt« läßt vermuten, daß auch diese Lieferung nur einen Teil der benötigten Leinwand abdeckte, möglicherweise also mit Fechhelms Ergänzungen in Zusammenhang zu bringen ist. Staatsbibliothek zu Berlin PK, Musikabteilung, KHM 6827, fol. 9. 
"Arborata«. Unklar ist indes, auf welche Szenen sich die Angabe "Vorhof " bzw. "kleiner Saal " bezieht. In Didone abbandonata käme nur die erste Szene in Frage, möglicherweise war das andere Bild für die Wiederaufnahme von Orfeo vorgesehen oder für einen im Libretto nicht festgelegten, weiteren Szenenwechsel. Nach Fechhelms Angaben läßt sich der Entwurf des dritten Bildes auf Galli Bibiena zurückführen, vermutlich auch das erste Bild. Unklar bleibt die Urheberschaft des Neptuntempels ${ }^{65}$ und der Waldszene, letztere wurde offensichtlich aus älteren, übermalten Bühnenelementen erstellt.

Die verbleibende vierte Szene "Porto di Mare ist im Inventaire detailliert unter den Entwürfen Galli Bibienas beschrieben; mit 42 Einzelteilen war sie ausgesprochen umfangreich: "Port de Mer 6. Culises, 7. pieces deriere la Ville et la Tour, 2. grands Navires, 2. petits Navires, La Tour, 7. pieces pour le Parterre et l'eau, 6. pieces pour l'Arc sur le devant, 3. pieces pour deux arcs, et un prospet, 3 . pieces de soupente, 2 . pieces pour couverture des colomnes, 2. pieces au devant de la couverture rouge. ${ }^{66}$

Eine Vorstellung der räumlichen Gestaltung des ersten und vierten Bildes geben zwei Giuseppe Galli Bibiena zugeschriebene Zeichnungen, die möglicherweise im Zusammenhang mit dieser Berliner Inszenierung zu sehen sind. ${ }^{67}$ Im Theatermuseum München findet sich ein aquarellierter Entwurf zum "Luogo Magnifico destinato alle pubbliche udienze $\star^{68}$ mit reicher Figurenstaffage im Vordergrund. Ähnlich repräsentativen Charakter besitzt eine in Wien erhaltene Entwurfszeichnung „Porto di Mare ${ }^{69}$, deren räumlicher Aufbau gut mit den Angaben im Inventaire vergleichbar ist. (Abb. 8) Beide Entwürfe verbindet die detaillierte Ausführung einzelner Raumelemente, das annähernd gleiche Format, die ähnliche Anlage der im Hintergrund sichtbaren Stadt und die zeichnerische Gestaltung der agierenden Bühnenfiguren.

$65 \mathrm{Im}$ Inventaire ist ein Neptun-Standbild unter den fragmentarisch erhaltenen Arbeiten Bellavites genannt. Inventaire (wie Anm. 29), S. $11 \mathrm{Nr} .6$.

66 Ebd., S. 14 Nr. 6. Die Rechnungen der ausführenden Maler konnten nicht ermittelt werden und sind vermutlich verloren.

67 Da ein persönliches Studium der Blätter nicht möglich war, bleiben die Formulierungen bewußt hypothetisch.

68 Deutsches Theatermuseum München, Inv. IV, 4838; Feder mit brauner Tinte, farbig aquarelliert, $46,5 \times 57,5 \mathrm{~cm}$. Siehe Maria T. Muraro, Elena Polovedo, Disegni teatrali dei Bibiena, Ausst. Kat. Venedig 1975, Kat. 75 mit Abb.

69 Graphische Sammlung Albertina Wien, Inv. 14401; Feder in brauner Tinte, 47,0 x $62,5 \mathrm{~cm}$. Siehe Veronika Birke u. Janine Kertész. Die Italienischen Zeichnungen der Albertina, Generalverzeichnis, Wien u. a. 1997, Bd. IV, S. 2061. Hingewiesen sei auf die annähernd gleichen Blattformate beider Zeichnungen, die etwas größer sind als der für Berlin gesicherte Britannico-Entwurf Galli

\section{SILLA, Dramma per Musica ${ }^{70}$}

Text von Friedrich II. nach Joseph-François Duché de Vancy, übersetzt von Giovanni Pietro Tagliazucchi, Musik von Carl Heinrich Graun

Uraufführung 27. März 1753, weitere Aufführungen 12. und 14. Oktober anläßlich des Besuches von Wilhelmine von Bayreuth, 28. und 31. Dezember 1753, 4., 7. und 11. Januar 1754

Das Textbuch weist folgende Szenenbilder aus:

1. Cortile nel Palazzo di Fulvia

2. Interno del Tempio di Giove Capitolino

3. Appartamenti di Fulvia

4. Gabinetto di Silla

5. Giardino

6. Gabinetto di Silla altra volta

7. Foro Romano, con veduta di magnifico Tempio

Die Kenntnisse über die Ausstattung von Silla waren bislang recht lückenhaft, da im Textbuch kein Bühnendekorateur genannt ist.

Aus den Monaten Februar und März 1753 sind verschiedene Rechnungen von Theatermalern erhalten $^{71}$, die es nun erlauben, im fünften und siebenten Bild Galli Bibienas Entwurf zu erkennen. Neben allgemeinen Abrechnungen über geleistete Arbeitsstunden sind drei Rechnungen aufschlußreich, und zwar diejenigen des Malers August Berger für "Arbeit bey Mons. Bibiena«, ferner von dem so unterschreibenden Fechhelm senior « ${ }^{72}$ "vor die Tropheen und 4 Statuen sambt Springbrunnen, dere orange wie Vasen, das Bassein und alle [...unleserlich] waßer zu mahlen an der garthen decoration des Mons. Bibiena« sowie dessen Rechnung vom 27. März »vor den großen Tempel gantz neu aufgemahlt und neue Plafonds, Statuen und [...unleserlich] die Gallerie mit 8 Szenen 250 th.«

Im Inventaire finden sich diese Entwürfe Galli Bibienas bestätigt. Für die Garten-Szene ${ }^{73}$ fanden acht Kulissenteile Verwendung, die von Bellavites

Bibienas. Das Wiener Blatt weist zudem eine Mittelfalte auf und könnte aus einem Skizzenbuch stammen.

70 Verwendete Quellen: Textbuch 1753, Staatsbibliothek zu Berlin PK, Musikabteilung Sign. T 48 (3); Inventaire (wie Anm. 29), S. 5 Nr. 1, S. 11 Nr. 7, S. 16 Nr. 10, S. 17 Nr. 11, GStA PK, I. HA Rep. 36, Nr. 2628; „Rechnung über die Aufführung der Oper Sylla am 27. März 1753«, GStA PK, I. HA Rep. 36, Nr. 2653; „Kosten für die Ausstattung der Oper Silla, Okt. 1753«, GStA PK, I. HA Rep. 9 LL7c Fasc. 9; „Rechnungen und Schriftwechsel über die Aufführung der Opern Sylla und Cleofide sowie über die Redouten im Dezember 1753 und Jan. 1754«, GStA PK, I. HA Rep. 36, Nr. 2654.

71 GStA PK, I. HA Rep. 36, Nr. 2653, unpaginiert.

72 Es ist dies der älteste der Fechhelm-Brüder, Carl Friedrich; im Gegensatz dazu wird sein um 1740 geborener Bruder Georg Friedrich als junior bezeichnet.

73 Inventaire (wie Anm. 29), S.16 Nr. 10 »Autre Jardin fait pour l'Opera Sylla«. 
"Salle Magnifique« aus Cinna stammten, ferner sechs Kulissen von Galli Bibienas eigenem Gartenbild aus Fetonte, das damit zum dritten Mal verwendet wurde. Neu entworfen und gemalt wurden hierzu ein großer Rückprospekt in 40 Teilstücken sowie " 3 Toiles au fond, une grande et 2 petites ". Auch das letzte Bild - Forum mit Tempel - wurde teilweise aus älteren Dekorationsteilen gefertigt; Galli Bibiena griff auf die restlichen Teile von Bellavites "Salle Magnifique» aus Cinna zurück, die er nicht schon im Gartenbild benutzt hatte. Im Inventaire findet sich bei dieser Szene ferner der Eintrag: "Mr. Bibiena a fait deux differents Prospets au fond de cette decoration. « ${ }^{74}$ Weitere Anhaltspunkte zu dieser ungewöhnlichen Praxis bieten Malerrechnungen Carl Friedrich Fechhelms vom September 1753. Die erhaltenen Belege bestätigen, daß Fechhelm mit einigen Maler-Kollegen an der letzten Dekoration Veränderungen - "auf allerhöchste ordre $«^{75}$ - vornehmen mußte. Seine Rechnung vom 21. September 1753 über 72 Taler (»zur königl. Opera Sylla habe die Stadt zur letzten Decoration von Mons. Bibiena gemalt«) wurde auch von Galli Bibiena abgezeichnet. ${ }^{76}$ Diese Akte erlaubt weiterhin, als Anlaß für die Umarbeitungen zwei bislang undokumentierte Aufführungen von Silla zu benennen. ${ }^{77}$ Anfang September wurde im Opernhaus die Dekoration von Didone abbandonata, seit der Aufführung im April 1753 unbenutzt, abgebaut; zwischen 9. und 15. September wurde die Bühne für Silla eingerichtet, nach der Generalprobe am 9. Oktober fanden am 12. und 14. Oktober Aufführungen statt, vermutlich anläßlich des Besuchs von Friedrichs Schwester Wilhelmine aus Bayreuth.

Eine dritte, im Inventaire als »Salle magnifique« dokumentierte Szene in Silla wurde nach Entwürfen von Bellavite realisiert, der hierfür große Teile seiner "Salle magnifique $«^{78}$ aus Coriolan weiterbenutzte. Obgleich die für Silla geforderten Verwandlungen keinen Festsaal verlangten, dürfte mit diesem Innenraum das dritte Bild "Appartamenti di Fulvia« gestaltet worden sein. Die übrigen drei Szenenbilder - Palasthof, Tempelinneres und Sillas Kabinett - sind weder im Inventaire noch in den Akten nachzuweisen, es bleibt deshalb offen, welche weiteren Entwürfe auf Galli Bibiena zurückgehen.

74 Ebd., S. 17 Nr. 11 „Foro Romano pour l'Opera Sylla. Are Trionphal, Char Trionphal«.

75 GStA PK, I. HA Rep. 36, Nr. 2653, unpaginiert. Die Gesamtkosten der Änderungen beliefen sich auf 461 Taler.

76 GStA PK, I. HA Rep. 9 LL7c Fasc. 9, fol. 5.

77 Ebd., fol. 16, 19, 21, 27 und 34 ff.

78 Inventaire (wie Anm. 29), S. 5 Nr. 1

79 Verwendete Quellen: Textbuch 1754, Theaterwissenschaftliche Sammlung Köln Sign. KnTh OT Inv. 10606; Inventaire (wie Anm.

\section{CLEOFIDE, Dramma per Musica ${ }^{79}$}

Text von Pietro Metastasio, Musik von Johann Friedrich Agricola

Uraufführung 14. Januar 1754, weitere Aufführungen 18., 21., 25. und 28. Januar 1754

Das Textbuch weist folgende Szenenbilder aus:

1. Campo di battaglia su le rive dell'Idaspe. Soldati dispersi, armi, insegne, ed altri Avanzi dell'Esercito di Poro disfatto da Alessandro

2. Recinto di Palme, e cipressi con piccolo tempio nel mezzo dedicato a Bacco nella Reggia di Cleofide 3. Campo di battaglia di Alessandro con Padiglione vicino all'Idaspe, con vista della Regia di Cleofide su l'altra sponda. Due sedili

4. Gabinetti Reali

5. Campagna sparsa di Fabbriche antiche con allogiamenti militari preparati da Cleofide per l'Esercito greco. Ponte su l'Idaspe. Di la dal fiume Campo numeroso di Alessandro disposto in ordinanza con istromenti da guerra

6. Appartamenti nella Reggia di Cleofide

7. Portici de'Reali Giardini

8. Tempio magnifico dedicato a Bacco con rogo nel mezzo, che poi si accende

Abweichend von den bisher zitierten Libretti-Eintragungen sind im Cleofide-Textbuch die beiden beteiligten Bühnenbildner erstmalig mit den von ihnen entworfenen Szenen genannt: „Il Campo di Battaglia distrutto, gli Appartamenti, e il Tempio magnifico di Bacco sono del Signor Giuseppe Galli Bibiena; tutte le altre Decorazioni sono del Sign. Innocente Bellavite, ambidue Architetti Teatrali, e Decoratori di Sua Maestà.»

Diese Aufteilung - drei Bilder nach Entwürfen von Galli Bibiena (1., 6. und 8. Szene) sowie fünf Bilder von Bellavite - läßt sich weitgehend mit den Eintragungen im Inventaire in Einklang bringen. Unter den neu entworfenen Dekorationen Galli Bibienas finden sich ein "Champ de Battaille pour l'Opera Cleophide « ${ }^{80}$, sowie als nachfolgende Eintragungen: »Appartemens pour l'Opera Cleophide und "Le Temple de Baccus pour l'Opera Cleophide ${ }^{81}$. Bellavites Palmenhain wird als scene refaitte toute de nouveau de vieilles decorations « ${ }^{82}$ bezeichnet: Sie bestand aus 8 älteren Kulissen-Elementen,

29), S. 8 Nr. 9, S. 17 Nr. 12 , S. 18 Nr. 13 und 14, GStA PK, I. HA Rep. 56, Nr. 2628; »Rechnungen und Schriftwechsel über die Aufführung der Opern Sylla und Cleofide sowie über die Redouten im Dezember 1753 und Jan. 1754", GStA PK, I. HA Rep. 36, Nr. 2654;, "Rechnungen über die Aufführung der Oper Semiramis am 27. März 1754«, GStA PK, I. HA Rep. 36, Nr. 2655.

80 Inventaire (wie Anm. 29), S. 17 Nr. 12

81 Ebd., S. 18 Nr. 13 und 14.

82 Ebd., S. 8 Nr. 9 
der Rückprospekt wurde in illusionistischer Malerei ausgeführt. ${ }^{83}$

Widersprüchlich sind die Angaben von Libretto und Inventaire für das dritte Bild. Folgt man dem Libretto, so wurde das Feldlager Alexanders von Bellavite entworfen. Im Inventaire wird ein "Champ de Battaille ${ }^{84}$ jedoch lediglich unter den nicht näher bezeichneten Dekorationen Galli Bibienas angeführt. Da es sich auf keine andere Oper als Cleofide beziehen kann, muß offen bleiben, welche der beiden Quellen fehlerhaft ist bzw. welcher der beiden Entwerfer dieses Bild realisiert hat.

Wesentlich bedeutsamer ist der Hinweis in der oben zitierten Libretto-Angabe, daß sowohl Bellavite als auch Galli Bibiena in ihrer Funktion als "Architetti Teatrali, e Decoratori di Sua Maestà für Cleofide tätig waren. Bislang wurde die Festanstellung Galli Bibienas am Preußischen Hof stets mit dem Fortgang Bellavites am 1. Februar 1754 in Verbindung gebracht. ${ }^{85}$ Das Libretto zu Cleofide ging wahrscheinlich um die Jahreswende 1753/54 in Druck. Wenn hier Galli Bibiena bereits als königlicher Theaterarchitekt genannt ist, darf davon ausgegangen werden, daß Galli Bibiena mindestens seit Dezember 1753 im Dienst Friedrich des Großen stand.

\section{SEMIRAMIDE, Dramma per Musica ${ }^{86}$}

Text von Friedrich II. nach Voltaire, übersetzt von Giovanni Pietro Tagliazucchi, Musik von Carl Heinrich Graun

Uraufführung 27. März 1754, weitere Aufführungen 20., 23., 27. und 30. Dezember 1754, 3. Januar 1755

Das Textbuch weist folgende Szenenbilder aus: 1. Vasto Peristile con veduta nel mezzo della Reggia di Semiramide ornata di Giardini Pensili, da un lato del Tempio de Maghi alla medesima Reggia corrispondente, dall altro del Mausoleo di Nino ornato d'obelischi

2. Gabinetto di Semiramide

3. Galleria, che conduce a diversi Appartamenti

4. Gran Tempio de'Maghi dedicato al Sole

83 Eine einzige Malerrechnung Carl Friedrich Fechhelms für seine Arbeitstage zwischen 28. Dezember 1753 und 3. Januar 1754 hat sich innerhalb der Semiramide-Belege erhalten; siehe GStA PK, I. HA Rep. 36, Nr. 2655 unpaginiert. Sämtliche andere Cleofide-Rechnungen sind offensichtlich verloren.

84 Inventaire (wie Anm. 29), S. 14 Nr. 4.

85 Zuletzt Henzel (wie Anm. 2), S. 40 und Anm. 107. In unseren Augen interpretiert Henzel den am 22. Februar 1754 unterzeichneten Nachtrag Sveerts' im Inventaire falsch, wenn er daraus Galli Bibienas Anstellung ab Februar 1754 ableitet. Da Bellavite bei der Besichtigung des Kulissendepots anwesend war, muß dies vor dem 1. Februar geschehen sein. Und auf eben diese Zeit - vor Anfang
5. Parte del Giardino reale

6. Gran Atrio interno della Reggia con veduta del Mausoleo; Trono, e Sedili

7. Sala

8. Collonato intorno al Mausoleo, e del Tempio.

9. Il Mausoleo si cangia in magnifico, e luminoso Tempio

"Le decorazioni sono di nuova invenzione, e disegno del Sign. Giuseppe Galli Bibiena Architetto, e Decoratore de'Teatri di Sua Maestà«-diese im Textbuch gedruckte Feststellung wird durch die Tatsache relativiert, daß auch für Semiramide lediglich drei der insgesamt neun Szenenbilder auf neuen Entwürfen Galli Bibienas basierten, der nun alleiniger Bühnenbildner an der Hofoper war.

In den Rechnungsakten hat sich ein undatiertes "Verzeichnis der Decorationen zur neuen Opera Semiramis" von unbekannter Hand erhalten, das wohl den Planungsstand am Beginn der Vorbereitungszeit wiedergibt:

»1.er Act

Erste Decoration Ein großer Vorhof, mit den Prospecten der prächtigen Gärten [...unleserlich] Säulen. ganz neu

Zweite Dec. Das allte Cabinet, so neu angefanget wird

Dritte Dec. Die alte Gallerie

2.er Act

Vierte Dec.

Der neue Tempel aus der letzten Opera

Fünfte Dec. Ein alter Garten

Sechste Dec. Vorhof aus der ersten Decoration, wozu das Mausoleum neu gemacht wirdt

3. Act

Siebendte Dec. Ein alter kleiner Saal

Achte Dec.

Das Mausoleum erscheint, und der Palast der Semiramis an der anderen, wird von alten Stücken neu gemacht

Neunte Dec. Ein großer magnifique Temple ganz neu ${ }^{87}$

Februar - ist die erste Formulierung Sveerts' zu beziehen: „Sa Majesté le Roi ayant pris a Sa Service le Sr. Bibiena en qualité de Decorateur et Architecte Teatral, [...]« Inventaire (wie Anm. 29), S. III. 86 Verwendete Quellen: Textbuch 1754, Baverische Staatsbibliothek München, Musikabteilung, Sign. Her 1611; Inventaire (wie Anm. 29), S. 19 Nr. 1-3, GStA PK, I. HA Rep. 36, Nr. 2628; "Rechnungen über die Aufführung der Oper Semiramis am 27. März 1754", GStA PK, I. HA Rep. 36, Nr. 2655; "Rechnungen und Schriftwechsel über die Aufführungen der Opern Semiramis und Montezuma im Dezember 1754 und Januar 1755«, GStA PK, I. HA Rep. 36, Nr. 2656.

87 GStA PK, I. HA Rep. 36, Nr. 2655, unpaginiert 


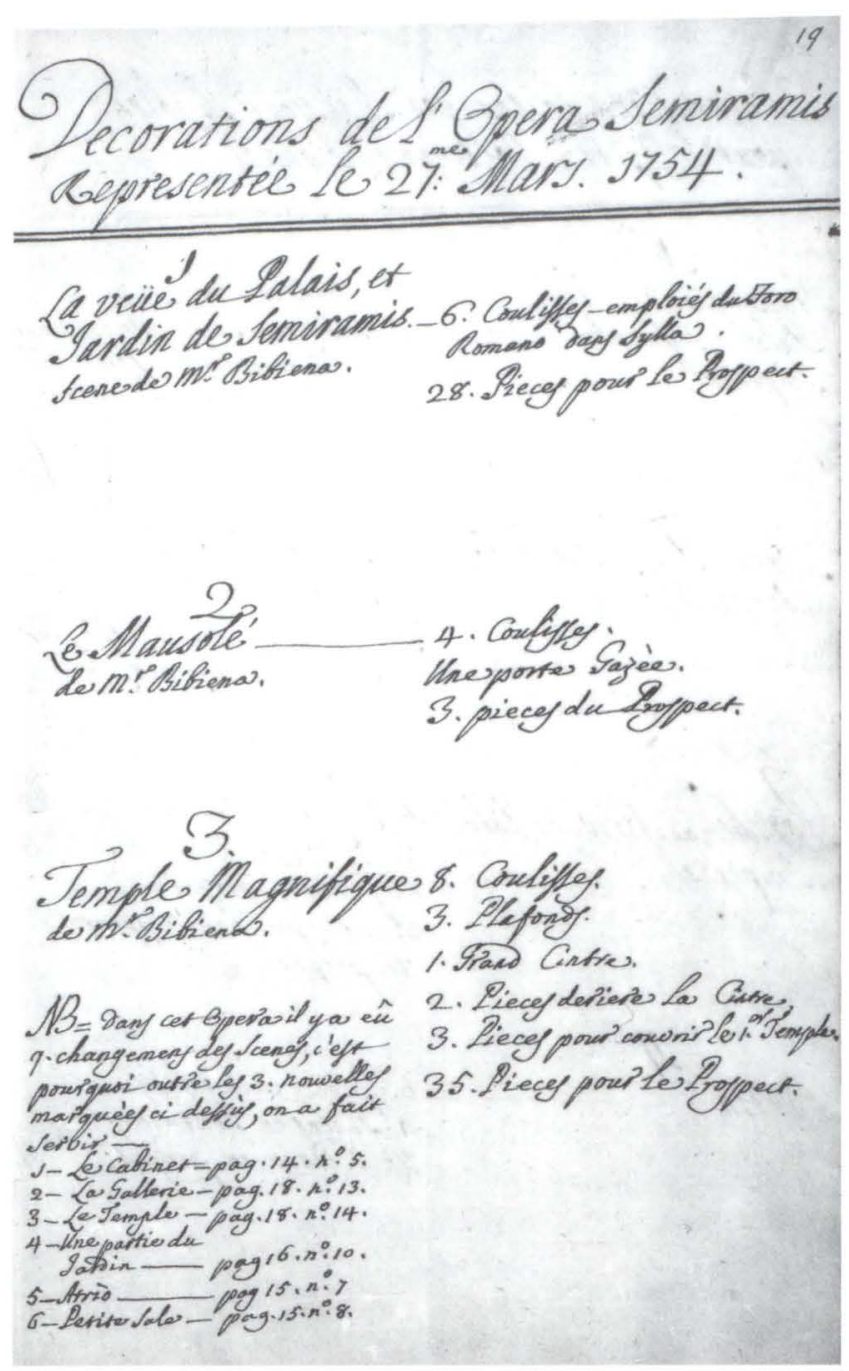

Abb. 9 Inventaire des decorations de l'Opera du Roi, Berlin 1754-1756, S. 19. Geheimes Staatsarchiv Preußischer Kulturbesitz, I. HA Rep. 36 Hofverwaltung, Nr. 2628

In Abweichung zu den im Textbuch geforderten Verwandlungen wurde im ersten Bild offensichtlich nur der Säulenhof mit Blick auf die Gartenanlage vorgesehen, Mausoleum und Tempel erschienen erst im vierten bzw. sechsten Bild. Ebenso plante man eine Vereinfachung des achten Bildes, das einen Säulengang in der Nähe des Mausoleums und Tempels vorstellen sollte, indem hier wiederum das Mausoleum des vierten Bildes Verwendung fand.

Folgt man diesem »Verzeichnis der neuen Decorationen«, sollten das erste und neunte Bild komplett neu entstehen, das zweite Bild überarbeitet werden, zur sechsten Szene das Mausoleum und zum achten Bild der Semiramis-Palast realisiert

88 Ebd.

89 Staatliche Museen zu Berlin, Kunstbibliothek, Lipp-HdZ 5132; Feder mit brauner Tinte, 38,8 x 26, 8 cm; mit eigenhändiger Beischrift, verso Architekturskizze; sowie Lipp-HdZ 5133, Feder mit brauner Tinte, $38,3 \times 26,5 \mathrm{~cm}$, verso mit eigenhändiger Beischrift, mehrere Architekturskizzen. Siehe Schulze Altcappenberg (wie Anm. 58), Kat. Nr. 32 und 33. Unkorrekt die dortige Beschreibung werden. Mit den Arbeiten an diesen Bühnendekorationen wurde Mitte Februar 1754 begonnen, insgesamt beliefen sich die Rechnungen der ausführenden Handwerker auf 2.300 Taler. ${ }^{88}$

Eine detaillierte Auflistung derjenigen Bühnenbilder, die schlußendlich tatsächlich für Semiramide erstellt wurden, liefert das Inventaire, wo auch die weiterverwendeten Dekorationen angegeben sind. (Abb. 9) Zum ersten Bild fanden die bereits einmal übermalten Kulissen aus Galli Bibienas Forum Romanum für Silla Verwendung, um den neuentworfenen Säulenhof zu bilden; der zugehörige Prospekt bestand aus 28 Stücken. Als zweites Bild nutzte man unverändert ein von uns Britannico zugeordnetes "Cabinet", das dritte Bild spielte in den "Appartemens pour l'Opera Cleophide“, das vierte Bild im »Temple de Baccus pour l'Opera Cleophide«. Auch der Garten des fünften Bildes kam aus dem Depot und war ursprünglich für Silla entstanden. Das siebente und achte Bild lassen sich auf die "Petite Salle" bzw. "Avant Cour" in Britannico zurückführen. Neu entworfen und realisiert wurden schließlich das sechste und das letzte Bild. Aus wenigen Elementen entstand das Mausoleum, zusätzlich kam im sechsten Bild der Säulenhof des ersten Bildes zum Einsatz. Mit großem Aufwand wurde dagegen der "Temple Magnifique» des Schlußbildes gebaut, allein der Prospekt bestand aus 35 Elementen.

Die Gründe für die gegenüber der ersten Planung reduzierte Ausführung sind nicht überliefert, vermutlich waren sowohl Zeit wie finanzielle Mittel knapp bemessen und erlaubten lediglich eine teilweise Ausführung der ursprünglich vorgesehenen Entwürfe.

Zum ersten Bild in Semiramide haben sich zwei Entwurfsskizzen (Abb. 10 bis 13) Giuseppe Galli Bibienas erhalten, die vor kurzem erstmals publiziert wurden. ${ }^{89}$ Durch eine eigenhändige Aufschrift ist die Zuordnung zweifelsfrei bestätigt: "Sala Prima scena/della seconda opera/ Semiramide/ D'ordine dorico/ secondo porta il suo ornato", die Bezeichnung »Sala« darf als Variante zu dem im Libretto geforderten »weitläufigen, inwendig mit Säulen gezierten Ort« gelten. ${ }^{90}$ Beide Blätter zeigen Varianten der architektonischen Anlage eines gedeckten Säulenhofes, dessen Hintergrund durch die auf Leinwände gemalten Gärten der Semiramis gebildet werden sollte. Galli Bibiena legte in den vorliegen-

des Gesamtumfanges mit sieben Bildern, die auf einem 1774 publizierten Textbuch mit reduzierten Verwandlungen beruhte. Ferner Ausst. Kat. Paradies des Rokoko (wie Anm. 7). S. 119, Abb. 6. 90 Wieder abweichend lesen sich die Bezeichnungen im zitierten "Verzeichnis der Decorationen« und im Inventaire, nämlich »ein großer Vorhof [...] Säulen« bzw. »La veue du Palais de Semiramis*. 


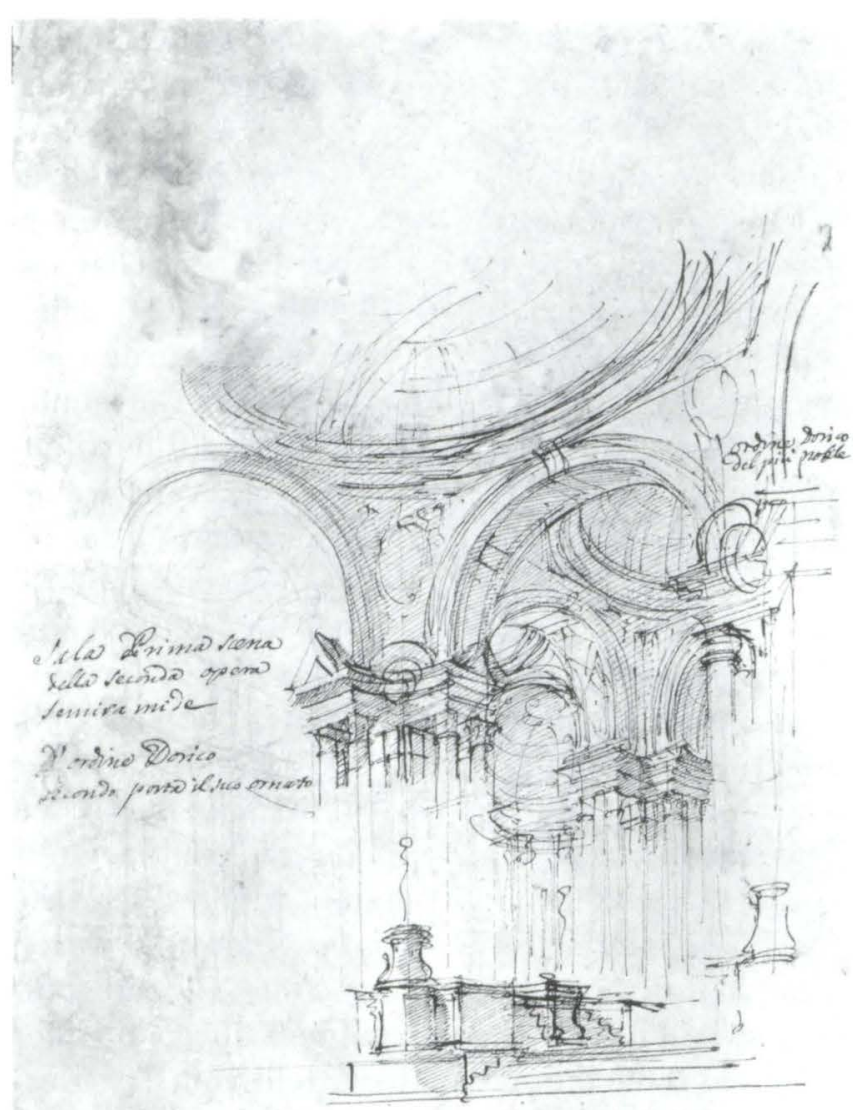

Abb. 10 Giuseppe Galli Bibiena, Entwurf zum ersten Bild in Semiramide, 1754, Feder mit brauner Tinte. Staatliche Museen zu Berlin, Kunstbibliothek (Lipp-HdZ 5132 recto)

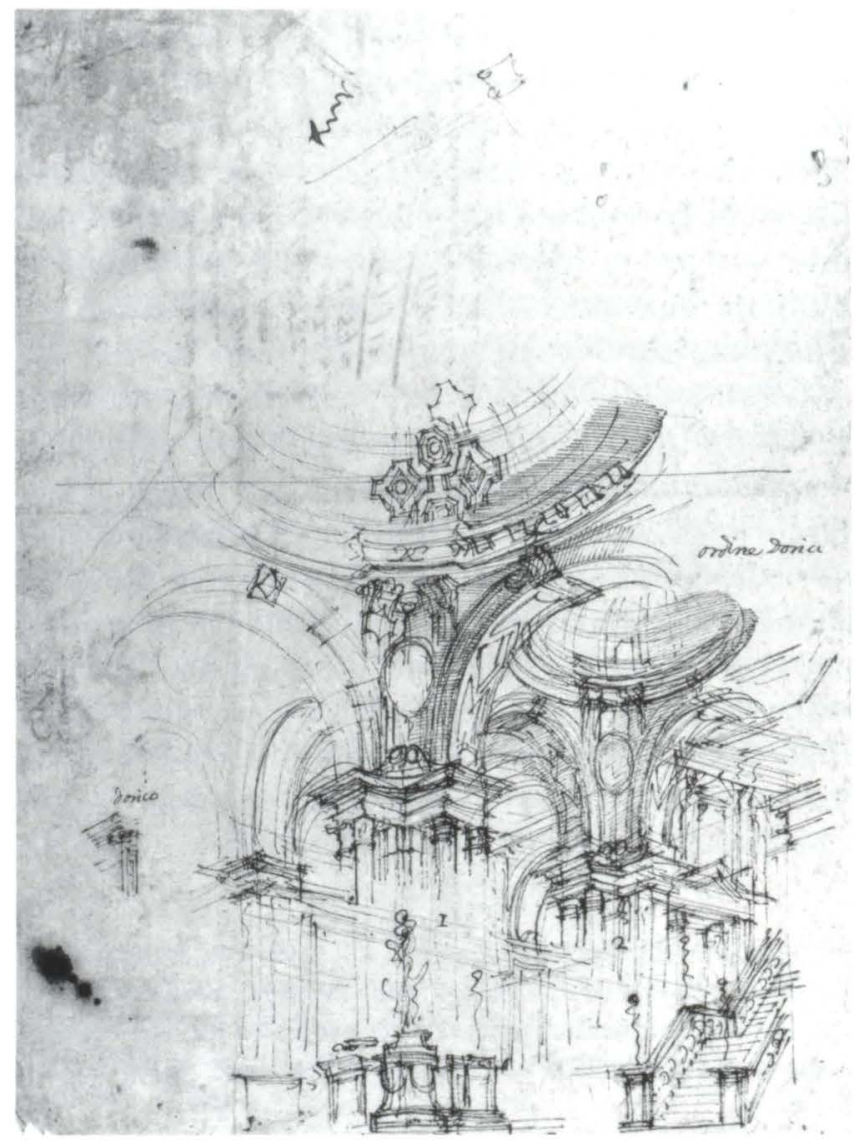

4bb. 12 Giuseppe Galli Bibiena, Entwurf zum ersten Bild in Semiramide, 1754, Feder mit brauner Tinte. Staatliche Museen zu Berlin, Kunstbibliothek (Lipp-HdZ 5133 recto)

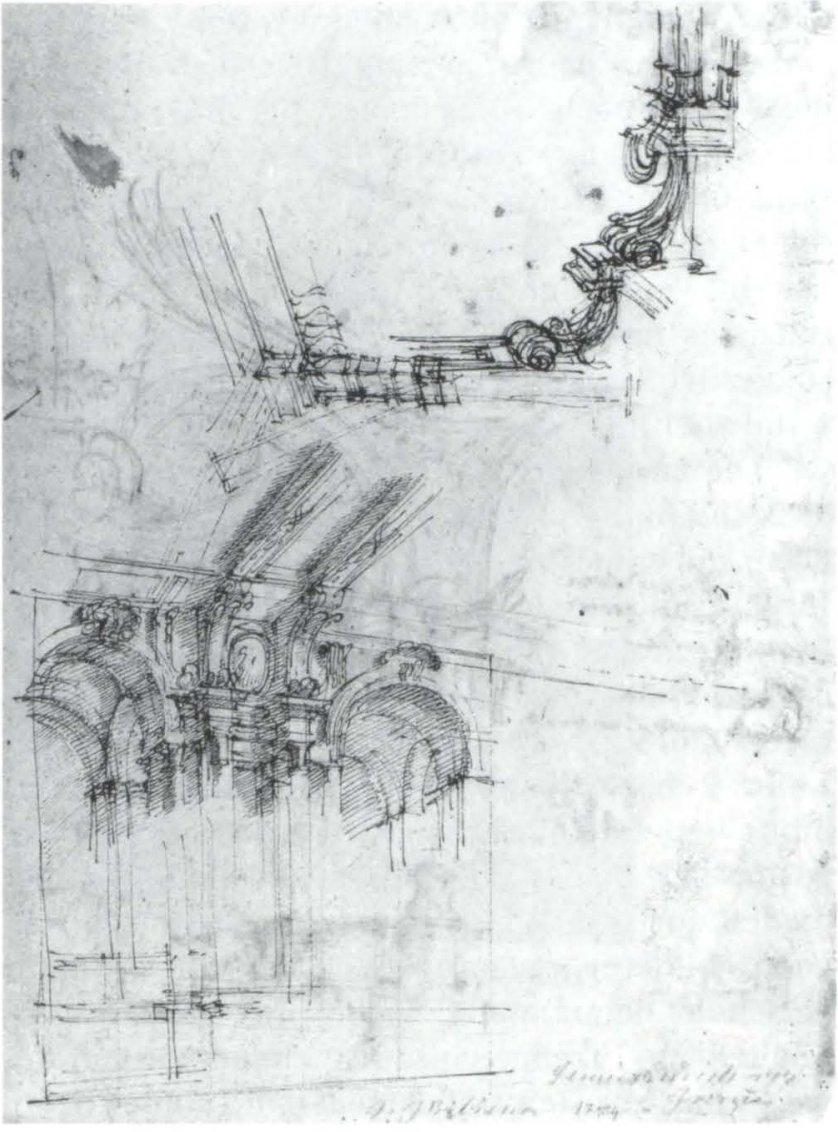

Abb. 11 Giuseppe Galli Bibiena, Detailstudien, 1754, Feder mit brauner Tinte. Staatliche Museen zu Berlin, Kunstbibliothek (Lipp-HdZ 5132 verso)

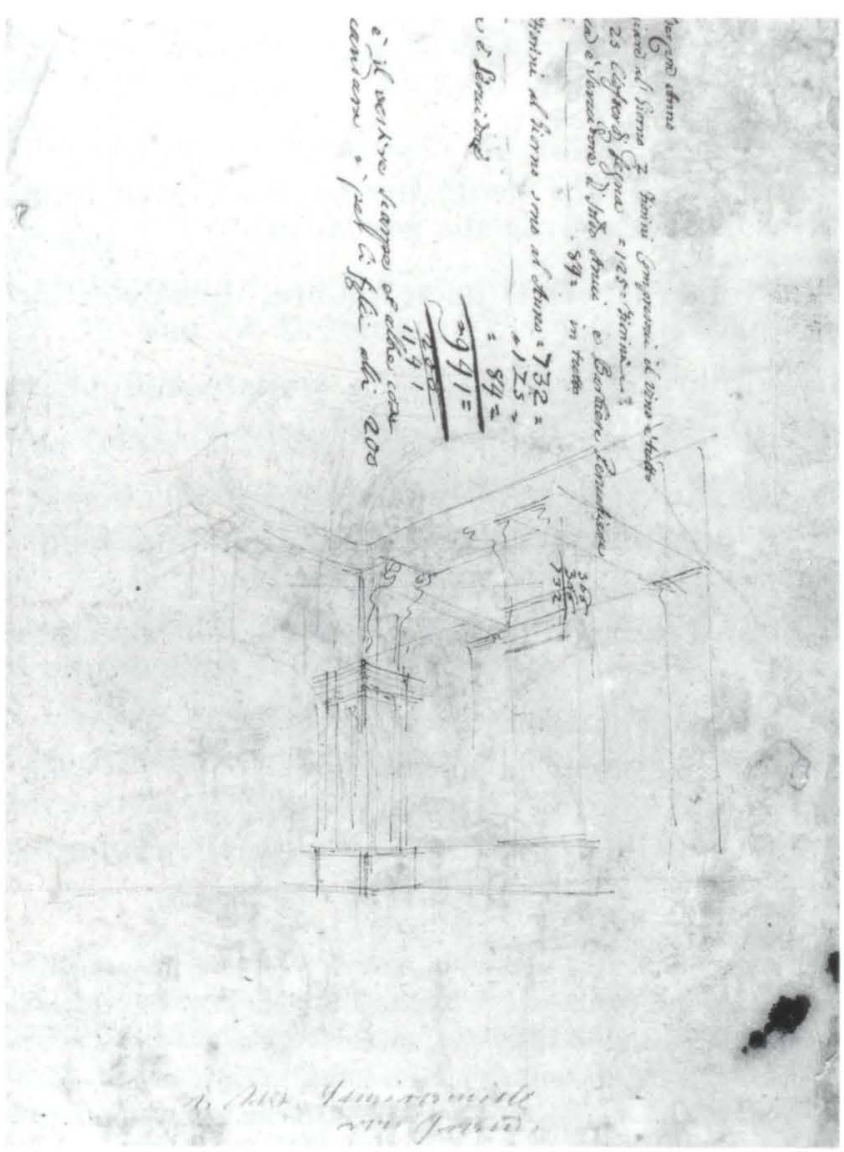

Abb. 13 Giuseppe Galli Bibiena, Entwurfszeichnung und Honorarberechnung, 1754, Feder mit brauner Tinte. Staatliche Museen zu Berlin, Kunstbibliothek (Lipp-HdZ 5133 verso) 
den Zeichnungen mit schwungvoller Linienführung und in sicherer perspektivischer Darstellung die wesentlichen Einzelheiten der Bühnenarchitektur fest: im Vordergrund eine überkuppelte, allseitig offene Raumzone, dahinter weiterführende, mit Pfeilern und Säulenvorlagen gegliederte Bereiche mit Pendentifkuppeln. Die diagonale Ausrichtung des mehrschichtigen Raumes bewirkt eine suggestive Tiefenwirkung der im ausgeführten $\mathrm{Zu}$ stand eher flachen Bühnendekoration. ${ }^{91}$

Die zweite Zeichnung (Abb. 12 und 13) zeigt dasselbe Bühnenbild in erweiterter und variierter Form, mit einem ergänzten Treppenaufgang und im Hintergrund eingefügten Raumzonen. Der zentrale, mittig gesetzte Pfeiler mit gekuppelten Säulen im dorischen Stil bildet nun die vorderste Ebene, der rechts hinter der Treppe sichtbare Pfeiler - mit der Ziffer $\approx 2$ « bezeichnet - ist bereits der nächsten, vermutlich nicht mehr bespielbaren Raumschicht zugewiesen. ${ }^{92}$ Beide Skizzen dienten Galli Bibiena lediglich zur ersten Darlegung der gebauten Bühnenarchitektur, entsprechend sind nur die dafür entscheidenden Details - Sockel- und Kuppelzonen, Kapitelle und Treppenansatz - genauer ausgeführt. Rasch hingeworfen sind dagegen die an den Treppenabsätzen und am vorderen Pfeiler vorgesehenen Figuren auf hohen Sockeln, die wir ähnlich in anderen Entwurfsskizzen Giuseppe Galli Bibienas wiederfinden. ${ }^{93}$ Der Entwurf zu dem im Hintergrund vorgesehenen Gartenprospekt ist nicht erhalten.

\section{MONTEZUMA, Tragedia per Musica ${ }^{94}$}

Text von Friedrich II. nach Voltaire, Musik von Carl Heinrich Graun

Uraufführung 6. Januar 1755, weitere Aufführungen 10., 13., 17., 20., 24. und 27. Januar 1755

Das Textbuch weist folgende Szenenbilder aus:

1. Tre gran viali di Palme nel Giardino Imperiale

2. Appartamenti destinati alla Regina

3. Gran Piazza su la riva del fiume, che divide la Città

4. Atrio del Palazzo Imperiale

5. Parte del'Imperial Giardino

6. Prigione

91 Das erste Blatt ist rückseitig in drei verschiedenen Zeichenrichtungen für Architekturskizzen und Säulen- bzw. Pfeilerdetails verwendet, die sich nicht konkret auf Semiramide zuordnen lassen. 92 Die Rückseite nutzte Galli Bibiena für eine perspektivische Skizze eines Innenraumes und für die Berechnung einer Jahresgage, die alle Lebenshaltungskosten inklusive Holz, Friseur, Diener und Versorgung der Kinder beinhaltet.

93 Vgl. S. 123.

94 Verwendete Quellen: Textbuch 1755, Staatsbibliothek zu Berlin
7. Gran Cortile cinto di Colonne, fra le quali si vede parte della Città del Messico, che viena incendiata

Im Inventaire sind den Dekorationen für Montezuma zwei volle Seiten mit detaillierten Eintragungen gewidmet, aus denen hervorgeht, daß sechs der sieben Szenenbilder nach Galli Bibienas Entwürfen realisiert wurden. Alle Dekorationen wurden aus neuen Elementen gefertigt, nur für das Gartenbild fanden sechs Kulissen eines älteren „Lieu delicieux" von Fabris Verwendung, die bereits weiter vorne im Inventaire eingetragen sind. ${ }^{95}$ Für das offensichtlich nicht entworfene zweite Bild »Appartamenti destinati alle Regina«wurde vermutlich eine ältere Dekoration unverändert genutzt; passend wäre zum Beispiel die ein Jahr zuvor von Galli Bibiena entworfene "Reggia di Cleofide«. Ferner wäre auch denkbar, daß der Palmenhain der ersten Dekoration während der folgenden Szene weiterhin als Bühnenbild diente. Beide Bilder stellten Orte des königlichen Wohnbereiches dar und waren somit in ihrer Funktion austauschbar. Eine Bestätigung erhält diese zweite Hypothese durch eine der erhaltenen Rechnungen, ausgestellt vom Tischlermeister Hildebrandt am 5. Dezember 1754. Die Probenzeit für Montezuma war in diesen Tagen beendet, und Hildebrandt mußte die Bühne für die Aufführungen von Semiramide umbauen; er erstellte danach eine »specification die 6 neuen decorationes von der neuen opera Montezuma abzureumen ${ }^{96}$.

Besonders aufwendig war die Ausführung des ersten Bildes »Trois grandes allées des Palmiers dans le Jardin Imperial«. »82 pieces en Coulises, 22 pieces en souppente formantes la hauteur des palmiers« wurden hierfür - folgt man der Beschreibung im Inventaire - auf die Bühne gebracht, dies sind mehr als doppelt so viele Bauteile wie für alle anderen Bilder von Montezuma. In dieser illusionistisch raffinierten Realisierung läßt sich ein direkter Bezug auf die unterschwellige Konkurrenz Friedrich II. mit dem Bayreuther Opernbetrieb seiner Schwester Wilhelmine erkennen. Sie hatte im Jahr zuvor, anläßlich seines Besuches in Bayreuth, die Festa Teatrale L'Huomo ${ }^{97}$ gezeigt; das Libretto war von Wilhelmine selbst verfaßt worden, Carlo Galli Bibiena hatte das Bühnenbild entworfen. Als Szenenbild diente unter anderem ein »Bois de pal-

PK, Musikabteilung Sign. T 66; Inventaire (wie Anm. 29), S. 20f. Nr. 1-6, GStA PK, I. HA Rep. 36, Nr. 2628; "Rechnungen und Schriftwechsel über die Aufführungen der Opern Semiramis und Montezuma im Dezember 1754 und Januar 1755«, GStA PK, I. HA Rep. 36 , Nr. 2656.

95 Inventaire (wie Anm. 29), S. 3 Nr. 8.

96 GStA PK, I. HA Rep. 36, Nr. 2656, fol. 27.

97 Ausst. Kat. Paradies des Rokoko (wie Anm. 7), Kat. Nr. 258. 


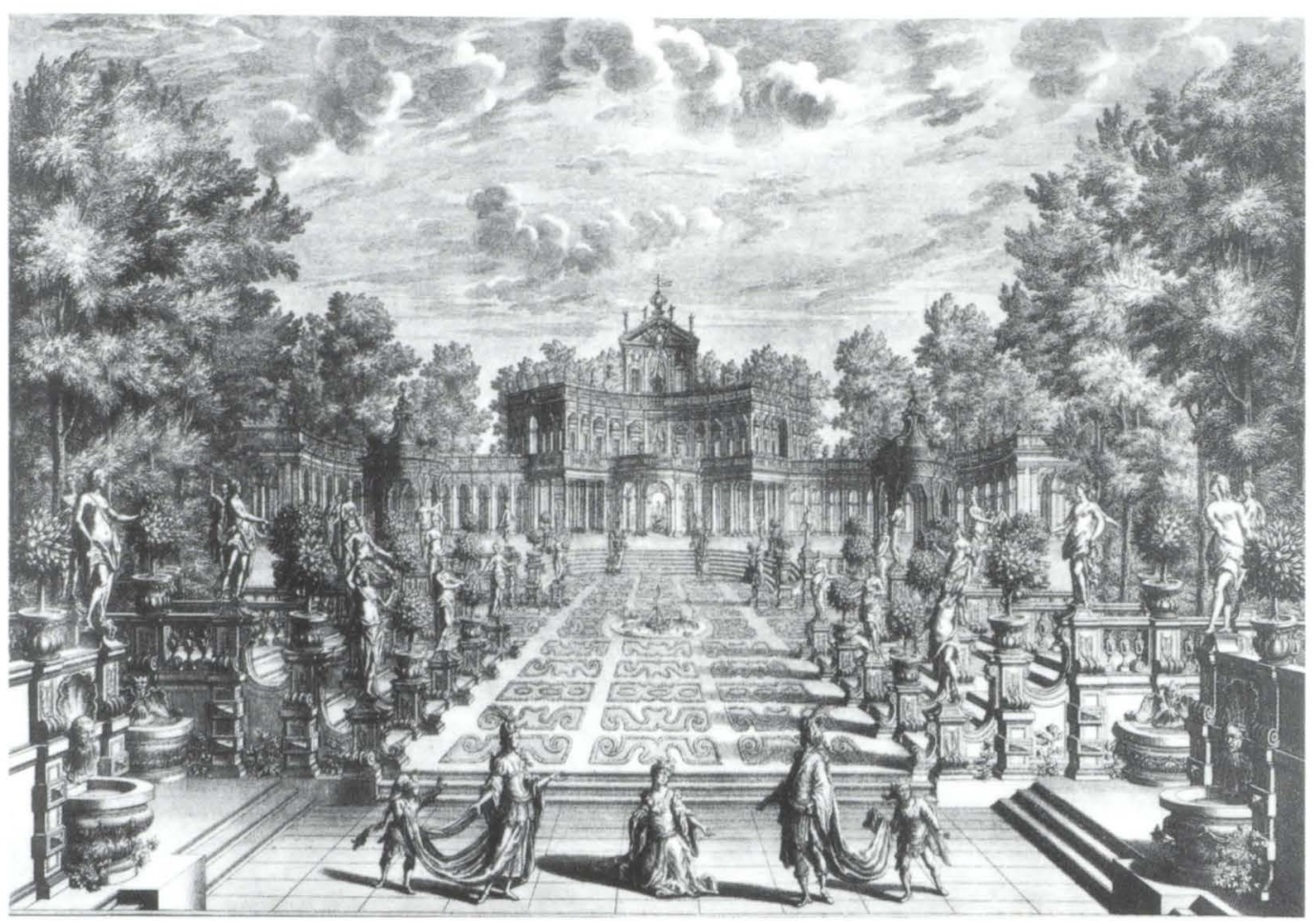

Abb. 14 Giuseppe Galli Bibiena, Gartendekoration, Kupferstich von A. Pfeffel in Architetture e Prospettive, Augsburg 1740. Nachdruck Berlin 1888

miers«, zu dem sich in St. Petersburg eine Reinzeichnung Carlo Galli Bibienas erhalten hat. ${ }^{98}$ Sie zeigt einen dichten Palmenwald, der sich in der Mitte in drei in die Tiefe führende Wege untergliedert, die in einem im linken Bühnendrittel gelegenen Fluchtpunkt zusammengeführt sind. Friedrich II. mag durch diese Bayreuther »Erfindung« angeregt worden sein, sein gerade zu dieser Zeit entstehendes Libretto zu Montezuma mit einer Szene in Palmenalleen beginnen zu lassen. ${ }^{99}$

Eine Vorstellung der räumlichen Gestaltung des fünften Bildes kann eine detailliert ausgeführte Entwurfszeichnung in St. Petersburg ${ }^{100}$ geben, die bis in Details mit einem Kupferstich in Galli Bibienas ab 1740 veröffentlichtem Stichwerk »Architetture e Prospettive «101 (Abb. 14) übereinstimmt. Der im Inventaire beschriebene Aufbau der Garten- Dekoration paßt erstaunlich präzise zu diesem Entwurf: »6 pieces en Coulises, 4 Pieces en Fontaines, Un Rideau en Prospet «102. Die relativ geringe Tiefenstaffelung entspräche der flach angelegten Zeichnung, die erkennen läßt, daß nur die untere Raumzone mit den auf Stufenpodesten angebrach-

98 Ebd., Kat. Nr. 299

99 Zur symbolischen Bedeutung der Palme und deren Verwendung durch das preußische Herrscherhaus, siehe Peter Krückmann. Paradies des Rokoko: Das Bayreuth der Markgräfin Wilhelmine, München 1998, S. 122-128.

100 Staatliche Ermitage St. Petersburg, Inv. 30871; Feder mit brauner Tinte, farbig aquarelliert, 30,5 x $46 \mathrm{~cm}$. Siehe Militsa Korshunova, Zeichnungen italienischer Bühnenbildner des 18. Jahrhunderts, Ausst. Kat. Staatliche Ermitage Leningrad, 1975, Nr. 7 mit Abb. ten vier Brunnenschalen bespielbar ist. Möglicherweise realisierte Galli Bibiena hier eine wesentlich ältere »Invention« auf der Berliner Opernbühne.

\section{EZIO, Dramma per Musica ${ }^{103}$}

Text von Pietro Metastasio, überarbeitet von Giovanni Pietro Tagliazucchi, Musik von Carl Heinrich Graun

Uraufführung 1. April 1755, weitere Aufführungen 22., 26. und 29. Dezember 1755, 2. und 5. Januar 1756

Das Textbuch weist folgende Szenenbilder aus:

1. Parte del Foro Romano, con Trono imperiale da un Lato, Vista di Roma illuminata in tempo di notte con Archi trionfali, ed altri apparati festivi \& preparati per celebrare le feste decennali, e per onorare il ritorno d'Ezio vincitore di Attila

2. Camere imperiali

3. Orti Palatini, corrispondenti agli Appartamenti Imperiali

4. Galleria di Statue, e Pitture con sedili intorno, fra

101 Saxon (wie Anm. 19).

102 Inventaire (wie Anm. 29), S. 20 Nr. 4.

103 Verwendete Quellen: Textbuch 1755, Staatsbibliothek zu Berlin PK, Musikabteilung Sign. Tg 866; Inventaire (wie Anm. 29), S. 22 Nr. 1-3, GStA PK, I. HA Rep. 36, Nr. 2628; »Rechnungen und Schriftwechsel über die Aufführung der Opern Ezio und I fratelli nemici und einige Intermezzi im März/April und Dezember 1755 sowie im Januar 1756«, GStA PK, I. HA Rep. 36, Nr. 2658. 
quali uno innanzi alla mano destra capace di due persone

5. Atrio delle carceri con cancelli di ferro in prospetto, che conducono a diverse prigioni con guardie a vista su la porta di detti cancelli

6. Campidoglio antico

Zur Klärung, welche Szenen für Ezio neu realisiert wurden, stehen lediglich die Angaben des Inventaire zur Verfügung. Galli Bibiena entwarf demnach drei Dekorationen, nämlich das erste, vierte und sechste Bild. Die "Grande Galerie« wurde mit »36. pieces en Coulises, 15. pieces pour la Soupente sehr umfangreich und bis in die Bühnentiefe bespielbar realisiert.

Für die übrigen drei Bilder - königlicher Palast, Garten sowie Kerker-Vorhof - standen offensichtlich Dekorationen aus früheren Aufführungen zur Verfügung, die unverändert wiederverwendet wurden. ${ }^{104}$

\section{FRATELLI NEMICI, Tragedia per Musica ${ }^{105}$}

Text von Friedrich II. nach Jean Racine, vervollständigt und übersetzt von Giovanni Pietro Tagliazucchi, Musik von Carl Heinrich Graun Uraufführung 9. Januar 1756, weitere Aufführungen 12., 16., 19., 23., 26. und 30. Januar 1756

Das Textbuch weist folgende Szenenbilder aus:

1. Cortile nel Palazzo Reale

2. Galleria

3. Antro di dove esce la voce dell'Oracolo

4. Appartamenti

5. Le Mura di Tebe da una parte con Torri, dall'altra ruine. Nel fondo il campo di Plinice, e in lontano alte montagne

6. Machina di nuvole fra le quali Apollo discende

Wiederum erweisen sich die Eintragungen im Inventaire (Abb. 15) als hilfreich, um Galli Bibienas neue Entwürfe zu benennen: »Pour cet Opera on n'a point fait des nouvelles decorations, excepté, les Nuages en Carton pour la Machine d'Apollon. Et on a retouché, et on a fait servir les scenes ci dessous.« Die ersten vier Szenenbilder wurden aus dem Depotbestand genommen: der Vorhof stammte vermutlich aus Britannico, die Galerie aus Ezio - 1751 bzw. 1755 nach Entwürfen von Galli Bibiena ausgeführt. Als Höhle im dritten Bild bediente man sich einer bereits einmal ergänzten Dekoration von der Hand Bellavites: Seine Grotte zur Oper Iphigenie

104 Denkbar ist eine Nutzung des vierten, fünften und sechsten Bildes aus Montezuma.

105 Verwendete Quellen: Textbuch 1756, Staatsbibliothek zu Berlin PK, Musikabteilung Sign. T 65 (2); Inventaire (wie Anm. 29),

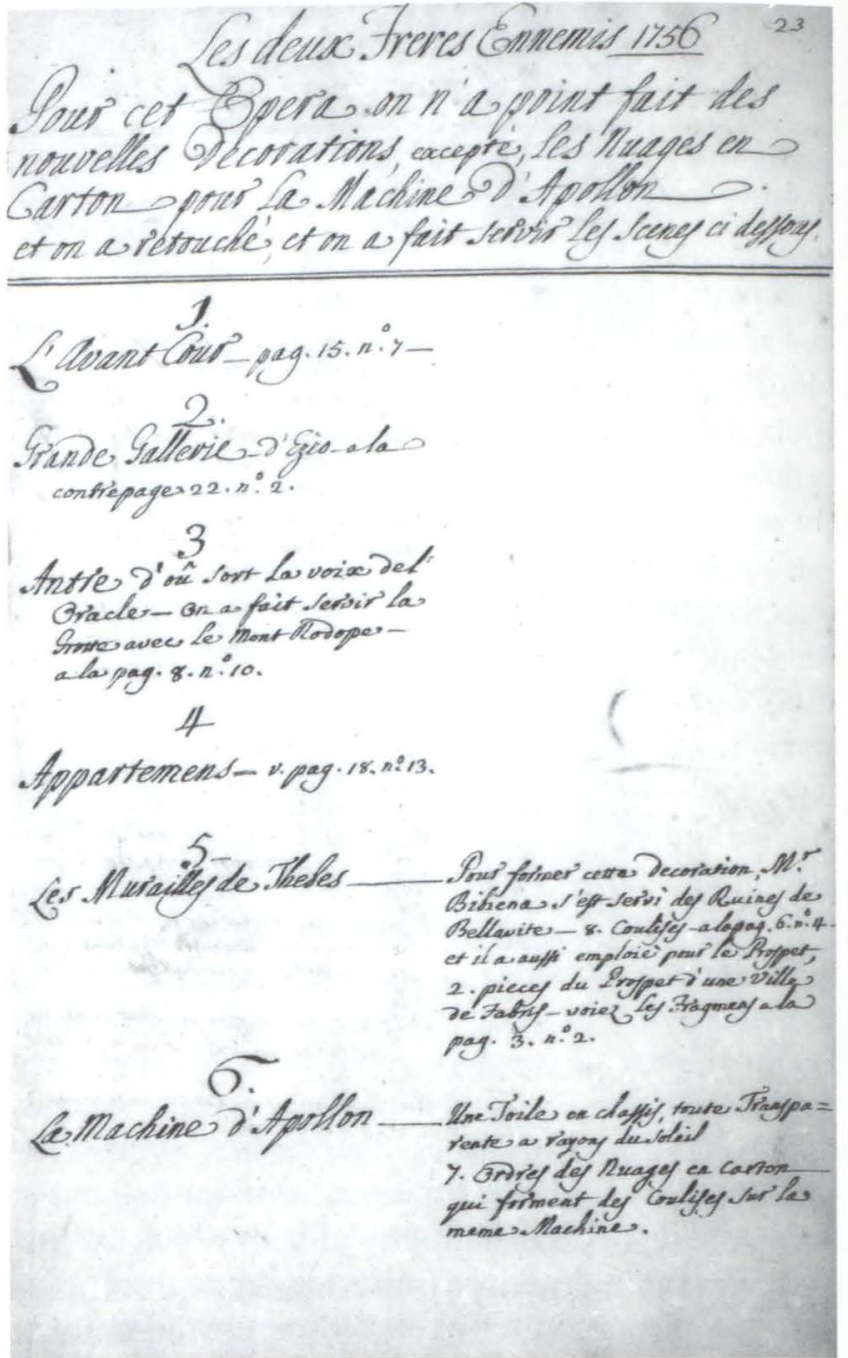

Abb. 15 Inventaire des decorations de l'Opera du Roi, Berlin 1754-1756, S. 23. Geheimes Staatsarchiv Preußischer Kulturbesitz, I. HA Rep. 36 Hofverwaltung, Nr. 2628

war im März 1752 erneut für das 6 . Szenenbild von Orfeo genutzt worden, allerdings erweitert mit einem Prospekt, der den Berg Rodope zeigt. In dieser Fassung kam die Dekoration nun unverändert zum Einsatz. Für das vierte Bild fanden Galli Bibienas königliche Gemächer aus Cleofide Verwendung.

Lediglich die beiden letzten Szenen waren - in Teilen - neu: Für das fünfte Bild benutzte Galli Bibiena acht Kulissen von Bellavite, die ursprünglich als Ruinen-Bild in L'Europe Galante Verwendung gefunden hatten. Als Rückprospekt dieser Szene nutzte er zwei fragmentarisch erhaltene, bemalte Leinwände von Fabris, die früher bereits als "Murailles d'une ville" eingesetzt worden sind, vermutlich wurden alle Elemente nach seinen Entwürfen übermalt. Aus neuen Teilen wurde die unaufwendige Wolkendekoration erstellt, die die The-

S. 23 Nr. 1-6, GStA PK, I. HA Rep. 36, Nr. 2628; »Rechnungen und Schriftwechsel über die Aufführung der Opern Ezio und I fratelli nemici und einige Intermezzi im März/April und Dezember 1755 sowie im Januar 1756«, GStA PK. I. HA Rep. 36, Nr. 2658. 
atermaschine umgab, auf der Apollo herabschweben sollte. Sie bestand aus $" 7$ ordres de Nuages en carton« und einer "toile en chassis, toute Transparente a rayons de soleil«. ${ }^{106}$

I Fratelli Nemici bestand somit zu zwei Dritteln aus bereits früher eingesetzten Bühnenbildern zweier Entwerfer für unterschiedliche Opern, ein optisches Pasticcio, für das vermutlich finanzielle Gründe verantwortlich waren.

\section{LA MEROPE, Tragedia per Musica ${ }^{107}$}

Text von Friedrich II. nach Voltaire, vervollständigt und übersetzt von Giovanni Pietro Tagliazucchi, Musik von Carl Heinrich Graun

Uraufführung 27. März 1756, Wiederaufnahme dieser Inszenierung 1764

Das Textbuch weist folgende Szenenbilder aus:

1. Atrio del Palazzo Reale

2. Appartamenti di Merope

3. Piazza con Tempio accanto all'ingresso del quale si vede il Mausoleo di Cresfonte

4. Sala aperta fra il colonnato della quale si vede un delizioso Giardino

5. Camera del Palazzo Reale

6. Interno di un Tempio con Ara nel mezzo

7. Gran Piazza di Messene, con veduta di buona parte della Città

Für die einzige Aufführung dieser neuen Oper im März 1756 wurde vermutlich kein Textbuch gedruckt, sondern erst zur Aufführungsserie nach dem Siebenjährigen Krieg. Die darin beschriebenen, oben zitierten Verwandlungen werden als "d'invenzione e disegno" Giuseppe Galli Bibienas vermerkt; es kann daher davon ausgegangen werden, daß die Erstausstattung verwendet wurde, auch wenn nun sein Sohn Carlo leitender Bühnenarchitekt Friedrichs II. war.

Die bereits bekannte Praxis der unveränderten Wiederverwendung bestehender Dekorationen läßt sich auch bei Merope beobachten. In den erhaltenen Rechnungsakten liegt eine Übersicht »derer sämtlichen Rechnungen, über die Kosten von Anfertigung der 4 neuen, und Reparirung einiger Alten Decorationes, zu der Mart. Opera Mero-

106 Alle Angaben aus dem Inventaire (wie Anm. 29), S. 23.

107 Verwendete Quellen: Textbuch 1764, Staatsbibliothek zu Berlin PK, Musikabteilung Sign. Tg 878; Inventaire (wie Anm. 29), S. 24 Nr. 1-2, S. 25 Nr. 3-4, GStA PK, I. HA Rep. 36, Nr. 2628; „Rechnung über die Aufführung der Oper Merope am 27. März 1756«, GStA PK, I. HA Rep. 36, Nr. 2659; »Kosten für die Ausstattung der Oper Merope, Februar und März 1756«, GStA PK, I. HA Rep. 9, LL7c Fase. 11. 108 GStA PK, I. HA Rep. 9 LL 7c Fasc. 11, fol. 2. 109 GStA PK, I. HA Rep. 36, Nr. 2659, unpaginiert. pe betitult, so den 27ten Mart. 1756 repraesentiret worden «. ${ }^{108}$ Die zugehörigen, an anderer Stelle erhaltenen Einzelrechnungen der Tischler, Schlosser, Nagel-Schmiede, Seiler, Klempner, Farbenreiber und Theatermaler beliefen sich insgesamt auf 3.327 Taler, davon entfielen allein 1.340 Taler auf die Theatermaler. ${ }^{109}$ Letztere haben am 1. Februar 1756 mit ihren Arbeiten begonnen, in den folgenden sieben Wochen bis zur Aufführungen waren bis zu 17 Maler tätig. Neben den in Berlin ansässigen Theatermalern ${ }^{110}$ wurden ab der dritten Woche auch auswärtige Maler bezahlt, darunter ein gewisser Walther aus Dresden ${ }^{111}$, Joseph Hager aus Prag und schließlich in der siebten Woche noch Christian Gottlob Fechhelm aus Dresden, der zweitälteste der Fechhelm-Brüder. Diese große Zahl zusätzlich engagierter Maler, die jeweils auch Reisegeld zu ihren Wohnorten erhielten, verteuerte die Produktion erheblich, selbst wenn nur vier der sieben Bühnenbilder neu entworfen und realisiert wurden.

Einzelheiten bieten die Eintragungen im Inventaire, die lediglich das dritte, vierte, sechste und siebente Bild umfassen. Dies bedeutet, daß die beiden Szenen im Königspalast sowie in Meropes Gemächern in existierenden Dekorationen gezeigt wurden. Das dritte Bild ist im Inventaire detailliert beschrieben, hierfür wurden einzelne Elemente neu entworfen - darunter das Mausoleum, ein groBer gemalter Prospekt mit der Ansicht eines Tempels und eines Stadtplatzes, ferner fanden die retouchierten Kulissen zum Forum Romanum aus Silla Verwendung. Aus neuen Elementen baute man Galli Bibienas viertes Bild "Sala terrena«; sie bestand aus 16 stehenden Rahmen, sechs Kulissen und einem Rückprospekt, die eine doppelte Kolonnade mit Statuen und Blumenschalen zeigten, in deren Hintergrund eine Grotte mit Wasserfall zu sehen war. Zum sechsten Bild nutzte man weitgehend die vorhandenen Bühnenelemente des Bacchustempel aus Cleofide, die übermalt wurden. Das Schlußbild schließlich - ein großer Platz mit Blick auf die Stadt - wurde neu entworfen, gemalt und gebaut, als auffälliger Schmuck zierten zwei gebaute Obelisken, zwei Bildsäulen mit Flachreliefs und ein im Hintergrund sichtbarer Springbrunnen die Bühne.

110 In diesem Kontext kann nicht weiter auf die darin dokumentierte Bezahlung eines "Bibiena jun." genannten Malers eingegangen werden, vermutlich ist damit Carlo Galli Bibiena gemeint. Es wäre dies der Nachweis seiner frühesten Tätigkeit in Berlin, wo er ab 1763 als königlicher Theaterarchitekt Anstellung fand.

111 Vermutlich Carl Siegmund Walther, siehe Thieme/Becker, Bd. 35, S. 128. 
IV.

"von alten Stücken neu gemacht «112 -

Überlegungen zur mehrfachen

Verwendung von Bühnendekorationen

Die an einzelnen Beispielen detailliert dargestellte Bühnenbild-Praxis der Berliner Hofoper der 1750er Jahre läßt sich zusammenfassend in vier Kategorien beschreiben, denen jeweils unterschiedliche Nutzungskonzepte zugrundeliegen.

1. In beinahe jeder Opernproduktion gelangten vorhandene Szenenbilder ohne jegliche Umarbeitung zum Einsatz. Über diese Weiternutzung liegen detaillierte Beschreibungen im Inventaire vor; demnach wurden in Galli Bibienas Ausstattungen vor allem folgende Bilder mehrfach eingesetzt: „Gabinetto«, "Appartamenti Reali«, »Galleria«, "Tempio«, "Atrio delle Carceri« und „Cortile«. Durch die im 18. Jahrhundert übliche Form des typologischen Szenenbildes, in dem bestimmte Grundräume festgelegt waren, konnte in der Praxis problemlos auf eine kostensparende Zweitnutzung zurückgegriffen werden.

2. Andere Szenenbilder entstanden durch eine teilweise Wiederverwendung vorhandener Bühnenelemente, die mit neu entworfenen Teilen kombiniert wurden. In Montezuma verwendete Galli Bibiena zum fünften Bild „Parte del Imperial Giardino" sechs vorhandene Kulissen eines »Lieux delicieux« von Fabris, neu entstanden »4 Pieces en Fontaines« und »Un Rideau en Prospet«. In Merope nutzte er für das dritte Bild "Piazza con Tempio« sechs unveränderte Kulissen aus seinem für Silla entworfenen »Forum Romanum», ergänzt wurden »Un grand Rideau ou on y a peint un Temple d'un coté, et une Place dans l'autre" sowie andere Elemente. Durch solche Ergänzungen, vor allem durch die illusionistisch gemalten Rückprospekte konnte der Gesamteindruck entscheidend verändert werden.

3. Sehr häufig läßt sich ferner die Umarbeitung bzw. Neubemalung älterer Bühnenelemente nachweisen, was eine erhebliche Einsparung von neuen Materialien - wie Holz, Leinwand, Nägel und Metallstangen - bedeutete. Vorhandene Kulissen, Dekkenelemente, Rückprospekte und hängende Dekorationsteile aus abgespielten Opernproduktionen

112 GStA PK, I. HA Rep. 36, Nr. 2655, unpaginiert.

113 Es ist kaum erforscht, wie geläufig dieses Vorgehen an anderen Opernbühnen der Zeit war. Vielleicht sah sich Galli Bibiena erstmalig in Berlin mit der Aufgabe konfroniert, in sein Entwurfskonzept zu einzelnen Neuinszenierungen ältere Dekorationen einbeziehen zu müssen. Mag dies auf der einen Seite eine interessante Herausforderung an die eigene Begabung und Phantasie darstellen, aus unterschiedlichen Teilen ein stimmiges Gesamtbild zu erstellen, so muß auf der anderen Seite berücksichtigt werden, dal jede Opernausstattung unweigerlich eine optische Kompromiß- wurden in neuem Zusammenhang, übermalt und mit anderen Elementen kombiniert, erneut auf die Bühne gebracht. Der doppelte Vorteil dieser Vorgehensweise liegt auf der Hand: Zum einen konnten die Kosten einer Neuproduktion deutlich reduziert werden, zum anderen mußte das Opernhaus weniger Lagerfläche für ausgediente Dekorationen zur Verfügung stellen. ${ }^{113}$

Die 4. Möglichkeit schließlich war ein völliger Neuentwurf einer Dekoration aus neuen Materialien. Wie gezeigt wurde, entwarf Galli Bibiena lediglich in Britannico alle geforderten Szenenbilder von Grund auf neu. In allen anderen Opern - außer Didone abbandonata - läßt sich beobachten, daß immer ein neues Schlußbild entworfen und realisiert wurde, sehr häufig auch das erste Bild. Beiden Dekorationen kam innerhalb der Dramaturgie der Aufführung eine besondere Stellung zu. Am Beginn der Vorstellung mußte dem Publikum ein optisch interessanter Eindruck geboten werden, schwer vorstellbar wäre an dieser Stelle eine bereits bekannte Dekoration einer älteren Opernaufführung. Zur dramatischen Schlußszene, in der zusätzlich häufig Theatermaschinen oder Feuerwerk eingesetzt wurden, muß eine entsprechend prächtige und einprägsame Bühnendekoration als optische Unterstützung des Handlungshöhepunktes verstanden werden.

"Die Auszierungen sind von neuer Erfindung und Zeichnung « ${ }^{114}$

Überlegungen zu den Entwurfszeichnungen Giuseppe Galli Bibienas

Die beschriebene Bühnenpraxis der preußischen Hofoper der 1750er Jahre wirft ein neues Licht auf die konkrete Entwurfstätigkeit der in Berlin beschäftigten Bühnendekorateure Bellavite und Galli Bibiena. Ausgehend von den im vorigen Abschnitt genannten vier Möglichkeiten lassen sich drei knapp formulierte Thesen entwickeln.

- Wenn eine vorhandene Dekoration unverändert weiterverwendet wurde, ist davon auszugehen, daß für diese zweite Nutzung keine Entwurfszeichnung des Bühnendekorateurs entstand. ${ }^{115}$

lösung darstellte, vor allem wenn Bildelemente anderer Bühnendekorateure die stilistische Einheit durchbrachen.

114 Textbuch Semiramide (wie Anm. 86).

115 Eine ältere Zuschreibung der Entwurfszeichnung eines »Königlichen Gartens« im Berliner Kupferstichkabinett (KdZ 22218) für das fünfte Bild in Semiramide erweist sich folglich als falsch, da hier das Garten-Bild aus Silla auf die Bühne kam. Vgl. Werner Bertram, Die Galli- Bibiena und ihre theatergeschichtliche Bedeutung, Dissertation Marburg 1923, S. 84-86. 
- Wenn Galli Bibiena im fünften Bild von Montezu$m a$ ältere Seitenkulissen weiterverwendete und lediglich den Rückprospekt ergänzte, läßt sich vermuten, daß er in zeichnerischen Entwurfsskizzen vor allem die gemalte Vedute ohne die bereits gebauten, fertig gestalteten Architekturelemente festhielt.

- Falls das Szenenbild aus vorhandenen Dekorationen neu zusammengestellt und übermalt wurde, wird der verantwortliche Bühnengestalter ähnlich wie bei einer vollständig neu gebauten Dekoration verschiedene Entwürfe und Konstruktionsskizzen gezeichnet haben.

Überträgt man diese Überlegungen auf Galli Bibienas Berliner Aufgaben, so stellt sich rasch eine differenzierte Sicht auf seine hiesige Entwurfstätigkeit her. Ging man bislang davon aus, daß er für jede Neuproduktion zwischen fünf und neun Szenenbilder entworfen hat, so muß deren Anzahl nun deutlich reduziert werden. Bei den ersten sechs vorgestellten Opern - mit Ausnahme von Britannico war Galli Bibiena gemeinsam mit Bellavite für die Ausstattung verantwortlich und übernahm durchschnittlich lediglich zwei Dekorationsentwürfe. Bereits bei seinem zweiten Berliner Engagement für Armida griff er dazu auf ältere Bühnenelemente nach eigenen Entwürfen zurück, die unverändert weiterverwendet wurden, und kombinierte sie mit neuen Rückprospekten in illusionistischer Theatermalerei. Auch in den Opernproduktionen ab 1754, als Galli Bibiena alleiniger Bühnenbildner der Hofoper war, wurde diese Praxis fortgesetzt.

Das detaillierte Wissen um Galli Bibienas Operndekorationen während der Berliner Jahre könnte die Zuschreibung erhaltener Entwurfszeichnungen erleichtern. Dennoch bleibt dieses Unterfangen problematisch, weil man mit komplexen, teils unlösbaren Fragestellungen und Schwierigkeiten konfrontiert wird. Die bereits angesprochene Gestaltung einzelner Opernszenen mit typologischen Bühnendekorationen macht es nahezu unmöglich, erhaltene Zeichnungen einer konkreten Produktion zuzuordnen, wenn keine zusätzlichen Hinweise in Form von Aufschriften vorliegen. Für Galli Bibienas späte Jahre sind bislang außer den drei vorgestellten Skizzen zu Britannico und Se-

116 Darin eingegangen war die umfangreiche Sammlung von Louis Schneider (heute Stiftung Stadtmuseum Berlin), siehe: Rolf Badenhausen (Hrsg.), Die Bildbestände der Theatersammlung Louis Schneider im Museum der Preußischen Staatstheater Berlin, Systematischer Katalog, Berlin 1938. In der Rubrik "Dekorationen befanden sich 2 Blätter von Giuseppe Galli Bibiena, 1 Zeichnung von Ferdinando Galli Bibiena sowie 21 Entwürfe »Art der Galli Bibiena«. Weitere 13 Zeichnungen der Bibiena sind innerhalb des Nachlasses von Bartolomeo Verona einsortiert, eigenartigerweise miramide keine weiteren Blätter bestimmt worden. Es ist nicht bekannt, ob er während des Entwurfsprozesses lediglich Skizzen zur eigenen Ideenfindung und Werkzeichnungen für die ausführenden Handwerker fertigte oder auch repräsentative Gesamtansichten zur Vorlage beim Opernintendanten bzw. beim König.

Ausgesprochen lückenhaft ist ferner die Überlieferung von Bühnenentwürfen an den Nachfolgeinstitutionen der Preußischen Hofoper. Im kürzlich aufgelösten Archiv der Deutschen Staatsoper und in dem während des Zweiten Weltkrieges zerstörten Museum der Preußischen Staatstheater ${ }^{116}$ befanden sich verschiedene Zeichnungen der »Bibiena-Schule«, die aufgrund ihrer lückenlos nachweisbaren Berliner Provenienz höchstwahrscheinlich mit Giuseppe oder seinem Sohn Carlo Galli Bibiena, der zwischen 1763 und 1766 in Berlin war, in Verbindung zu bringen sind. Da die Entwürfe teilweise nur in Textbeschreibungen oder als fotografische Reproduktionen bekannt sind, können sie hier nur mit der gebotenen Vorsicht einbezogen werden. ${ }^{117}$

An drei Beispielen soll abschließend verdeutlicht werden, welche Möglichkeiten einer Neuzuschreibung trotz der erwähnten Einwände gegeben sind.

Eine nachträglich beschnittene und kaschierte, detailreich ausgeführte Federzeichnung ( Abb. 16) zeigt die Ansicht einer Gartendekoration mit Springbrunnen, Treppenanlagen und Terrassen, die zu einem prächtigen Palast überleiten. ${ }^{118}$ Eine ausführliche Beischrift läßt sich durch Schriftvergleich als Giuseppe Galli Bibienas Handschrift bestimmen. Er erläutert darin Einzelheiten für zwei Bühnenszenen, von denen offensichtlich durch den Beschnitt des Blattes nur noch die »Vedutta di Giardino Delitioso« erhalten ist. In engen Strichlagen ist die linke Seite der Dekoration detailliert mit allen architektonischen Gestaltungselementen angelegt. In auffälligem Gegensatz dazu steht die zeichnerische Verkürzung der zierenden Statuen auf den umlaufenden Terrassen und Dächern. Beide Stilelemente finden sich in den bereits vorgestellten Blättern wieder: Die Entwürfe für Semiramide zeigen die an den Pfeilern plazierten Statuen in gleicher Weise als rasch in einer mehrfach geschwungenen mit der Bezeichnung „Schüler des Bartolomeo Verona«, obwohl der Letztgenannte erst 1773 nach Berlin kam.

117 Sammlungen außerhalb Berlins wurden von der Autorin nicht einbezogen, da Babette Ball-Krückmann hierzu eine Veröffentlichung vorbereitet. Von Interesse sind vor allem die Bestände in St. Petersburg und im Moskauer Puschkin-Museum.

118 Stiftung Stadtmuseum Berlin, Sammlung Louis Schneider, NachlaB Bartolomeo Verona Nr. 6174; Feder in brauner Tinte, $28,8 \times 36,2 \mathrm{~cm}$ 


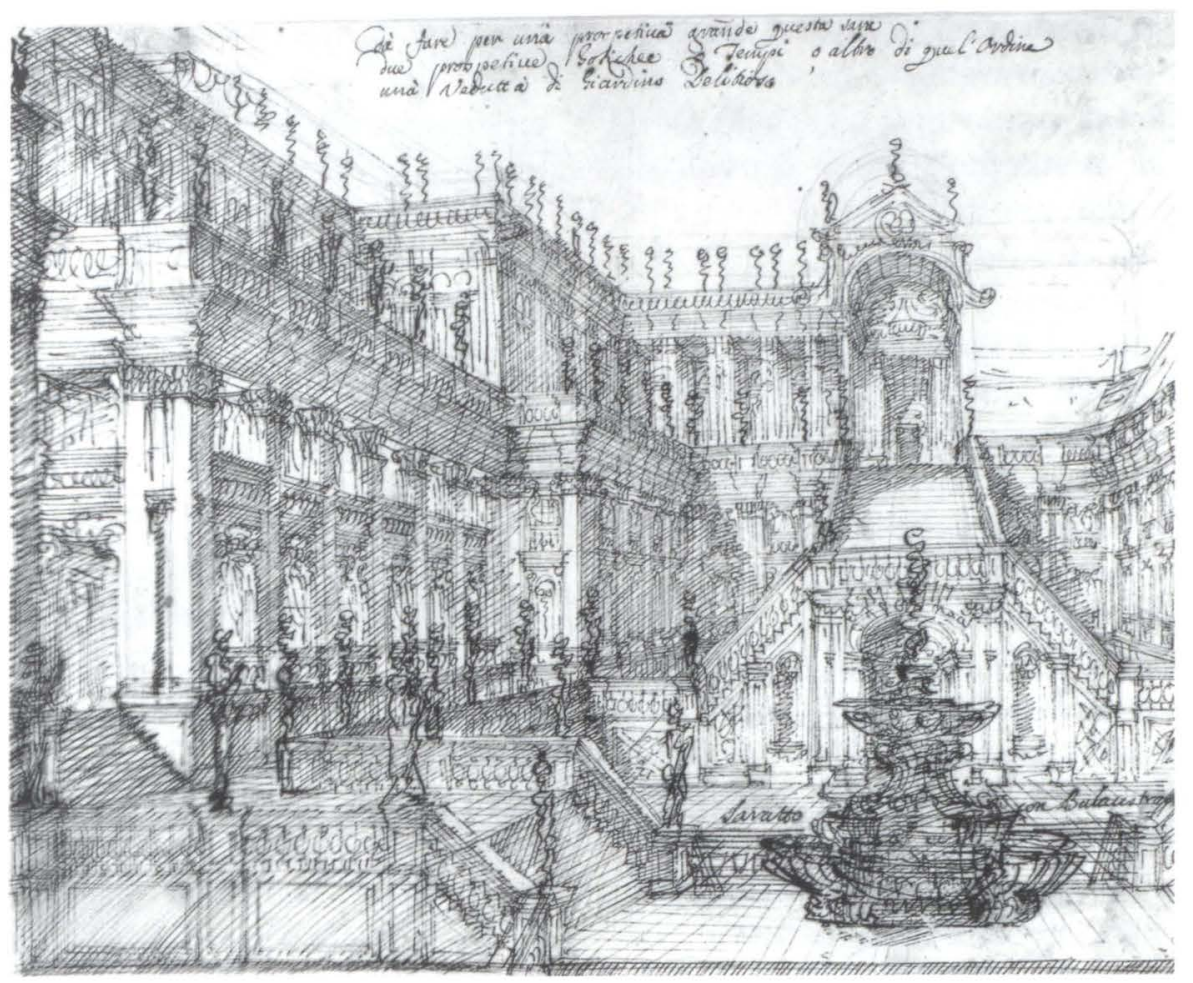

Abb. 16 Giuseppe Galli Bibiena, Entwurf für eine Gartendekoration, 1750er Jahre. Feder mit brauner Tinte, Stiftung Stadtmuseum Berlin, Sammlung Louis Schneider, Nachlaß Bartolomeo Verona (Nr. 6174)

Linie hingeworfene Details; die stark schattierten Raumzonen der Terrassenanlage und Palastwände sowie die Treppenanlage entsprechen in ihrer zeichnerischen Ausführung Galli Bibienas Britannico-Entwurf. Ungleich schwieriger ist die Zuweisung des Blattes zu einer bestimmten Szene einer in Berlin gezeigten Oper. ${ }^{119}$ Sein erstes Gartenbild entwarf Galli Bibiena 1750 für Fetonte, dort sollte gemäß den Beschreibungen im Libretto - im Hintergrund das Meer zu sehen sein, was im vorliegenden Entwurf nicht gegeben ist. Auch für Silla wurde eine Gartenszene benötigt, Galli Bibiena nutzte die Kulissen aus dem Fetonte-Garten und ergänzte sie mit acht übermalten Kulissen, einem vierzigteiligen Prospekt und drei Rückprospekten. Diese umfangreiche Dekoration könnte sich durchaus in dem komplexen Aufbau des zeichnerischen Entwurfes widerspiegeln. Dagegen stehen jedoch die Ausführungen in den Rechnungen des Theatermalers, der diese Garten-Dekoration realisierte. Er spricht von Tropheen, vier Statuen, einem Springbrunnen, Orangenbäumen, Vasen und Bassins - nur einige dieser Elemente sind in der Zeichnung wiederzufinden. Die letzte nachweisbare Garten-Dekoration entwarf Galli Bibiena für Montezuma, die

119 Da die Zeichnung aus Bartolomeo Veronas Nachlaß stammt, ist ihr Zusammenhang mit der Berliner Hofoper eindeutig. Aufgrund der Kaschierung ist unbekannt, ob auf der Rückseite weitere Skizzen sind.
Beschreibung des realisierten Bildes im Inventaire läßt rasch erkennen, daß die Zeichnung nicht in diesem Zusammenhang entstanden sein kann. Es läßt sich zusammenfassend festhalten, daß die Zeichnung möglicherweise eine erste Entwurfsidee für das fünfte Bild in Silla darstellt, deren letztendliche Realisierung auf der Bühne in Details abweichend erfolgte.

Eine in der Kunstbibliothek aufbewahrte lavierte Federzeichnung (Abb. 17) zeigt zwei Varianten eines "Cortile" in einem königlichen Palast ${ }^{120}$, das beidseitig verwendete Blatt war bisher Ferdinando Galli Bibiena zugeschrieben. Wieder erlaubt die Aufschrift der Vorderseite, wenngleich knapp beschnitten, eine Bestätigung der Handschrift Giuseppe Galli Bibienas. Auch der zeichnerische Duktus und die Raumgliederung entspricht seiner Auffassung, charakteristisch sind wiederum die im Hintergrund und als Dekor des Flachdaches angedeuteten Statuen. Dem Charakter eines Präsentationsblattes entsprechend sind die Einzelheiten der beiden, je halbseitig ausgeführten Varianten detailliert durchgezeichnet und mit feinen Lavierungen versehen, womit eine gute Vorstellung des zu realisierenden Bühnenbildes vermittelt werden

120 Kunstbibliothek Staatliche Museen zu Berlin, Lipp-HdZ 1145; Feder und Pinsel in brauner Tinte, 27.6 x $41.1 \mathrm{~cm}$; Aufschrift: „Cortile Reggia con Scale che introducono agl'Appartamenti Reali«; 1888 aus dem Kupferstichkabinett übernommen. 


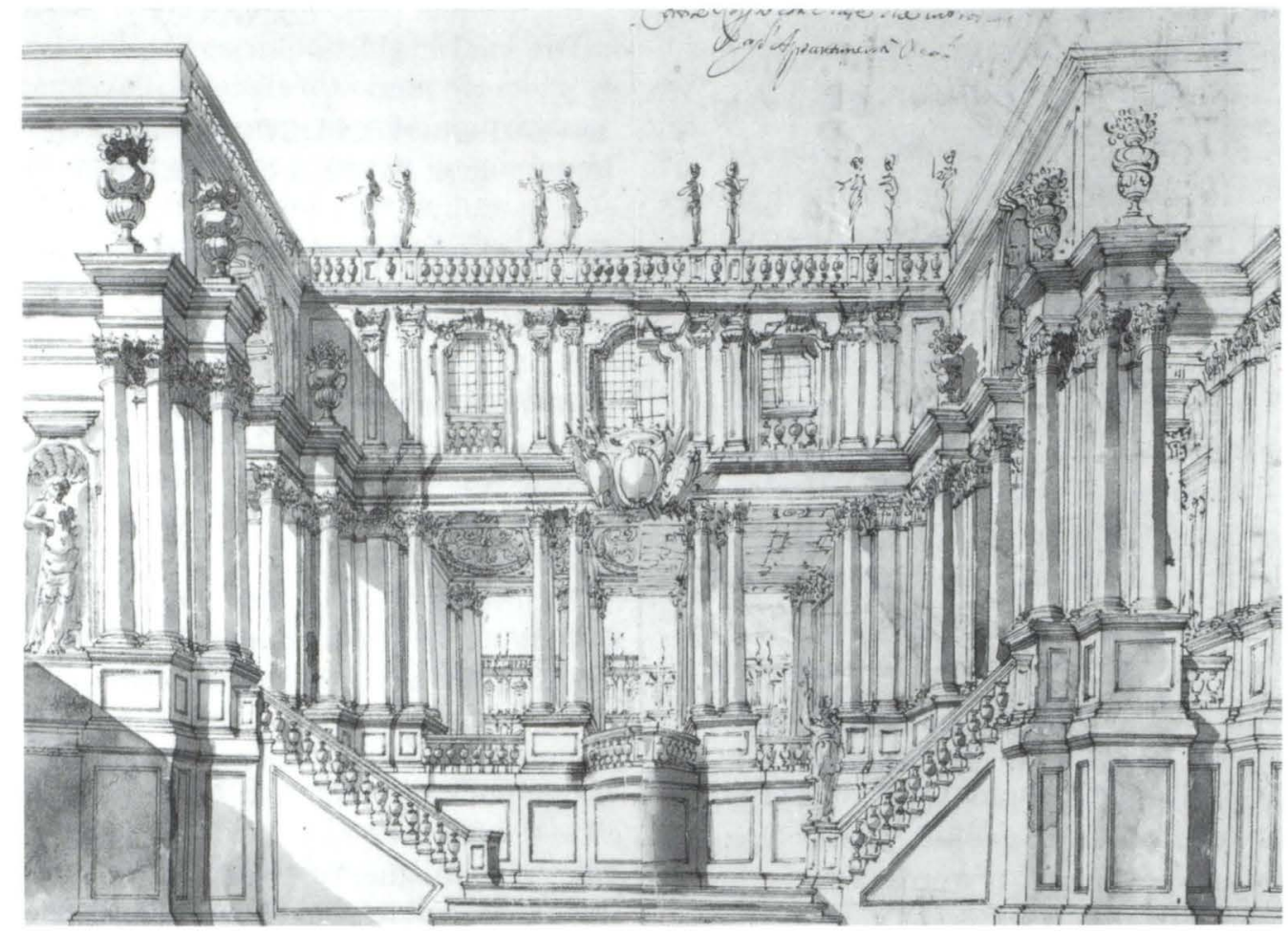

Abb. 17 Giuseppe Galli Bibiena, Alternativentwurf für eine Bühnendekoration, Feder und Pinsel mit Tinte. Staatliche Museen zu Berlin, Kunstbibliothek (Lipp-HdZ 1145 recto)

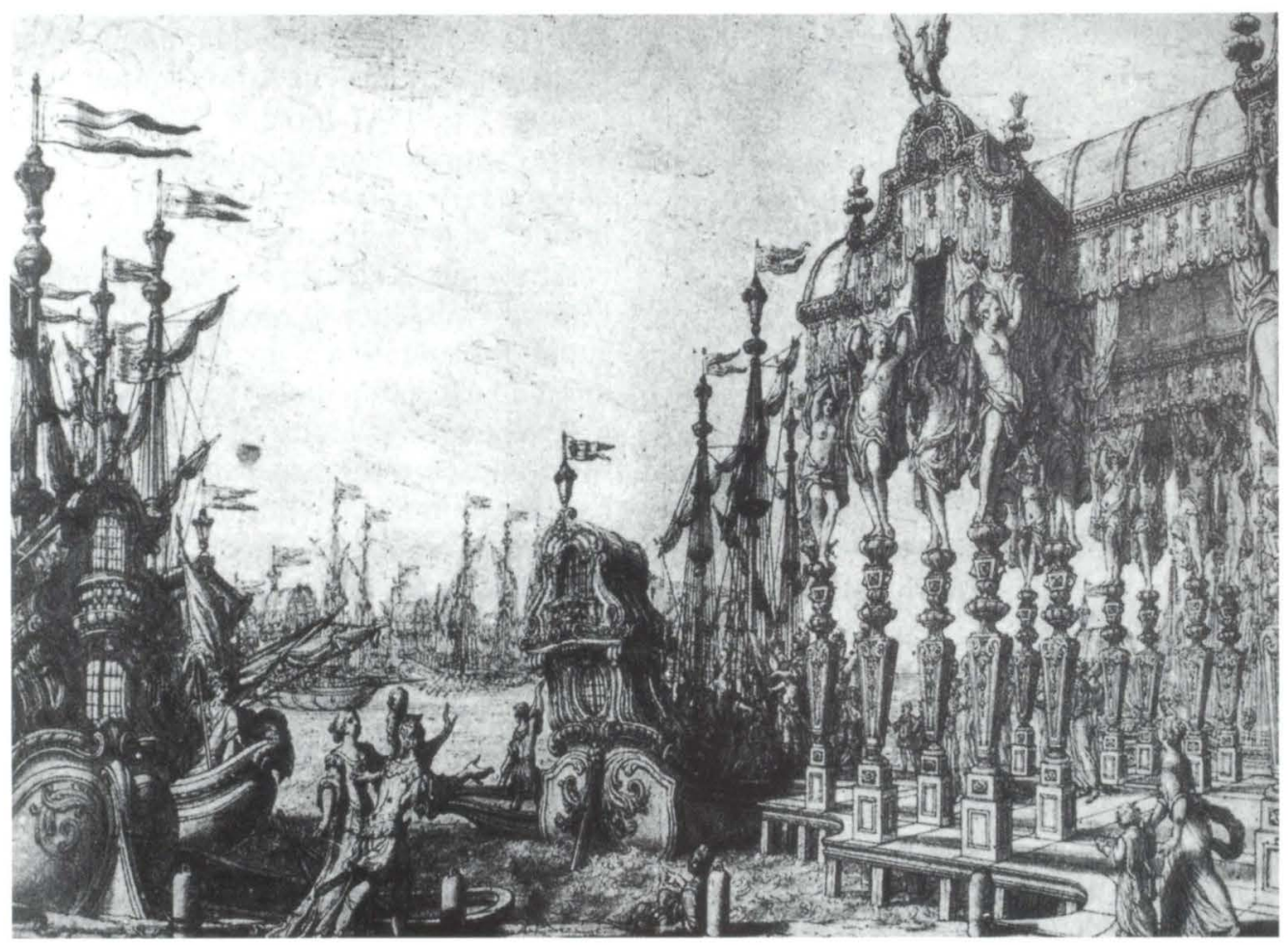

Abb. 18 Giuseppe Galli Bibiena (zugeschrieben), Entwurf für eine Bühnendekoration, 1750er Jahre, Fotografie im Archiv der Deutschen Staatsoper Berlin

konnte. Eine Hofarchitektur ist in zwei Berliner Opernaufführungen nachzuweisen, in Cleofide und Montezuma, jedoch reichen die vorhandenen Informationen nicht für eine gesicherte Zuschreibung aus. Da die Zeichnung nicht aus den Beständen des Opernhauses stammt, kann die Szene möglicher- weise bereits in früheren Jahren für einen anderen Spielort entstanden sein.

Als problematisch erweist sich auch die Bestimmung einer nur als Abbildung erhaltenen Zeichnung (Abb. 18) aus dem Bestand des Berliner Opernhauses, die Giuseppe Galli Bibiena zuge- 
schrieben ist. ${ }^{121}$ Das dekorative, zeichnerisch gut durchgestaltete Blatt zeigt eine Abschieds- oder Begrüßungsszene am Ufer eines Gewässers mit zahlreichen üppig geschmückten Prunkschiffen. Die rechte Bühnenseite nimmt ein offener Pavillon ein, der zum Teil auf Pfählen im Wasser steht und so den Zutritt zum dort angelegten Schiff erlaubt. Im Vordergrund und auf den beiden großen Schiffen sind Personen zu sehen, deren Interesse sich auf das zentrale Schiff und den Pavillon richtet. Inhaltlich läßt sich die Szene auf das vierte Bild in Didone abbandonata beziehen, das einen "Porto di Mare" erforderte. Diese auf den ersten Blick reizvolle $\mathrm{Zu}$ ordnung wird indes durch die Beschreibung der realisierten Bühnendekoration im Inventaire erschwert, denn die dort genannten Bildelemente (s. S. 129) sind nicht in der Zeichnung angelegt. Möglicherweise war die vorliegende Zeichnung als erster Vorschlag Galli Bibienas beim Opernintendanten eingereicht worden und verblieb in der Oper, ohne auf der Bühne realisiert zu werden.

Abschließend läßt sich festhalten, daß die vorstehenden Analysen der erhaltenen schriftlichen Quellen eine differenzierte und realitätsnahe Sicht auf das erste Jahrzehnt der Berliner Hofoper ermöglichen. Insbesondere läßt sich der Mythos der oft mit auratischer Übertreibung beschriebenen "glanzvollen Bühnendekorationen « insoweit relativieren, als in vielen Fällen eine durchaus kostenbewußte Mehrfachnutzung vorhandener Szenenbilder nachgewiesen werden kann. Galli Bibiena bezog in seine Entwürfe für Neuproduktionen häufig vorhandene Dekorationen ein, ließ ältere Bühnenelemente übermalen und neu kombinieren, nicht selten wurden komplette Szenenbilder ohne jede Veränderung erneut eingesetzt. Die erhaltenen Gesamtaufstellungen der jeweiligen Produktionskosten einer Oper und die Einzelrechnungen der ausführenden Handwerker zeigen, daß dadurch die Herstellung der Bühnendekorationen finanziell verhältnismäßig günstig ausfiel. Der überlegte Einsatz älterer Dekorationen tat der Gesamtwirkung einer neuen Opernproduktion offensichtlich keinen $\mathrm{Ab}$ bruch, und die im Rahmen des Hofzeremoniells gewünschten Repräsentationsmöglichkeiten blieben erhalten. Der König, sein Hofstaat und das geladene Publikum fanden in den »Lustbarkeiten«, zu denen die Opernaufführungen zählten, die unmittelbare Bestätigung, »daß der Glanz des Berlinischen Hofes, um das Jahr 1750 , recht sehenswürdig war «122.

121 Georg Quander (Hrsg.), Apollini et Musis - 250 Jahre Opernhaus Unter den Linden, Berlin 1992, S. 33, mit dem Bildtitel: Bühnenbildentwurf von Giuseppe Galli-Bibiena (um 1750).

122 Johann Friedrich Borchmann, Briefe zur Erinnerung an merkwürdige Zeiten und rühmliche Personen aus dem wichtigen Zeitlaufe 1740 bis 1778 , Berlin 1778, 27. Brief, S. 214.
ANHANG

INVENTAIRE DES DECORATIONS DE L'OPERA DU ROI, FAIT EN FEVRIER 1754, 55, 56

[Buntpapierband mit Mittelschild, bestoßen, berieben; ca. 35 x $22 \mathrm{~cm}$; 3 ungez. Seiten, 72 Seiten, davon 25 Seiten mit Text]

Geheimes Staatsarchiv Preußischer Kulturbesitz, I. HA Rep. 36, Hofverwaltung, Nr. 2628.

\section{[S. I]}

Avant Propos

Sa Majesté notre tres glorieux Souverain Frederic II. le Grand, Roi de Prusse, que dieu nous preserve par une tres longue durée des années, aiant dès le commencement de son Reigne fait battir le superbe, vaste et magnifique Theatre de l'Opera, comme un ornement nouveau ajouté au grand nombre des autres, qui rendent cette Capitale la plus noble et la plus belle de toutes les Villes d'Alemagne; ce Furent Monsieur Fabris et Monsieur Fanti tous les deux Peintres Italiens, qui donnerent les premiers leurs mains aux decorations de deux premiers Opera $=$ Cleopatre, et Tite $=$ representés a Berlin l'an 1742/3 avec la plus grande Magnificence, et avec le plus bon goût de tout ce, qui compose ce noble Spectacle; et le dit Monsieur Fanti aiant dû partir pour ses Interés particuliers, Monsieur Fabris continua dans cet Emploié jusqu'a l'an 1747 lorsque Monsieur Bellavite fut fait venir exprès d'Italie pour lui succeder. Celui ci a depuis ce temp là fourni au Theatre toutes les decorations selon le sujet, et les exigences des drammas representés successivement, a l'exception de La Roiale de Venus pour l'Opera = Angelica et Medoro - et d'un Temple dedie a Juppiter Capitolien pour l'Opera de Coriolan, comme aussi a l'exception de huit decorations, que le Fameux, et tres Renommé Monsieur Bibiena venu expressement et en plusieurs reprises par desir du Roi, y a inventé et executé pour entremeler a ce noble Spectacle quelque produit digne de son incomparable talent; et c'est ce Grand homme, qui succede actuelement, au dit Monsieur Bellavite; et qui a recherché son congé a Sa Majesté le Roi de Pologne pour jouir du grand honneur d'etre au Service du plus Grand de tous les Rois.

NB. La Roiale de Venus, et le Temple de Juppiter Capitolien furent inventés et executés par le Sieur Bonn.

Il est aisé a concevoir, que aiant Sa Majesté ordonné tous les ans une ou plusieurs decorations selon le sujet de chacque Opera, les Scenes faites dans ce long cours d'onze années consecutifs sont en grand nombre; et

\section{[S. II]}

comme (faute d'un Magazin absolument necessaire pour les preserver) plusieurs de ces scenes ont beaucoup souffert, et plusieurs ont peri presqu'entierement autant pour le continuel transport d'un endroit a l'autre, que pour la pluie, l'humidité, et l'angustie des memes endroits, oû on les a renfermée; Monsieur le Baron de Sveerts Notre tres digne Directeur a jugé bien a propos de faire emploier les plus vieilles decorations, et celles, qu'ont souffert le plus pour en faire des nouvelles; ce 
qu'a eté executé par consentement de Sa Majesté. C'est celleci la raison, qu'il est impossible de faire un Inventaire des Scenes faites depuis le commencement; et comme on a emploié successivement celles, qui ne pouvoient plus servir ou en entier ou en partie, on marquera distinctement les debris des scenes plus vieilles; et toutes les decorations, qui sont encor en entier, c'est a dire toutes celles faites de nouveau, ou retouchées par Mr. Bellavite, qui sont en bon ordre, et en etat de s'en servir, et toutes les decorations faites par Mr. Bibiena, qui doivent etre toutes aussi en entier, et en bon ordre, seront marques dans cet Inventaire.

Il est bien a souhaiter, que Sa Majesté veuille se resoudre a faire battir un Magazin; parceque si les scenes qui sont presentement en entier, et principalement celles faites par ce celebre Architect et Peintre, seront exposées comme les autres a l'humidité, à la pluie, à la poussiere etc. auront le mauvois sort des autres, et periront.

\section{[S. III]}

Sa Majesté le Roi ayant pris à Sa Servie le Sr. Bibiena en qualité de decorateur et architecte Theatral; j'ai fait examiner tout le Magazin des decorations, par l'Inspecteur de l'Opera le Sr. Cori, en presence du Sr. Bellavita, pour faire un Etat exact de ce qui étoit en bon état, et former le repertoire suivant. on a destiné tout ce qui se trouvoit endomagé, ou depareillé pour étre enployé au nouvel opera de Semiramis.

à Berlin ce 22 Febr. 1754 Sveerts

\section{[S. 1]}

Decorations de Monsieur Fabris, qui sont encore en entier, mais en tres mauvois etat

1. Piazza

$$
\text { 8. Culises. }
$$

15. pieces en prospet au fond.

2. Grand Bois, ou Champs Elises

15. Pieces en Arbres Isolés.

NB Mr. Bellavite, qui a repeinte cette decoration, $y$ a fait un Rideau nouveau en prospet pour la rendre Scene courte, selon le besoin.

NB 2do: Le meme a retouché toute cette decoration pour former le Bois de l'Enfer pour l'Opera Orphée, qui doit aussi etre en bon etat.

\section{Cabinet Plaphonné}

4. Prison

12. Pieces en tout. avec le Plaphon.

6. Culises,

8. Pieces pour le Prospet.

5. Pieces pour la Soupente.

Un grand Rideau pour le Prospet.

NB Cette decoration a beaucoup souffert par l'humidité, et par la poussiere faute d'un Magazin.

[S. 2]

5. Pavillons 6. Cour

8. Culisses repeintes par M. Bellavita.

8. Culises - repeintes par M. Bellavite.

1. Toile en Prospet fait de nouveau par Mr. Bellavite pour l'Opera Orphée.
NB. ces pieces ci dessus doivent etre en bon etat. mais les pieces ci dessous sont en tres mauvois etat.

1. toile en soupente.

1. une autre en soupente pour former le prospet.

6. chassis pour le Prospet.

7. Gallerie

22. Pieces en tres mauvois etat.

NB. le 5. pieces de soupente ont servi pour le nouveau Theatre de la Commedie.

[S. 3]

8. Lieu delicieux

6. Culises en tres mauvois etat.

NB. du Rideau en prospet on a fait le prospet du Village a la Commedie.

(später) ces 6. coulises donnés a Mr. Bibiena a page 20 no. 4

Fragmens des Vieilles decorations de Mr. Fabris, qui sont le reste, et les debris de celles, qu'on a emploié en plusieurs reprises pour en faire des autres, ce qu'a eté executé par ordre de Mons. le Baron de Sveerts.

1. Murailles d'une ville

4. Culises en tres mauvois etat.

2. Reste d'un Prospect de ville

8. Pieces en mauvois etat.

3. Reste d'une Cour

11. Pieces

Un Rideau pour le Prospet.

Une piece, qui forme les ares de la Cour.

[S. 4]

Decoration de Monsieur Fanti en entier

Cour ou Cortile

8. Culises.

1. Toile, qui descende en

soupente sur le Prospet

4 pieces de Soupente

NB Mr. Bellavite a retouché toute cette decoration, et il y a fait un Rideau nouveau pour Prospet, pour l'Opera Armida.

NB Ce meme Peintre Mr. Fanti fit une autre decoration qui representoit un Jardin pour l'Opera Artaxerse l'an $1743 / 4$ mais cette decoration avoit beaucoup souffert autant pour le trop frequent transport d'un endroit a l'autre, que par l'humidité \& des endroits on l'a emploié entierement pour en faire des autres.

[S. 5]

Decorations faites par Monsieur Bellavite qui sont en entier; et en etat de servir.

1. Salle Magnifique, faite pour l'Opera Coriolan, et retouchée par le meme Bellavite pour l'Opera Sylla

4. Pieces pour le Plaphon.

8. Culises

6 . pieces sur l'hauteur de

6. premieres Culises

8. Colomnes Isolées.

10. Pieces qui forment le Prospet.

16. autres pieces pour completer le Prospet.

1 Toile qui descende sur le Prospet en distance. 
1 Toile sur le Grand Arc du Milieu.

2. Toiles sur les deux Arcs collatereaux.

4. nouveaux soupentes ajoutés pour l'Opera Sylla

a la place du Plaphon.

2. Port de Mer fait pour l'Opera Iphigenie
8 . Culises.
40. Navires pour former la Flotte.

NB. La piece de toile vert qui formoit l'etendue de la Mer a eté coupée pour former des rivieres.

NB.2do. il y a un grand rideau fait par Mr. Bellavite pour l'Opera Mitridate, qui a formé une scene courte avec les Culises.

[S. 6]

3. Gallerie, fait pour Cinna, et retouchée pour Mitridate 8. Culises

Un grand Rideau en prospet.

4 toiles en Soupente.

4. Ruines fait pour l'Europe Galante

8. Culises

Un Rideau en prospet.

5. Delicieuse, fait pour les Fetes Galantes.

84. pieces qui on ouffert beaucoup par l'humidité.

NB. les 8. petites culises qui representent un bois sont transportées dans la Salle de Son A: R. la Princesse Emilie.

[später] ils en sont de retour au Magazin.

\section{[S. 7]}

6. Bois sombre, ou Sotterranei qui se transforment en un lieu delicieux [Armida]

8. Culises toutes de Bois.

Une chassis de Bois au milieu.

4 chassis de Bois en prospet.

4 pieces de toile double en soupente.

Une piece de toile qui descende et se joigne au

Prospet.

4. statues pour la delicieuse.

7. La Roiale du Soleil pour Phaeton

42. chassis de toile.

16. colomnes de Christal.

16. Piedestals

4. Pilastres

Le char de Phaeton avec deux cheveaux

Le Trone du Soleil environné des rayons de

Christal.

[S. 8]

8. La Roiale de Didon, ou Cartage, Scene de Geants avec le Palais de Didon

8. Culises faites des vielles scenes.

5. pieces pour la Soupente.

Au milieu une montée.

Au fond la Ville de Cartage sujette a l'incendie.

9. Enceinte des Palmiers Scene refaitte toute de nouveau des vieilles decorations pour Cleophide

8. Culises

Un Rideau nouveau en prospet.

[später] 10. Grotte pour l'Opera Iphigenie

4. Coulises

4. pour le Prospet en chassis.

Un Rideau qui forme un Prospet au fond.
1. NB. Mr. Bellavite a ajouté a cette decoration une toile pour former le Mont Rodope in Orphée.

2. NB. Cette decoration a servi pour l'Antre d'où sort la voix de l'Oracle pour l'Opera les 2 . Freres ennemy. pag. 23 no. 3

[S. 9]

11. [früher 10.] Edifices antiques avec un grand Pont, et l'armée d'Alexandre au fond

[später]

la vue de l'armée faite en chassis, a été employé pour Semiramis.

12. [früher 11.]

NB. Une partie de la Salle magnifique fait pour Cinna. qui a servi, et peut servir pour decorer un petit Theatre. Le grandes Culises et tout le reste de cette grande decoration a eté emploié par Mr. Bibiena pour la Scene Foro Romano in Sylla.

8. petites Culises.

8. pieces au Prospet

2. pieces au fond du Prospet.

[S. 10]

Plusieurs Fragmens et Pieces faits par Mons. Bellavite selon l'exigence

1. Prospet du Temple Isis pour Phaeton

NB. Ce temple fut fait par Mr. Bonn, mais depuis a eté emploié par Mr. Bibiena.

4. Pieces en Prospet.

4. Portes.

Rideau qui represente le dome du Temple.

2. Le Simulacre de Mars

3. Un Rideau en prospet de la Scene du Bois pag.1, no. 2 pour rendre ce Bois en Scene courte.

[S. 11]

4. Le vieux Orizont peint pour la Montagne in Orphée.

5. Les Nuages en carton pour le Temple d'Apollon. [später] tout pourri par l'humidité

6. Le Simulacre de Neptun. avec son Piedestall.

7. Le simbole de la Paix pour l'Opera Sylla.

[S. 12]

Grand Pavillon

6 . pieces

Une Toile en prospet.

Une Toile en soupent.

[S. 13]

Decorations faites par Mons. Bibiena Lesquels doivent etre toutes en entier

1. Jardin [Fetonte]

44. pieces en prospet presque toutes peintes en carton.

6. culises

4 pieces pour la supente.

2. Le Palais d'Armida

44. Pieces toutes de Bois qui forment le Prospet du Palais.

3. Campagne pour l'Opera Phaeton 40. Pieces, qui forment le Prospet en Scene longue. 
8. Culises.

Un Rideau en prospet pour la rendre Scene

Courte

4. grandes pieces detachées.

2. autres petites pieces.

[S. 14]

4. Champ de Battaille [Cleofide]

8. Culises

38 pieces en Prospet

2. Arbres entremelés au champ.

5. Cabinet [Britannico]

4. Culises

4. pieces pour former l'Arc.

1. piece pour le haut de l'Arc.

3 pieces pour le grand Prospet

2 supentes

6. Port de Mer [Didone]

6. Culises

7. pieces deriere la Ville, et la Tour

2. grands Navires.

2. petits Navires.

La Tour

7. pieces pour le Parterre, et l'eau

6. pieces pour l'Arc sur le devant.

3. pieces pour deux arcs, et un prospet.

3. pieces de soupente.

2. pieces pour couverture des colomnes.

2. pieces au devant de la couverture rouge.

[S. 15]

7. Avant Cour [Britannico?]

6. Culises

6. pieces sur les Culises.

2. pieces pour le prospet de deux cotés du

Theatre.

1. piece qui forme l'Arc.

8. pieces des Arcs du dessous.

4. pieces de soupente.

2. pieces au parterre.

3. pieces de soupente

8. Petite Salle [Britannico ?]
6. Culises.
5. pieces pour l'arc
1. piece pour couvrir l'arc.
4. pieces pour couvrir le prospet.

[S. 16]

9. Sale magnifique Transparente. [Britannico]

6. Culises

42. au dessous des colomnes, et des prospets =

42 pieces.

15. pieces au haut du Pont.

4. pieces au Prospet du Pont, ou sont les

Battailles.

5. Pieces pour le Plaphon, et le petit fond.

3. pieces pour couverture avec Cadres et

Corniches.

2. Pieces a la couverture rouge avec des Cadres.

4. Colomnes Superflues.

10. Autre Jardin fait pour l'Opera Sylla

8. Culises [gestrichen: faites de vieilles Culises de la Sale de Bellavite page 9. no. 11]

Les memes du jardin pag. 13 no.1

40 Pieces pour le prospet.

3 Toiles au fond une grande, et 2 . petites.

[S. 17]

11. Foro Romano pour l'Opera Sylla. Are Trionphal, Char trionphal.

NB. Pour faire cette decoration Mr. Bibiena a emploié toute la decoration pag. 7 [wohl verschrieben - 9], no. 12 exepté les petites pieces du fond de cette scene.

8. Culises faites de vieilles culises de la Sale de

Mr. Bellavite pag. 9, No.12.

NB. Mr. Bibiena a fait deux differents Prospets au fond de cette decoration.

[später]

Le Premier est de 21. Pieces

Le 2d. Prospet est de 16. pieces.

12. Champ de Battaille pour l'Opera Cleophide 6 Coulisses

10. Pieces pour le Prospet.

[gestrichen] 3 pieces pour la Soupente.

[gestrichen] Une piece qui fait la voute.

Un Rideau.

[S. 18]

13. Appartemens pour l'Opera Cleophide.

6 Coulisses

7 pieces pour le Prospet.

3 pieces pour la Soupente.

1. piece qui forme la voute.

Un Rideau.

14. Le Temple de Baccus pour l'opera Cleophide.

6 Coulisses.

3 pieces de soupente

1 piece pour la voute.

3. pieces de Rideau du Prospet.

13. pieces qui forment le Prospet.

[später] le nouveau pont dans cet Opera est de 6 pieces.

[S. 19]

Decorations de l'Opera Semiramis Representée le 27me

Mars 1754 .

1. La veue du Palais, et Jardin de Semiramis, Scene de Mr. Bibiena

6 Coulisses emploiés du Foro Romano dans Sylla. 28 Pieces pour le Prospect.

2. Le Mausolé de Mr. Bibiena.

4. Coulisses.

Une porte Gazée.

3. pieces du Prospect

3. Temple Magnifique de Mr. Bibiena

8. Coulisses.

3. Plafonds.

1. Grand Cintre.

2. Pieces deriere la Cintre.

3. Pieces pour couvrier le 1er Temple.

35. Pieces pour le Prospect.

NB. Dans cet Opera il y a eû 9 changemens des scenes, c'est pourquoi outre les 3. nouvelles marquées ci dessus, on a fait servir

1. Le Cabinet pag. 14 , no. 5 
2. La Gallerie pag. 18, no. 13

3. Le Temple pag. 18, no. 14

4. Une Partie du Jardin pag. 16 , no. 10

5. Atrio pag. 15 , no. 7

6. Petite Sale pag. 15 , no. 8

\section{[S. 20]}

Decorations faites par Monsieur Bibiena pour l'Opera

Montezuma l'année 1754/5

1. Trois grandes allées des Palmiers dans le Jardin Imperial

82 pieces en Coulises.

22 pieces en souppente formantes la hauteur des palmiers.

2. Grande Place sur le bord de la Riviere

6. pieces en Coulises.

1 Rideau au fond.

32 pieces en souppente pour completer leprospet.

3. Porche, ou Atrio du Palais Imperial.
6. pieces en Coulises
2. Rideaux
6. pieces en prospet
6. autres pieces en souppente
Un plaphon.

4. Jardin

6. pieces en Coulises

4. Pieces en Fontaines

Un Rideau en prospet.

[S. 21]

5. Prison

2. pieces en Coulisses.

2. Plaphons

2. Rideaux pour le prospet

2. pieces en souppente

6. Grande Cour environnée des Colonnes, par lesquelles on voit une partie de la Ville de Mexico.

6. pieces en Coulises.

15. pieces en rang des Colonnes.

8. pieces au fond en prospet.

8. pieces en souppente.

4. Plaphons.

NB. pour faire le Jardin no. 4 pag. 20, il a emploié 6 . coulises du lieu delicieux de Mr. Fabris pag. 3 no. 8.

\section{[S. 22]}

Decorations faites par Monsieur Bibiena pour l'Opera Ezius au Mois de Mars 1755

1. Forum Romanum

6. pieces en Coulises

5. pieces en rideaux pour le Prospet

5. autres pieces pour le Prospet de la Ville de Rome

2. Grande Galerie

36. pieces en Coulises.

15. pieces pour la Souppente.

3. Capitole Antique de Rome

8. pieces en Coulises

4. pieces en petits rideaux pour le prospet.

28. pieces en souppente, qui forment l'entier

du Prospet.

4. Plaphons.
[S. 23]

Les deux Freres Ennemis 1756

Pour cet Opera on n'a point fait des nouvelles decorations, excepté, les Nuages en Carton pour la Machine d'Apollon. Et on a retouché, et on a fait servir les scenes ci dessous.

1. L'Avant-Cour pag. 15 , no. 7

2. Grande Gallerie d'Ezio a la contrepage 22 no. 2

3. Antre d'ou sort la voix de l'Oracle - on a fait servir la Grotte avec le Mont Rodope a la pag. 8 no. 10

4. Appartemens, v. pag. 18 no. 13

5. Les Murailles de Thebes

Pour former cette decoration Mr. Bibiena s'est servi des Ruines de Bellavite - 8 Coulises a la pag. 6 no. 4 - et il a aussi emploié pour le Prospet, 2. pieces du Prospet d'une ville de Fabris - voiez les Fragmens a la pag. 3, no. 2

6. La Machine d'Apollon

Une Toile en chassis, toute Transparente a rayons de soleil

7. ordres de Nuages en carton qui forment des coulises sur la meme machine.

[S. 24]

Decorations faites par Monieur Bibiena pour l'Opera Merope du 27me Mars 1756

1. Petite Place

Un grand Rideau oû on y a peint un Temple d'un coté, et une Place dans l'autre.

Un Tombeau isolé.

7. pieces devant le Prospet.

Une piece en souppente qui descende sur les pieces du Prospet.

NB On n'a point fait des coulises pour cette Scene, mais on a fait servir les Coulises du Foro Romano in Sylla a la pag. 12 no. 2 (wohl irrig, pag. 17 , no. 11), les quelles ont eté retouchées.

\section{Sale ou Sala terrena}

6 Coulises.

Un grand Rideau au jour en Prospet avec des amourets, et des-pots des Fleurs.

6. pieces en chassis au jour a double colomnade avec des Balaustrades et des Statues - au dessous du grand Rideau.

10. pieces en chassis placées en arrier peintes en verdure, et en des arbres au jour

Au Milieu une Grotte avec une cascade d'eau

[S. 25]

3. Temple

Les 6. Coulises de ce Temple sont celles du Temple de Baccus in Cleophide a la pag. 14 no. 14 (falsch, pag. 18 , no. 14) qu'on a retouché.

Un grand Rideau en Prospet oû on y voit peint un dome supporté par troix Arcades. 10 pieces en chassis au dessous de ce Rideau. 3 autres pieces en arriere en Prospet une au milieu, et les autres deux plus petites aux deux cotés.

NB les pieces ce dessous sont aussi du meme Temple de Baccus 
2 pieces en dedans aux deux Arcades avec deux chassis au dessous, qui les soutiennent.

4. Tres Grande Place

6 Coulises

La Facade de cette Scene consiste en 7. pieces en colomnade au jour.
10. pieces en chassis deriere cette colomnade oû on voit des Edifices aux deux cotés.

Au Fond du milieu 10. pieces en chassis par degradation.

2. Obelisques isolés.

2 Colonnes historiees en bas relief.

et une Fontaine Isolée tout au fond au milieu. 